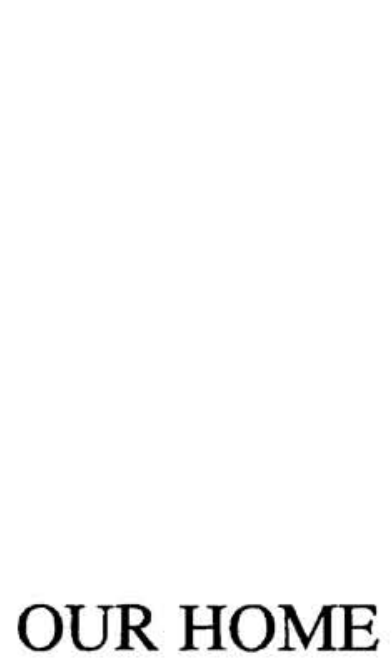

BUILDINGS OF THE LAND

ENERGY EFFICIENCY DESIGN GUIDE FOR INDIAN HOUSING

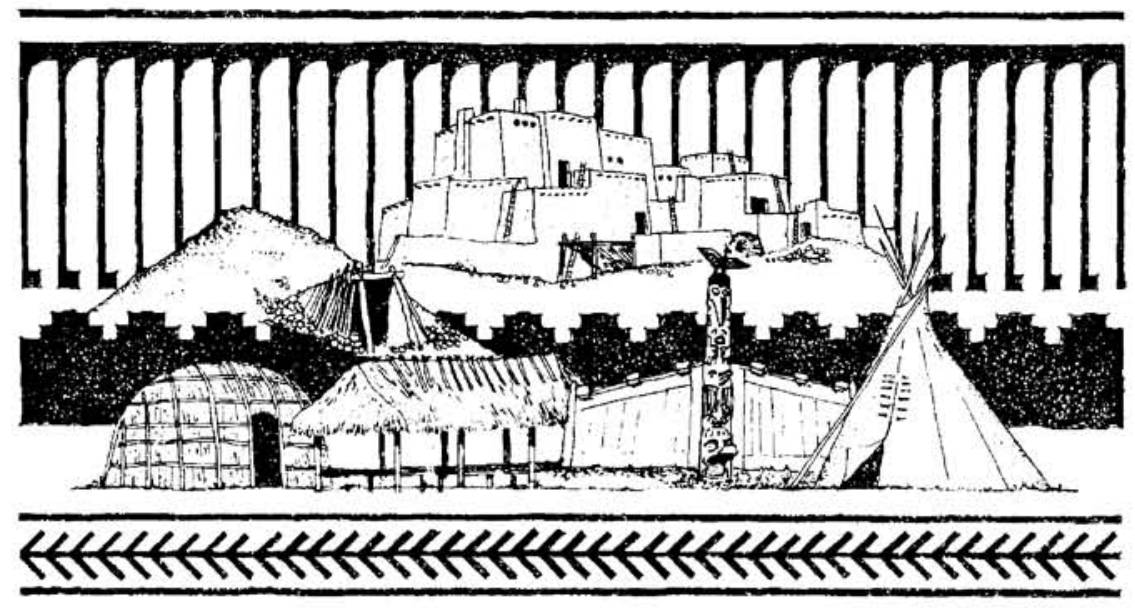




\section{OUR HOME}

BUILDINGS OF THE LAND

ENERGY EFFICIENCY DESIGN GUIDE FOR INDIAN HOUSING

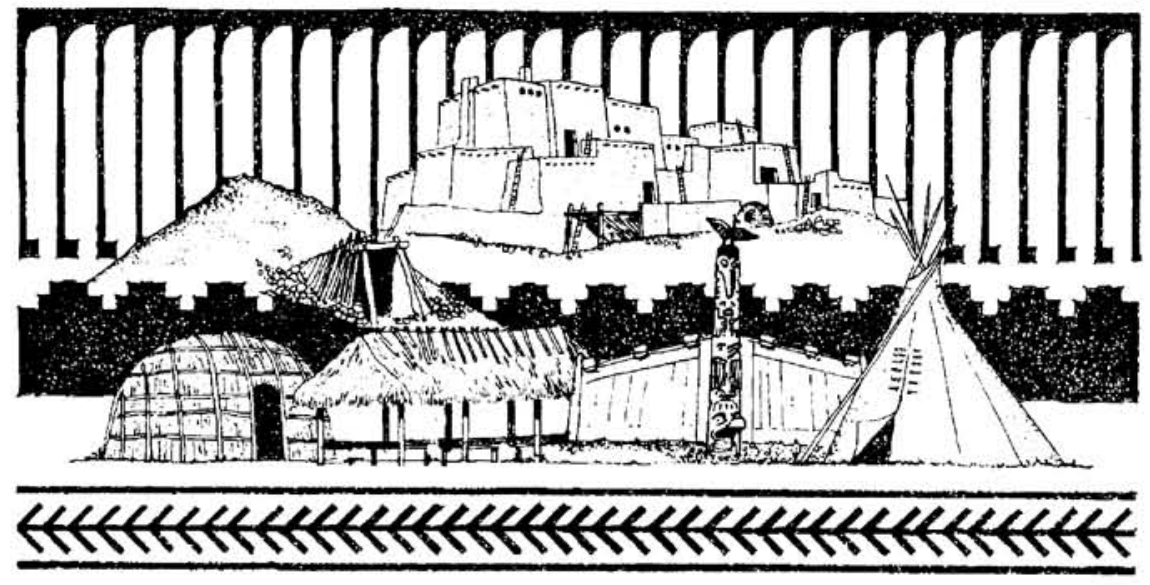

This guide was prepared for the DOE-HUD Initiative - U.S. Department of Energy and U.S. Department of Housing and Urban Development - by the National Renewable Energy Laboratory. 


\section{The DOE-HUD Initiative on Energy Efficiency in Housing}

This Design Guide is a product of the DOE-HUD Initiative on Energy Efficiency in Housing. The Initiative was created in 1990 as a collaborative framework to harness the technical skills of the Department of Energy's (DOE's) laboratories and programs for making energy efficiency improvements in Federally-aided housing. This multi-year Initiative supports both the Department of Energy's National Energy Strategy and the Department of Housing and Urban Development's (HUD's) mission to make low- and moderate-income housing more affordable.

Funding for the Initiative is provided by the Department of Energy through its existing conservation research and technical assistance programs. Technical support for projects is supplied by staff from DOE, including its Support Offices, the Department of Housing and Urban Development with its Field Offices, DOE's National Laboratories, and private contractors. Aid in incorporating project experience into ongoing HUD housing activities, through publication, guidance, technical assistance and regulations is also provided by the groups mentioned.

This Design Guide was prepared by the National Renewable Energy Laboratory (NREL) under contract to DOE. It is based on research sponsored by DOE and carried out primarily by the Los Alamos National Laboratory (LANL), NREL (formerly the Solar Energy Research Institute), and the Florida Solar Energy Center (FSEC). The Guide incorporates, by permission, major portions of the Passive Solar Design Strategies: Guidelines for Home Builders, published by the Passive Solar Industries Council (PSIC), and developed jointly by PSIC, NREL, and Charles Eley Associates, with funding support from DOE.

Dr. J. Douglas Balcomb, the Design Guide's author, wishes to acknowledge the American Indian Council of Architects and Engineers (AICAE) for the opportunity to become acquainted with the issues of Indian housing by participating in the Council's workshops. The AICAE wrote the companion document, Our Home: Giving Form to Traditional Values, Design Principles for Indian Housing, published at the same time and under the same auspices as this Guide. This book discusses the cultural issues of Indian housing. Dr. Balcomb also thanks the AICAE for permission to use two designs that came out of the workshops as examples in this Guide. He is particularly grateful to Louis Weller, Burke Wyatt, David Sloan, Gilbert Honanie, Charles Archamboult, Edmund Gongales, and Veronica Tiller of the AICAE and also Richard Hill for their guidance and help.

Nancy Carlisle, Terry Penney, and Ren Anderson of NREL all made important contributions to this project. Norm Weaver and Sara Farrar of Environmental Research Groups International performed many of the calculations using the ARES and BuilderGuide programs. 


\section{Preface}

\section{Energy Efficiency Guides and Software Today}

Today, as Native American cultures seek to return to culturally relevant building design, electronics-based software programs can become extremely valuable aids. Designers will soon have access to software systems that readily combine all the features that high energy efficiency, environmental quality, safety, soundness, and culturally related building design will require. This Design Guide offers a useful starting point for energy efficiency. It can be used by itself or with the BuilderGuide software that is available to accompany it.

Those considering using this Guide's software are probably aware that there are increasing numbers of such systems to consider using in the design and specification of buildings and for housing in particular. It is a field of rapid evolution. BuilderGuide is most useful for, but not limited to, design of passive solar systems. Other software systems also exist for passive solar. One new system now on the market provides designers with a program for preliminary design that includes energy efficiency and greatly simplifies the process of exploring the options and their building design consequences. Still others are available for defining such details as the times of annual peak use for cooling or heating (useful in designing for utility rebates), for evaluation and sizing of domestic heating plants, hot water appliances and other such details and for other technical purposes. It is presumed that the designer will make the best choice amongst all such alternatives in proceeding with a specific project's resolution.

Neither the United States Government nor any agency thereof, nor any of their employees, makes any warranty, express or implied, or assumes any legal liability or responsibility for the accuracy, completeness, or usefulness of any information, apparatus, product, or process disclosed, or represents that its use would not infringe privately owned rights. Reference herein to any specific commercial product, process, or service by trade name, trademark, manufacturer, or otherwise, does not necessarily constitute or imply its endorsement, recommendation, or favoring by the United States Government or any agency thereof. The views and opinions of authors expressed herein do not necessarily state or reflect those of the United States Government or any agency thereof. 


\section{Table of Contents}

Section I: GUIDELINES FOR DESIGN

Part One: Introduction

1. The Energy-Efficiency Design Guide

2. How Energy Efficiency Relates to Cultural Issues in Indian Housing

3. Energy-Efficiency Savings Potential

Part Two: Basics of Energy Efficiency

1. Why Energy-Efficient?

2. Key Concepts: Energy Conservation,

Suntempering, Passive Solar

12

3. Improving Conservation Performance

4. Mechanical Systems

5. South-Facing Glass

6. Thermal Mass

7. Orientation

8. Site Planning for Solar Access

9. Interior Space Planning

10. Putting it Together: The House as a System 30

Part Three: Passive Solar Strategies

1. Suntempering

2. Direct Gain

3. Sunspaces

4. Thermal Storage Wall

40

5. Combined Systems

44

Part Four: Natural Cooling Guidelines $\quad 44$

1. Glazing

2. Shading

3. Ceiling Fans

45

4. Ventilation

45

47

48

SECTION II. BuilderGuide

Part One: Description of BuilderGuide

Part Two: The Basecase House

51

Part Three: Worked Examples: The Method in Practice

55

Section III. ENERGY-EFFICIENCY PERFORMANCE GOALS 


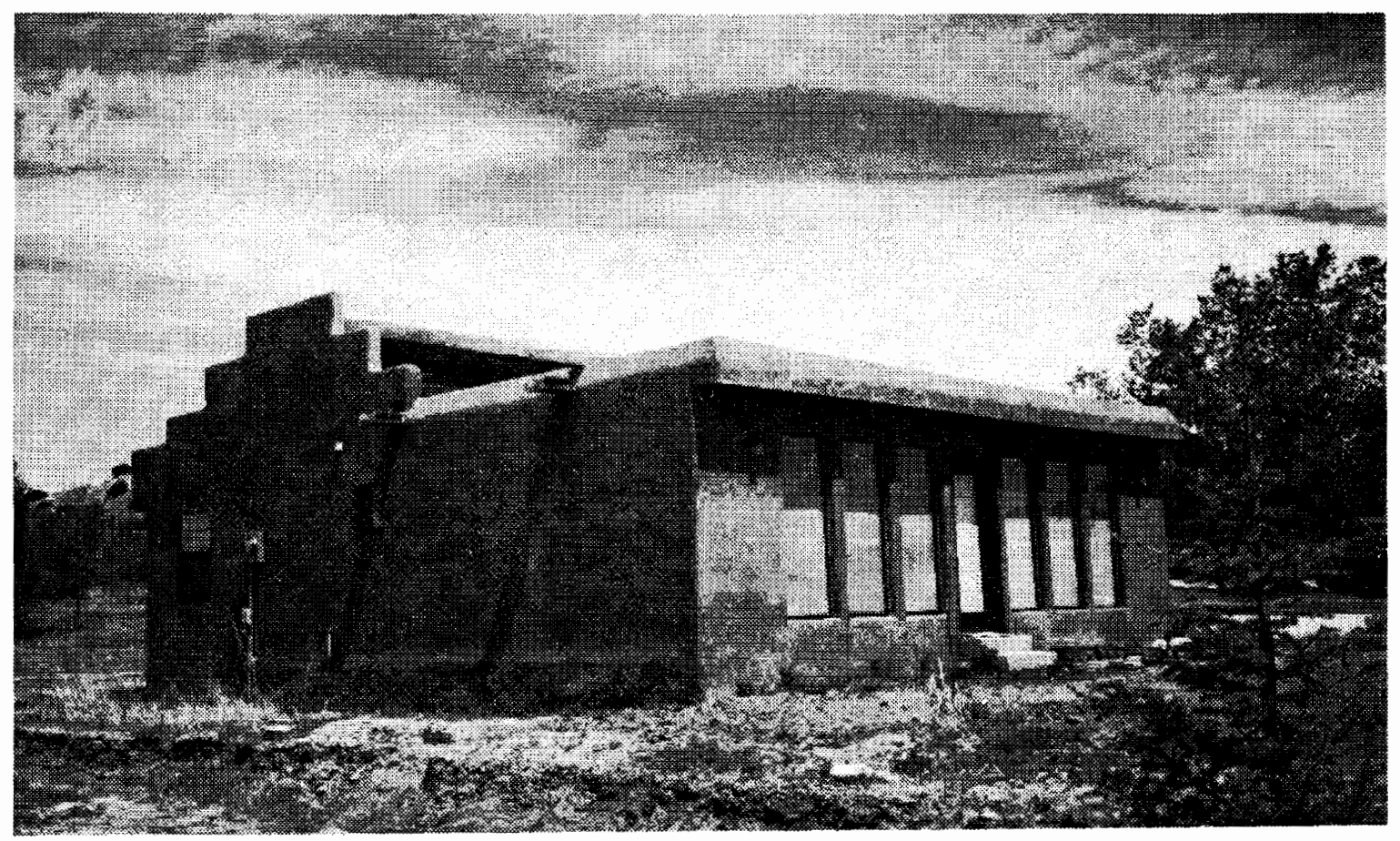

Direct-gain passive solar house on the Pojoaque Indian Reservation northwest of Santa Fe, New Mexico. Photo credit: D. Balcomb.

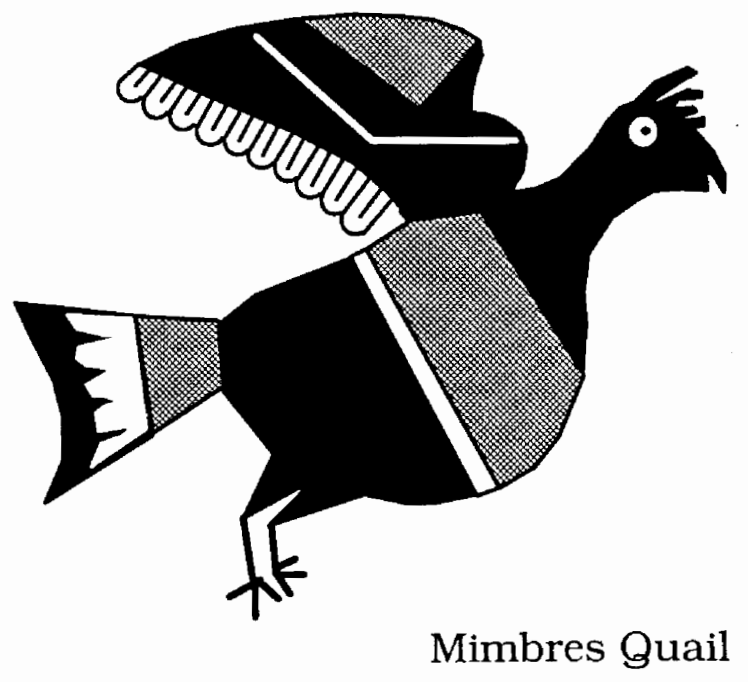




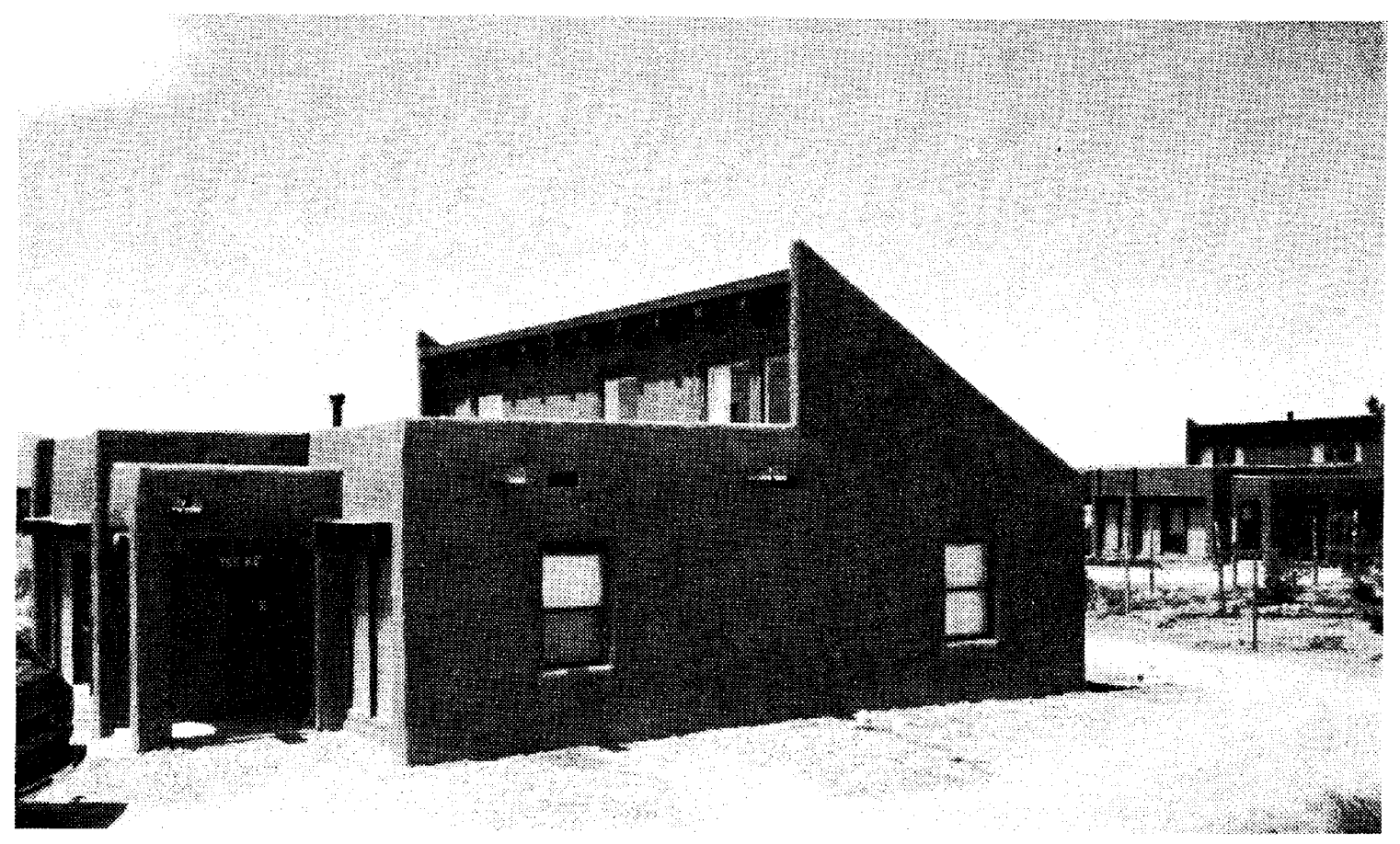

Passive solar house on the Nambe Indian Reservation in New Mexico. This house features Trombe walls on the south for delayed solar heat and clerestory windows for direct gain to the northern rooms. In the cold but sunny climate of the upper Rio Grande valley, good insulation and passive solar combine to produce good comfort and low heating bills. Photo credit: D. Balcomb.

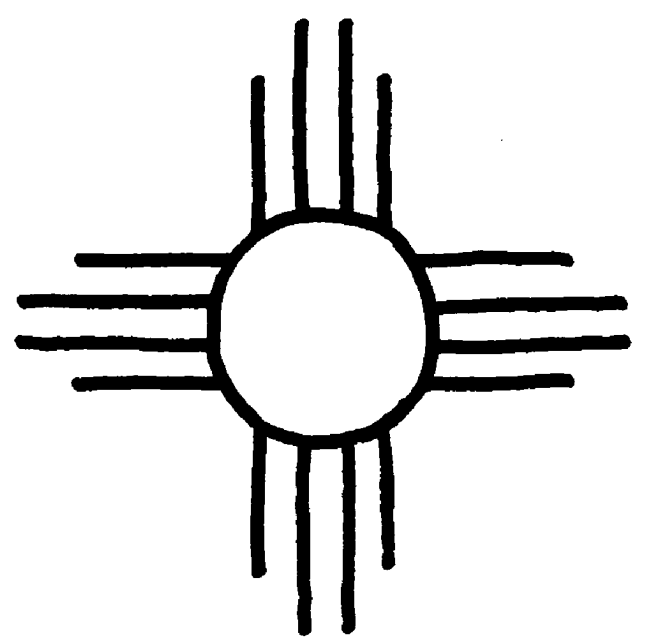

The Zuni sun symbol is the State Emblem of New Mexico. 


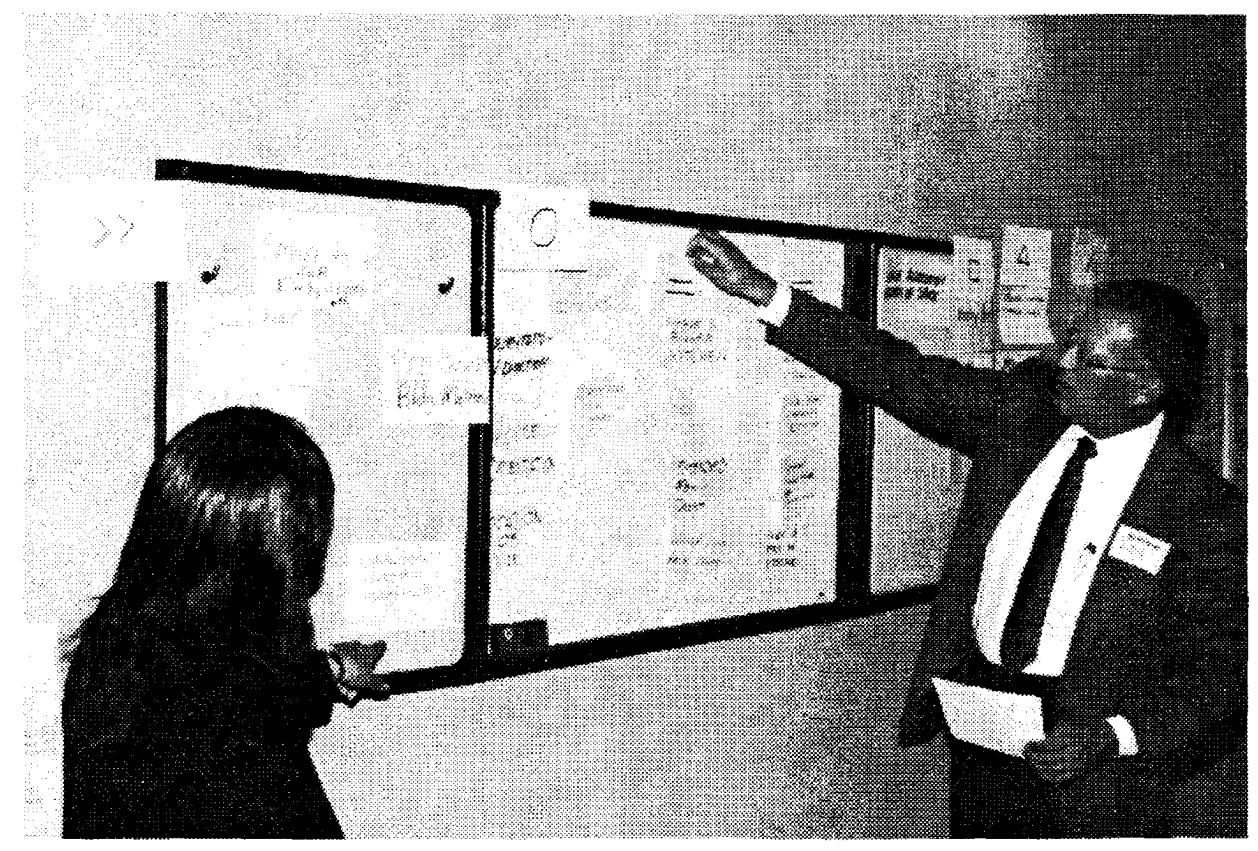

Opinion gathering: Louis Weller and Veronica Tiller at the American Indian Council of Architects and Engineers (AICAE) workshop in Seattle, Washington, April 10, 1991. Indians from the region were asked to comment on their housing needs and preferences. The AICAE report, Our Home: Giving Form to Traditional Values, Design Principles for Indian Housing, describes their findings. Participants were genuinely concerned with high heating costs and inadequate comfort.

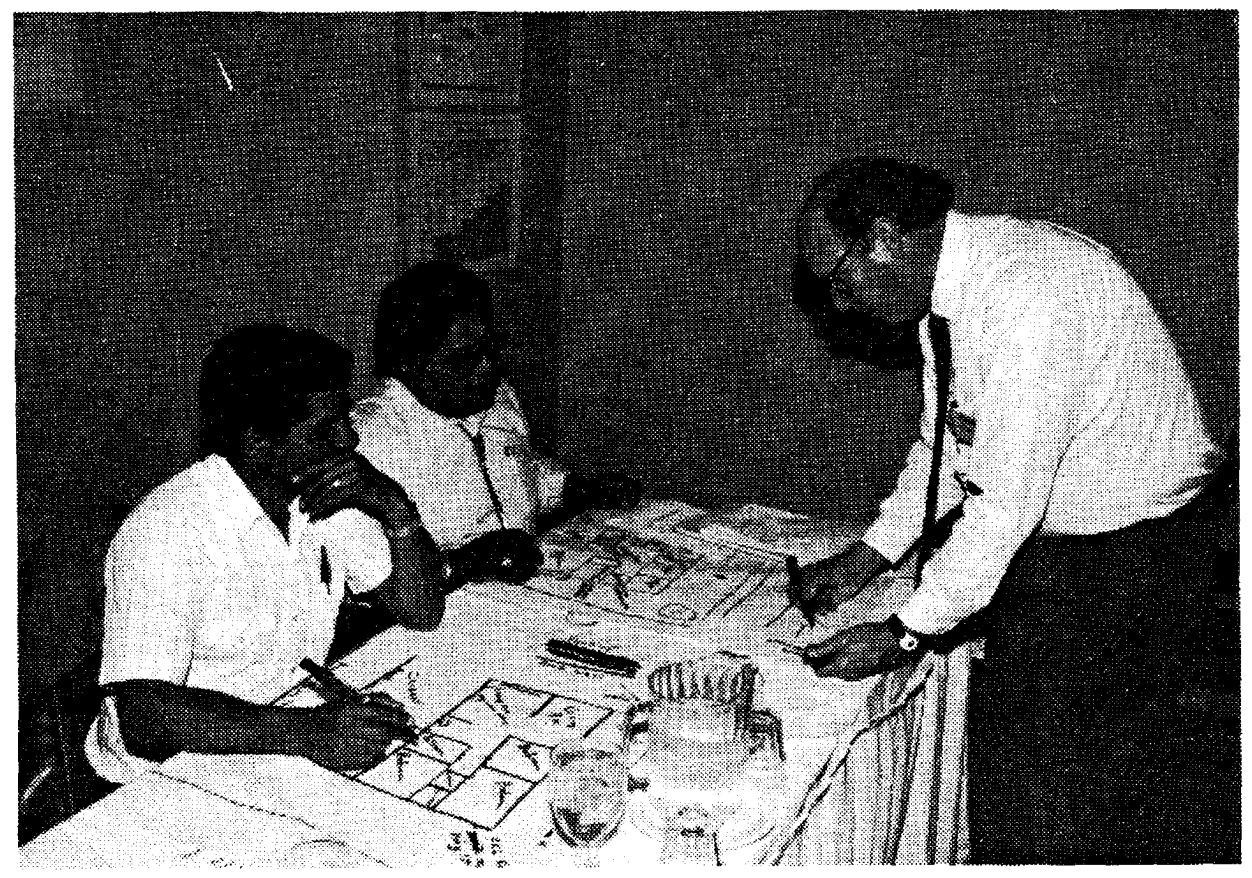

Design concepts in the making: Burke Wyatt working with participants at the AICAE workshop in Albuquerque, New Mexico, February 28, 1991. Indians from the region related their housing needs by sketching them. Two out of the dozens of design concepts that emanated from these workshops are included as examples in Section II starting on page 55. Photo credits: D. Balcomb. 


\section{SECTION I: GUIDELINES FOR DESIGN}

\section{Part One: Introduction}

\section{The Energy-Efficiency Design Guide}

The ideas behind energy-efficient housing are simple, but applying them effectively does require information and attention to the details of design and construction. In this design guide, energy efficiency includes the concepts of conservation, passive solar heating, and natural cooling. Some of these techniques are modest and very low cost, and require only small changes in a designer's standard practice. At the other end of the spectrum, an integration of several energy-efficient systems can almost eliminate a house's need for purchased energy--but perhaps at a somewhat higher first cost.

In between is a broad range of energy-efficient techniques. Whether or not they are cost effective, practical, and attractive enough to offer an advantage to any individual designer depends on very specific factors such as local costs and climate.

The Energy-Efficiency Design Guide is written to help give designers the information they need to make these decisions.

The Design Guide is a package in three basic sections:

- Section I contains information about energy-efficient techniques and how they work, and gives some specific design advice.

- Section II introduces the reader to the personal computer program BuilderGuide, which provides a simple, fill-in-the-blanks format you can use to quickly evaluate the performance of your specific design. It includes two worked examples for proposed Indian houses.

Section III gives designers and Indian Housing Authorities a realistic set of goals for energy-efficient design in different climates.

It is intended that these guidelines be used in conjunction with the BuilderGuide computer program. Nonetheless, it is entirely possible to use the guidelines without this program and get good results. The value of BuilderGuide is to add confidence by giving you a quantitative fix on the performance of the house you are planning to build. You will need BuilderGuide to ascertain whether your design conforms to the energyefficiency performance goals. 


\section{Overview of SECTION I: Guidelines for Design}

Some principles of energy-efficient design remain the same in every climate. But the important thing about energy efficiency is that it makes better use of the opportunities in a house's surroundings. So, many fundamental aspects of the energy-efficient house's design will depend on the conditions in a small local area, and even on the features of the building site itself.

Part One introduces the Energy-Efficiency Design Guide and presents a quick overview of the performance potential of energy-efficient systems. Although in practice many factors will affect actual energy performance, this information will give you a general idea of what to expect in your area. The relation of energy efficiency to Indian cultural issues is also discussed.

Part Two discusses the basic concepts of energy-efficient design and construction: what the advantages are of energy-efficient construction; how improved insulation, tight construction, passive solar heating, and natural cooling relate to each other; how the primary energy-efficient systems work; and what the designer's most important considerations should be when evaluating and using different strategies. Guidelines for insulation levels, window types, and solar glazing areas are given for 43 U.S. locations.

Part Three gives more specific advice about the passive solar techniques of suntempering, direct gain, sunspaces, and thermal storage mass walls.

Part Four gives more specific advice about the use of natural cooling to increase summer comfort.

These are the terms that will be used in this Design Guide:

- Added Insulation: increasing insulation levels without adding solar features.

- Tight Construction: decreasing air infiltration and the heat needed to warm this air.

- Suntempering: increasing south-facing glazing to a maximum of $7 \%$ of the house's total floor area, but without adding thermal mass (energy storage) beyond what is already in the framing, standard floor coverings and gypsum wall-board, and ceiling surfaces. Insulation levels are also increased.

- Passive Solar: using three different design approaches: Direct Gain, Sunspace, and Thermal Storage Wall. Passive solar includes all types of solar heating systems in which heat flow is by natural means--radiation, conduction, and natural convection. No pumps or fans are required for the system to operate. These systems are well 
integrated into the architecture of the house using normal materials of construction.

The Guide has been kept as brief and straightforward as possible, but more detailed information is available if needed. Some references are indicated in the text, and a list of other information sources can be found in the References. Also included at the end of the Guide are a brief Glossary and two pages explaining some of the background and assumptions behind the Guidelines and BuilderGuide called Technical Basis for the Design Guidelines.

\section{Overview of SECTION II: The BuilderGuide PC Program}

Few designers can confidently achieve good energy-efficient designs without "doing the numbers". In the past, this has been an onerous undertaking that involved extensive calculations. Most designers never did any calculations to support their design decisions because it took too long or required the assistance of an engineer who was knowledgeable in the complexities of the analysis. BuilderGuide changes all that.

BuilderGuide is a PC program that is easy to use, "builder friendly", as they say. Calculations that you will make with this program are a very important part of the energy-efficient design process because they allow you to quickly assess different energy-efficient strategies or combinations of strategies and the effect that changes will have on the overall performance of the house in your climate.

BuilderGuide provides a simple way to quickly calculate how well a design is likely to perform in four key ways: how well the house will conserve heat; how much the solar features will contribute to the total heating energy needs; how comfortable the house will be; and how much air conditioning will be needed to maintain summer comfort. You can compare your results with the appropriate performance goal to see how well you are doing. You can also do tradeoffs quickly, for example, to see the benefit of adding insulation or extra mass.

So, BuilderGuide provides you with four key numbers indicating the projected performance of the various designs you are evaluating.

Two Examples are included in Section II that demonstrate the use of BuilderGuide in evaluating the performance of two houses designed by Indians.

Note that the BuilderGuide computer program itself is not included with the Energy-Efficiency Design Guide. However, the computer disks and manual can be readily obtained from the Passive Solar Industries Council, together with data files for any of 205 locations in the United States. 


\section{Overview of SECTION III: Energy-Efficiency Performance Goals}

This section contains recommendations for the overall performance of the house, presented in terms of the maximum amount of auxiliary heat and auxiliary cooling the house should use, as computed by BuilderGuide. These are voluntary goals. Results are presented as tables of maximum allowable $\mathrm{Btu} / \mathrm{ft}^{2}$ for 43 U.S. locations.

For guidance on how to reach your conservation performance goal, refer to the insulation guidelines on pages 20 and 21 . These tables give suggestions for components, such as R-values for walls, ceiling, and perimeter, window type, and equipment efficiencies. If these component recommendations are followed, then the house will likely meet the conservation performance goal. For guidance on how to reach your auxiliary heating performance goal, refer to the guidelines for passive solar glazing area on page 25 .

The performance goals are presented in the spirit of voluntary compliance. They have no force in law or regulation. However, they have been developed based on the principle of economic optimization. This means that it is cost effective to install energy-efficient features as required to meet the performance goals, based on the payback in energy savings that will accrue over the life of the house. Different goals are given for houses heated by gas and those heated by electricity.

\section{Index to the Tables}

Tables for 43 cities are scattered throughout this guide. These tables and their page locations are as follows:

Table

Page

Savings of houses that meet the performance goals $\quad 10$ Insulation guidelines, houses heated with gas 20 Insulation guidelines, houses heated with electricity 21 Passive solar guidelines $\quad 25$ NAHB 1980 housing characteristics 53 BuilderGuide results for NAHB basecase $\quad 54$ Conservation performance goals $\quad 76$ Auxiliary heating performance goals $\quad 77$ $\begin{array}{ll}\text { Summer cooling performance goals } & 78\end{array}$ $\begin{array}{ll}\text { Heating and cooling degree days } & 79\end{array}$ 


\section{How Energy Efficiency Relates to Cultural Issues in Indian Housing}

Energy efficiency is not only completely compatible with culturally relevant Indian housing, but it should be part of it.

Indian cultures have always stressed living in harmony with their environment. That which is taken is replaced. The natural order is left intact. Modern American culture, by contrast, seems more inclined to exploit nature and to disrupt the natural order.

Original Indian cultures in America and early cultures in Europe did little to heat their houses. The home provided shelter from the wind, snow, and rain. Wood-burning stoves and fireplaces were used to keep a small area, a room or two, somewhat warmer than the outside, at least part of the time. People were tough, inured to the cold, and used to dressing warmly, even when inside.

We read of Indian homes in New England that were as "warm as the best English houses" and of tipis that were "warm in the winter and cool in the summer". These statements must be understood in the context of their time. Comfort can be relative. English houses of that time were really uncomfortable. Certainly conditions inside the Indian house on a harsh winter night would have been much better than outside. Enough people crowded around the tipi fire would maintain reasonable comfort for awhile. The natural ventilation of the tipi would be very effective in the plains but would hardly cope with the humidity of a Florida summer.

These are traditions that have been lost. Most people, Indian or not, do not yearn for a return to these conditions. It is now expected that houses will be kept comfortable. The loss of this lifestyle is no more mourned than the demise of the outdoor toilet. Comfort standards for Indians are no different than those for any other people. Indians expect and deserve comfortable places to live and work. The cost of this comfort is now accepted as a necessity, not a luxury.

\section{The Cost of Comfort}

But what should it cost to maintain modern standards of comfort? We have developed a culture of poorly insulated houses maintained comfortable only by the use of prodigious amounts of energy. If the energy equivalent of the 20 barrels of oil required to heat the house for one winter were to be stacked inside, it would fill the living room. We are not so aware of this because it usually arrives in the form of natural gas delivered quietly though a pipe. Awareness arrives with the utility bill.

The United States uses 13\% of its energy just to heat and cool its homes and hot water. The energy equivalent is that of some 1690 million barrels of oil at a cost of $\$ 55$ billion each year. That is $\$ 613$ per household each year. The irony is that most of this energy is not really needed. We now know how to build houses that can be kept comfortable on no more than $30 \%$ of this energy, and they do not cost much more to build (perhaps 
$5 \%$ added on to the total construction cost). The purpose of this Design Guide is to begin changing this situation--at least with new houses for Indians and Alaskan Natives.

The cost of supplying comfort goes beyond dollars. The cost to our environment is staggering--a cost measured in tons of particulates in the air, in dead ocean birds, in lost national and personal security, in trees killed by acid rain. Indians once lived in balance with their environment-a sustainable lifestyle--but no longer. Our present course is not sustainable.

It is a far better thing to use a cubic foot of natural gas in the manufacture of fiberglass insulation than in the heating of a house. The fiberglass will save dozens of cubic feet of gas that would otherwise be burned during the lifetime of the house.

A house that meets the auxiliary heating performance goals suggested in these guidelines is unlikely to ever freeze, even without backup heat.

\section{The Symbolism of Light}

The sunlight that enters a thoughtfully designed passive solar home will reinforce Indian cultural traditions. Most Indian cultures look to the morning sun. The door of a Navajo hogan opens to the east. This same light that nourishes the soul will warm the house on a winter morning.

The Indian sense of place is usually identified with the four directions, the cardinal points of the compass. Passive solar design principles also teach us to treat each of the four building facades differently--in response to the very different impact that sun and wind have on the house. The south side is the primary passive solar receiver. Most of the windows are placed on the south--to accept the winter sun and shut out the summer sun--a natural consequence of the changing sun path between winter and summer. Moderate use of east windows provides early morning wakeup, both visually and thermally. West windows are kept to a minimum to prevent summer overheating. Moderate use of north windows provides a high quality of daylight on the north side; summer heating is minimal and winter heat losses can be controlled with the use of modern low-loss windows. Summer breezes, usually from the west or south, ventilate the house through well-placed window openings, refreshing and cooling the house. The designer of the house must create a sensitive blend of these characteristics with the symbolism of the tribal perception of the four directions, embodying the appropriate use of light, texture, and color. No universal formula can be prescribed because the symbolism varies from one Indian culture to another.

Passive solar apertures are also often placed in the roof, as clerestories or roof monitors with the glass vertical and facing south. This same feature opens the possibility of visually opening the roof to the sky, symbolizing the duality of light above and dark below (which is also good passive solar design practice). The sun, perhaps the most important celestial 
symbol, is brought into the life of the house, blessing it with light and warmth.

\section{The Symbolism of Space}

As a general principle, a large and open central space is critical to Indian tradition. The space serves a communal function. The space is often circular, representing a "philosophy of the cycles of nature and the continuity of life". The circle also "symbolizes equality and the concept of sharing".

Openness of space also serves well in passive solar design. Solar heat is collected primarily on the south side of the house and must be distributed, primarily by natural convection, to the north side. A open floor plan facilitates this transfer. A large central area, with rooms radiating from it to the east, north, and west, is an ideal passive solar plan.

\section{The Symbolism of Materials}

Indians traditionally lived in constant contact with the materials of their natural environment and came to regard these materials as important symbols. Such materials can also serve important thermal and luminance functions within a house.

Massive natural materials, such as adobe and rock, are very effective for storing solar heat admitted into the house during the day. Their effectiveness in this role depends on their location and color, as discussed in Parts Two and Three of Section I. A massive floor, always a feature of traditional Indian houses, is very effective heat storage but only where the sun shines directly on it. Other mass in walls or roof is effective even without direct solar radiation. Generally, floors should be dark in color and other surfaces light in color for the greatest effectiveness. This may or may not be completely consistent with cultural tradition. These are factors that the designer must weigh.

Wood is another primary material used in traditional Indian houses. Unfortunately, wood is not particularly effective for energy efficiency. Although wood has a low thermal conductivity, it cannot compete with fiberglass for wall or roof insulation. Although it has a high heat capacity, the low conductivity prevents it from being very effective for thermal storage. The wonderful texture, color, and character of wood are justification enough for using it inside the house, but it should not be considered as a particularly effective insulating or heat-storage material.

\section{Harmony with Nature}

More than anything else, energy-efficient passive solar houses are designed to exist in harmony with nature. The natural environmental influences of sun, wind, heat, and cold are taken into account in the design. The pleasure of living in a house that naturally maintains comfort most of the time, both winter and summer, must be experienced 
to be appreciated. It is a marvel that will reinforce culturally relevant Indian housing.

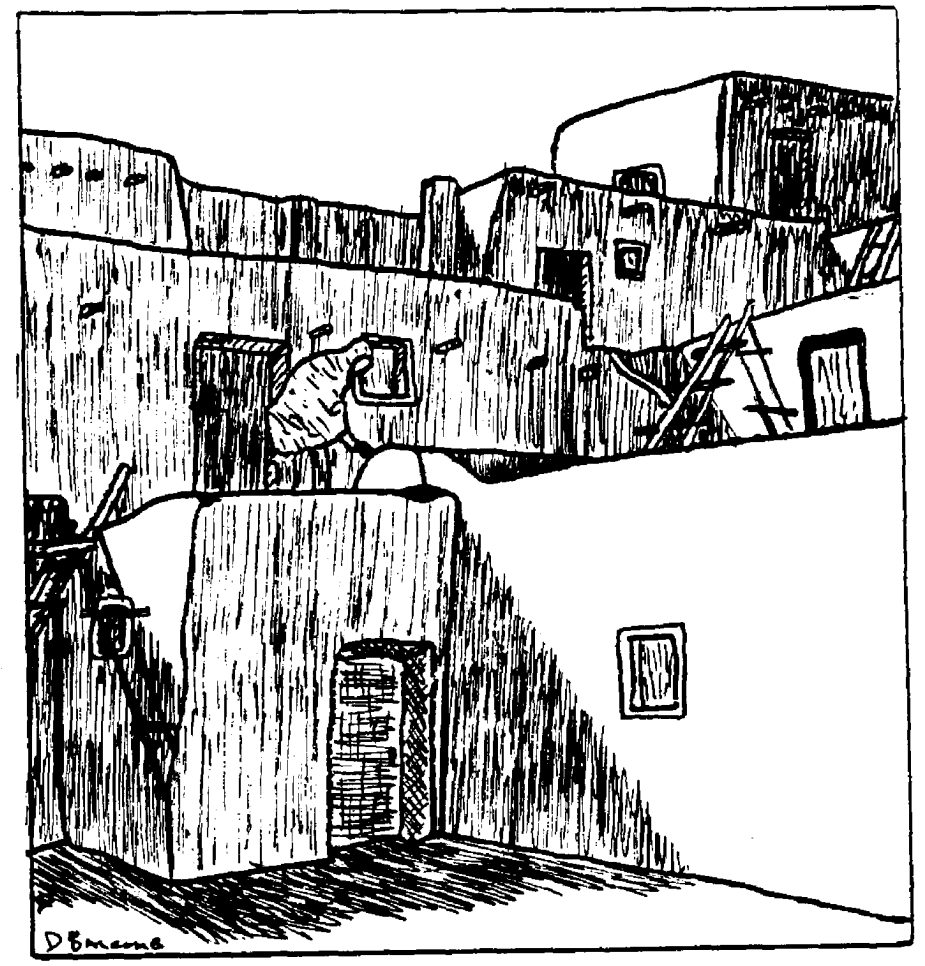

Indigenous materials, southerly orientation, and building form were used to enhance the comfort of pueblo structures such as Taos Pueblo. With modern insulation and windows, much greater thermal performance and comfort can be obtained while retaining traditional architectural texture and feel.

\section{Energy-Efficiency Savings Potential}

The energy performance of energy-efficient strategies varies significantly, depending on climate, the specific design of the system, and the way it is built and operated. Of course, energy performance is not the only consideration, but it is an important one.

As a starting point, we choose a $1500-\mathrm{ft}^{2}$ basecase single-story house insulated in accordance with a 1980 survey done by the National Association of Home Builders. These conservation levels are given on page 53 in Section II. To this we then add conservation, passive solar, and natural cooling measures to achieve the performance goals recommended in Section III. The total savings are listed for $43 \mathrm{U} . \mathrm{S}$. locations in the table on page 10 . For electrically heated homes, the overall annual energy savings vary from $18 \%$ in Brownsville, Texas, to $66 \%$ in Cheyenne, Wyoming. The savings are smaller for houses heated with gas but are still quite substantial.

Another figure of interest shown in the table is the solar savings fraction, SSF, assuming that you follow both the conservation and the passive solar guidelines. This number indicates the percentage of the heat required by the nonsolar elements of the house (all heat loss except the south glass) that is saved by solar heat trapped by the south glass. It is 
the net benefit of the solar elements accounting for both solar gains and heat losses. For electrically heated homes, these SSFs vary from $10 \%$ in Buffalo, New York, to $61 \%$ in Reno, Nevada.
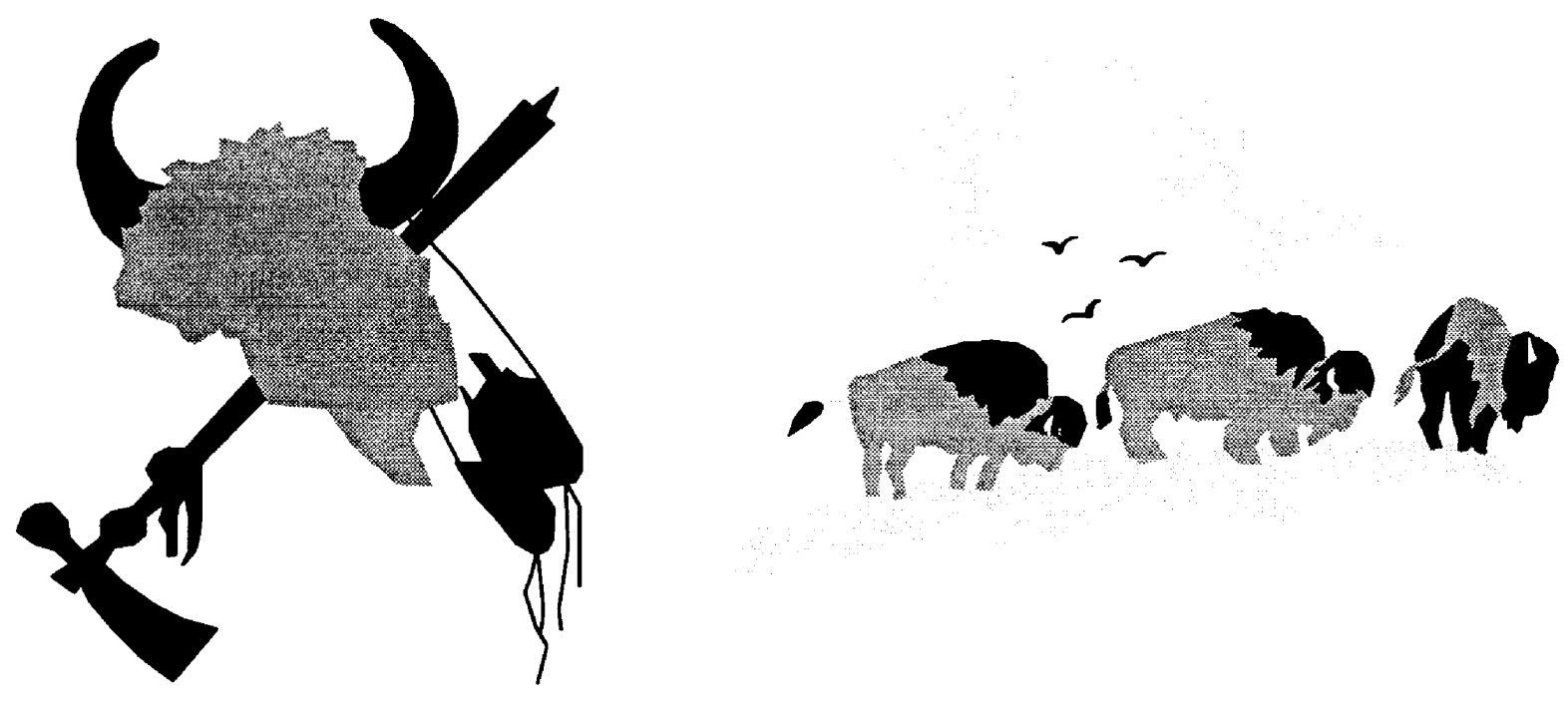

Images from the plains

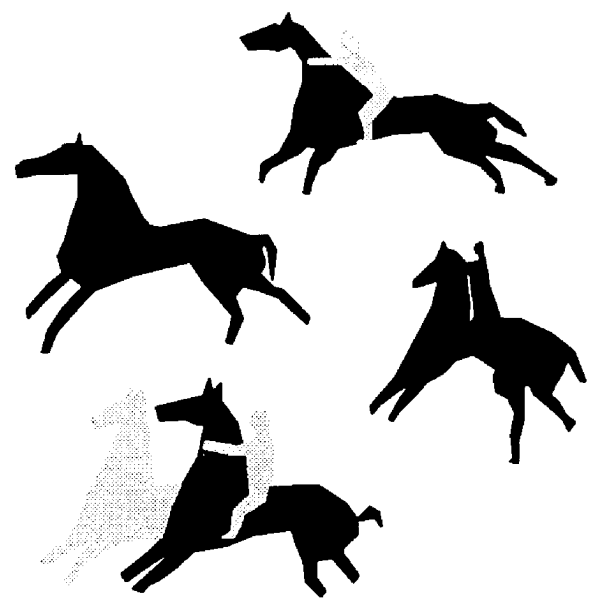


Energy Savings, percent of the annual energy requirements of the basecase house.

This table gives the percent savings for a house that follows the guidelines compared with the NAHB basecase house. The solar savings fraction of the house is also included.

House Heating:

Gas

Electricity

Heating Cooling Total SSFHeating Cooling Total SSF

\begin{tabular}{|c|c|c|c|c|c|c|c|}
\hline Albuquerque, NM & 31 & 24 & 29 & 38 & 61 & 36 & 55 \\
\hline Atlanta, GA & 26 & 22 & 24 & 19 & 53 & 33 & 47 \\
\hline Birmingham, AL & 23 & 27 & 24 & 20 & 54 & 40 & 49 \\
\hline Bismarck, ND & 40 & 41 & 40 & 12 & 49 & 48 & 49 \\
\hline Boise, ID & 42 & 40 & 42 & 19 & 60 & 45 & 58 \\
\hline Boston, MA & 47 & 44 & 46 & 14 & 55 & 50 & 54 \\
\hline Brownsville, TX & 27 & 6 & 11 & 51 & 35 & 13 & 18 \\
\hline Buffalo, NY & 39 & 41 & 39 & 8 & 53 & 48 & 53 \\
\hline Burlington, VT & 38 & 38 & 38 & 10 & 50 & 46 & 50 \\
\hline Charleston, SC & 28 & 19 & 24 & 27 & 52 & 30 & 43 \\
\hline Cheyenne, WY & 49 & 41 & 49 & 36 & 67 & 44 & 66 \\
\hline Chicago, IL & 41 & 31 & 39 & 12 & 50 & 38 & 48 \\
\hline Cincinnati, $\mathrm{OH}$ & 32 & 43 & 34 & 13 & 47 & 51 & 48 \\
\hline Denver, CO & 50 & 53 & 51 & 39 & 68 & 54 & 66 \\
\hline El Paso, TX & 39 & 30 & 36 & 36 & 58 & 21 & 43 \\
\hline Fort Worth, TX & 29 & 16 & 24 & 24 & 56 & 28 & 44 \\
\hline Fresno, CA & 42 & 24 & 34 & 28 & 54 & 37 & 47 \\
\hline Great Falls, MT & 41 & 33 & 41 & 15 & 58 & 34 & 57 \\
\hline Jackonsville, FL & 30 & 18 & 23 & 35 & 51 & 19 & 34 \\
\hline Lake Charles, LA & 29 & 16 & 22 & 28 & 45 & 18 & 31 \\
\hline Las Vegas, NV & 36 & 24 & 30 & 37 & 60 & 29 & 46 \\
\hline Los Angeles, CA & 29 & 14 & 24 & 47 & 58 & 29 & 48 \\
\hline Medford, OR & 15 & 34 & 19 & 17 & 40 & 55 & 43 \\
\hline Memphis, TN & 22 & 22 & 22 & 16 & 52 & 38 & 47 \\
\hline Minneapolis, MN & 32 & 35 & 32 & 10 & 48 & 41 & 47 \\
\hline Nashville, TN & 35 & 26 & 33 & 14 & 51 & 42 & 49 \\
\hline New York, NY & 38 & 34 & 37 & 12 & 51 & 39 & 49 \\
\hline Oklahoma City, OK & 36 & 40 & 37 & 21 & 58 & 44 & 54 \\
\hline Omaha, NE & 42 & 35 & 40 & 16 & 54 & 42 & 52 \\
\hline Philadelphia, PA & 37 & 42 & 38 & 13 & 53 & 48 & 52 \\
\hline Phoenix, AZ & 30 & 10 & 18 & 50 & 30 & 10 & 18 \\
\hline Pittsburgh, PA & 40 & 38 & 39 & 11 & 53 & 43 & 52 \\
\hline Portland, ME & 39 & 57 & 40 & 10 & 51 & 66 & 52 \\
\hline Portland, OR & 14 & 29 & 16 & 14 & 34 & 55 & 36 \\
\hline Reno, NV & 35 & 37 & 36 & 40 & 60 & 49 & 58 \\
\hline Salt Lake City, UT & 43 & 43 & 43 & 21 & 63 & 49 & 60 \\
\hline San Antonio, TX & 29 & 14 & 21 & 33 & 52 & 27 & 39 \\
\hline San Diego, CA & 9 & 12 & 10 & 44 & 54 & 25 & 42 \\
\hline San Francisco, CA & 43 & 28 & 41 & 34 & 58 & 31 & 55 \\
\hline Seattle, WA & 43 & 48 & 43 & 16 & 55 & 59 & 55 \\
\hline Tampa, FL & 29 & 7 & 13 & 57 & 40 & 14 & 21 \\
\hline Topeka, KS & 43 & 27 & 39 & 18 & 56 & 33 & 50 \\
\hline Washington, DC & 28 & 27 & 28 & 14 & 52 & 40 & 49 \\
\hline
\end{tabular}




\section{Part Two: Basics of Energy Efficiency}

\section{Why Energy-Efficient? More than a Question of Energy}

Houses today are more energy efficient than ever before. However, the vast majority of new houses still ignore a lot of energy-saving opportunities--opportunities available in the sunlight falling on the house, in the landscaping, breezes, and other natural elements of the site, and opportunities in the structure and materials of the house itself, which, with thoughtful design, could be used to collect and use free energy. Passive solar (the name distinguishes it from "active" or mechanical solar technologies) is simply a way to take maximum advantage of these opportunities.

In addition to economic and environmental advantages, energy-efficient homes are inherently more comfortable and adaptable to cultural and individual requirements. Other related advantages are simplicity, ease of maintenance, and reliability. A house that appropriately combines the three key ingredients emphasized in this guide--mass, glass and insulation--and meets the suggested performance goals for electrically heated homes-is very stable. It responds very slowly to weather changes and is unlikely to freeze during a power outage.

The public has become increasingly sophisticated about energy issues, although the average person is probably much more familiar with insulation than with passive solar. The "energy crisis" may have ups and downs, but very few people perceive their own household energy bills to be getting lower, in fact, quite the opposite. Everyone knows that energy efficiency is an investment in the future.

But there are many different ways to reduce energy bills, and some are more evident than others. For instance, adding insulation can markedly improve energy efficiency, but added insulation is invisible. A sunny, open living area lit by south-facing windows or a bright, attractive sunspace, on the other hand, not only reduces energy costs but enhances the quality of life of those living in the house. Windows, in general, are popular, and passive solar can make windows energy producers instead of energy liabilities.

Passive solar is a very important option to consider. The point is not that a designer should choose passive solar instead of other energyconserving measures. The important thing is that passive solar can add not only energy efficiency, but also very attractive amenities--style, comfort, and attractive interiors--and help associate the house with cultural traditions of the tribe. 


\section{Advantages of Energy Efficiency}

- Energy performance: lower energy bills year-round

- Attractive living environment: large windows and views, sunny interiors, open floor plans

- Comfort: quiet (no operating noise), solid construction, warmer in winter, cooler in summer (even during a power failure)

Value: high occupant satisfaction

Low maintenance: durable, reduced operation and repairs

Investment: independence from future rises in fuel costs will continue to save money long after any initial costs have been recovered

Environmental concerns: clean, renewable energy to combat growing concerns over global warming, acid rain, and ozone depletion

\section{Key Concepts: Energy Conservation, Suntempering, Passive Solar}

The strategies for enhancing energy performance that are presented here fall into four general categories:

- Energy Conservation: insulation levels, control of air infiltration, glazing type and location, and mechanical equipment.

- Suntempering: a limited use of passive solar techniques; modestly increasing south-facing window area, usually by relocating windows from other sides of the house, but without adding thermal mass.

- Passive Solar: going beyond conservation and suntempering to a complete system of collection, storage, and use of solar energy: using more south-facing glass, adding significant thermal mass, and taking steps to control and distribute heat energy throughout the house.

- Natural Cooling: Using design and the environment to both cool the house and reduce summer heating by the sun.

What is immediately clear is that these categories overlap. For instance, a good energy conservation package is the necessary starting point of all well-designed suntempered and passive solar houses. There's no use collecting solar energy if it is immediately lost through leaky windows or poorly insulated walls. Overdone or improperly done, passive solar will continue to heat the house in the summer, causing discomfort or high air-conditioning bills.

In the same way, many of the measures that are often considered part of suntempering or passive solar--such as orienting to take advantage of 
summer breezes, landscaping for natural cooling, or facing a long wall of the house south--can help a house conserve energy even if no "solar" features are planned.

The essential elements in a passive solar house are south-facing glass and thermal mass.

In the simplest terms, a passive solar system collects solar energy through south-facing glass and stores solar energy in thermal mass-materials with a high capacity for storing heat (for example, adobe, brick, concrete masonry, concrete slab, and tile). The more south-facing glass is used in the house, the more thermal mass must be provided, or the house will overheat, and the solar system will not perform as expected.

With too much glass and/or insufficient mass, solar energy can work too well, and the house can be uncomfortably hot even on a winter day.

Although the concept is simple, in practice, the relationship between the amount of glazing and the amount of mass is complicated by many factors, and has been a subject of considerable study and experiment. From a comfort and energy standpoint, it would be difficult to add too much mass. Thermal mass will hold warmth longer in winter and keep houses cooler in summer. But thermal mass has a cost, and so adding too much mass for just thermal storage purposes can be unnecessarily expensive.

The following sections of the Design Guide discuss the size and location of glass and mass, as well as other considerations that are basic to both suntempered and full passive solar houses: improving conservation performance; mechanical systems; orientation; site planning for solar access; interior space planning; and taking an integrated approach to the house as a total system.

\section{Improving Conservation Performance}

The most important measures for improving the house's basic ability to conserve the heat generated either by the sun or by the house's conventional heating system are in the following areas:

- Insulation

- Air infiltration

- Nonsolar glazing

Guidelines for insulation levels and window types are given for 43 U.S. locations.

\section{Insulation}

Adding insulation to walls, floors, ceilings, the roof, and the foundation improves their thermal resistance (R-value)--their resistance to heat flowing out of the house. 
A quality job of installing the insulation can have almost as much effect on energy performance as does the R-value, so careful construction supervision is important. An inspection just before the drywall is hung identifies improvements that are easy to complete at that time but will make a big difference in the energy use of the home for years to come.

The thermal resistance of ceiling/roof assemblies, walls, and floors is affected not only by the R-value of the insulation itself, but also by the resistance of other elements in the construction assembly--framing effects, sheathing, interior drywall, and so on. The help text in BuilderGuide includes tables that show Equivalent Construction R-values for walls, ceilings, and house perimeters, that account for these and other effects. For instance, ventilated crawlspaces and unheated basements provide a buffering effect. One of these BuilderGuide tables is reproduced below.

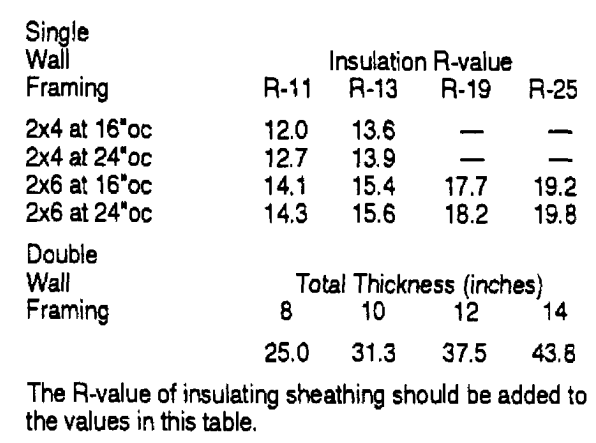

Source: BuilderGuide help text

\section{R-values for Particular Wall Constructions}

These numbers are overall effective $R$-values including allowance for framing, sheathing, and inside and outside film coefficients. To account for insulating sheathing added to the exterior, simply add the $R$-value of the sheathing to these values.

With attics, framing effects are minimized if the insulation covers the ceiling trusses, either by using blown-in insulation or by running an additional layer of batts in the opposite direction of the ceiling joists. Ridge and/or eave vents are needed for ventilation. 


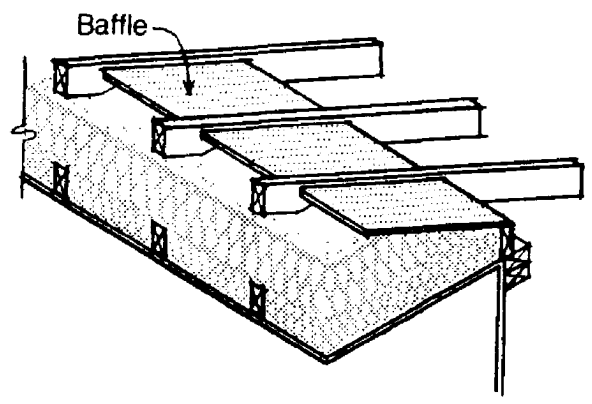

\section{Insulation in an Attic}

Insulation should extend over the top ceiling joists, and ventilation should be provided at the eaves.

In framed ceiling/roof assemblies, an insulating sheathing over the top decking will increase the R-value.

Slab edge insulation should extend at least 2-ft deep, measured from the surface of the floor. Materials for slab edge insulation should be selected for underground durability. One material with a proven track record is extruded polystyrene. Exposed insulation should be protected from physical damage by attaching a protection board, for instance, or by covering the insulation with a protective surface.

In colder climates, basement walls should be fully insulated to at least 4 -ft below grade, but the portion of the wall below that depth only needs to be insulated to about half the R-value of the upper portion. Insulation can be placed on the outside surface of the wall, on the inside surface of the wall, or in the cores of the masonry units.

If the basement walls are insulated on the outside, the materials should be durable underground, and exposed insulation should be protected from damage. In the case of a finished basement or walk-out basement, placing insulation on the interior may be less costly than insulating the exterior foundation.

\section{Air Infiltration}

Sealing the house carefully to reduce air infiltration--air leakage--is as necessary to energy conservation as adding insulation. Air will flow rapidly through cracks and crevices in the wall, in the same way water flows through the drain in a bathtub, so even a small opening can allow heat to bypass the insulation and lead to big energy losses.

The tightness of houses is generally measured in the number of air changes per hour $(\mathrm{ACH})$. A good, comfortable, energy-efficient house that follows the checklist on the next page will have approximately 0.35 to 0.50 air changes per hour under normal winter conditions.

Increasing the tightness of the house beyond that can improve the energy performance, but it can also create problems with indoor air quality, moisture buildup, and inadequately vented fireplaces and furnaces. 
Some kind of additional mechanical ventilation--for example, small fans, heat pump heat exchangers, integrated ventilation systems, or air-to-air heat exchangers--will probably be necessary to avoid such problems in houses with less than $0.35 \mathrm{ACH}$.

In cold climates (above about 6000 heating degree days), the combination of a super-tight house and an air-to-air heat exchanger will be quite cost effective. However, because this is a mechanical system, it is subject to failure. The builder should ensure that the occupants of the house are properly aware of the system, of the necessity of its continued operation through the years, and that repairs and replacement parts will be available.

The use of a house-sealing subcontractor to do the tightening and check it with a blower door can often save the designer time and problems, especially when trying to achieve particularly high levels of infiltration control. This may be warranted in cold climates.

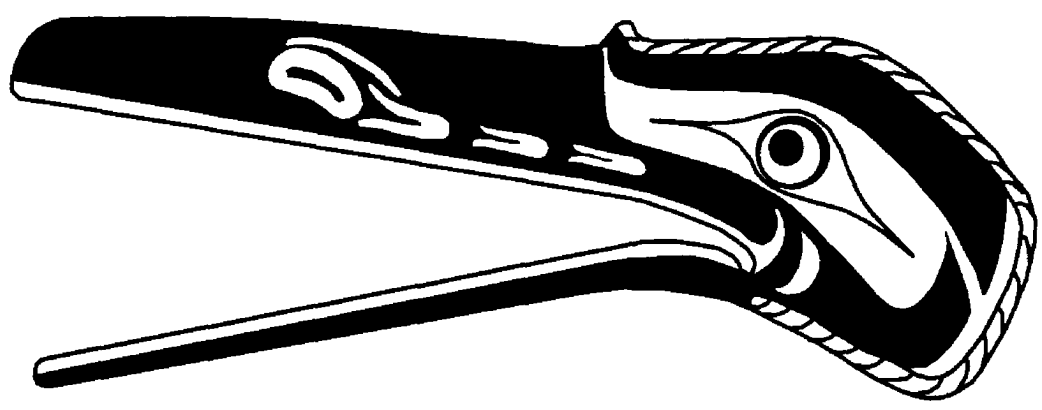

Kwakuitl raven 
Checklist for Minimizing Air Leakage

$\checkmark \quad$ Tighten seals around windows and doors, and weatherstripping around all openings to the outside or to unconditioned rooms

$\checkmark \quad$ Caulk around all windows and doors before drywall is hung; seal all penetrations (plumbing, electrical, etc.)

$\checkmark \quad$ Insulate behind wall outlets and/or plumbing lines in exterior walls

Caulk under headers and sills

Chink spaces between rough openings and millwork with insulation, or for a better seal, fill with foam

$\checkmark \quad$ Seal larger openings such as ducts into attics or crawlspaces with taped polyethylene covered with insulation

$\checkmark$ Locate continuous vapor retardants located on the warm side of the insulation (building wrap, continuous interior polyethylene, etc.)

$\checkmark$ Install dampers and/or glass doors on fireplaces, combined with outside combustion air intake

Install backdraft dampers on all exhaust fan openings

Caulk and seal the joint between the basement slab (or the slab on grade) and the basement wall

Remove wood grade stakes from slabs and seal

Cover and seal sump cracks

Close core voids in top of block foundation walls

Control concrete and masonry cracking

Using air tight drywall methods is also acceptable (see Reference 11)

Employ appropriate radon mitigation techniques (see References 13 and 14).

\section{Nonsolar Glazing}

South-facing windows are considered solar glazing. The south windows in any house are contributing some solar heat energy to the house's heating needs--whether it's a significant, usable amount or hardly worth measuring will depend on design, location, and other factors that are dealt with later under the discussions of suntempering and passive solar systems.

North windows in almost every climate lose significant heat energy and gain very little useful sunlight in the winter. East and west windows are likely to increase air conditioning needs unless heat gain is minimized with careful attention to shading. 
But most of the reasons people want windows have very little to do with energy, so the best design will probably be a good working compromise between efficiency and other benefits, such as bright living spaces and views.

Double glazing of all glazing is advisable. Storm windows over double glazing or double glazing with a low-e coating is advisable in cold climates. Low-e glazing on all windows may be an especially useful solution because some low-e coatings can insulate in winter and shield against unwanted heat gain in summer.

Manufacturers will provide actual R-values for their windows (the thermal performance of glazing can be expressed either as an R-value or its reciprocal, the U-value; here all thermal performance values are given in terms of R-value). The chart shows approximate window R-values for various types. (The Overall Effective R-value pertains to the entire rough-frame window opening.)

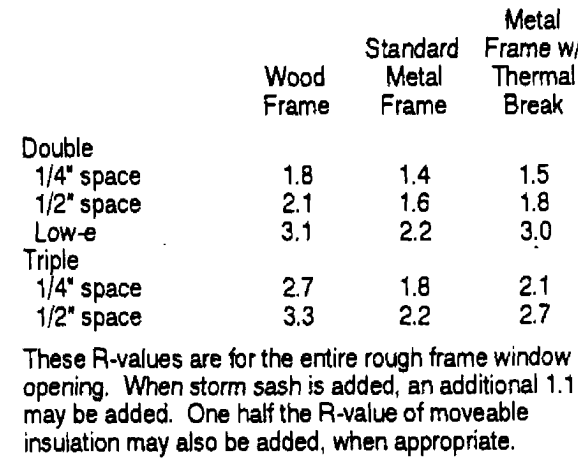

Source: BuilderGuide help text

\section{Overall Effective R-values for Windows}

This table accounts for the frame and is based on the rough frame opening area.

North windows should be used with care. Sometimes views or diffuse northern light are desirable, but in general, north-facing windows should not be large. Because north windows receive relatively little direct sun in summer, they do not present much of a shading problem. So if the choice were between an average-sized north-facing window and an east or west-facing window, north would actually be a better choice, considering both summer and winter performance.

East windows catch the morning sun. This can be particularly important in Indian housing because openings to the east have a special symbolism in most Indian cultures. Be careful, however, not to oversize, because the net energy benefit may be small, and, unfortunately, an east orientation can cause potential overheating problems in summer. Shading may be advised.

West windows may be the most problematic, and there are few shading systems that will be effective enough to offset the potential for 
overheating from a large west-facing window. Glass with a low shading coefficient may be one effective approach--for example, tinted glass or some types of low-e glass that provide some shading while allowing almost clear views. The cost of properly shading both east and west windows should be balanced against the benefits.

As many windows as possible should be kept operable for easy natural ventilation in summer. (See also Orientation, page 27, Recommended Non-South Glass Guidelines, page 45, and Shading, page 45).

\section{Conservation Guidelines}

The two tables on pages 20 and 21 can be used for guidance in selecting insulation levels and window type. The first table is for houses heated by gas and the second is for houses heated by electricity. If you use these numbers in your design, you should come close to the conservation performance goal given in Section III. You can deviate up or down from these values, depending on your favorite construction technique, but the overall building heat loss should still be below the goal.

The tables provide minimum values for the following quantities:

\begin{tabular}{|c|c|}
\hline $\mathrm{Rc}$ & ceiling insulation R-value \\
\hline Rw & wall insulation $\mathrm{R}$-value \\
\hline Floor & prevalent floor type \\
\hline Rf & floor insulation R-value, crawl space \\
\hline $\mathrm{Rp}$ & perimeter insulation R-value, slab or basement \\
\hline Windows & $\begin{array}{l}\text { windows and frame (TB is thermal break) } \\
\text { windows with low-e should also have a thermal break }\end{array}$ \\
\hline$I$ & $\begin{array}{l}\text { heating annual fuel utilization efficiency, percent } \\
\text { ER refers to electric-resistance heat }\end{array}$ \\
\hline SEE & oling seasonal energy efficiency rating, Btu/kWh \\
\hline
\end{tabular}

The tables have been developed using the Automated Residential Energy Standards (ARES) computer program developed at the Pacific Northwest Laboratory. This means that they are the economic-optimum values for the climate. See page 80 in Section III for a discussion of the basis for these guidelines. 


\section{Conservation Guidelines, Houses Heated with Gas}

\begin{tabular}{|c|c|c|c|c|c|c|c|c|}
\hline ity & $\mathrm{Rc}$ & Rw & Floor & $\mathrm{Rf}$ & $\mathrm{Rp}$ & \multicolumn{3}{|c|}{ AFUE SEER } \\
\hline lbuquerque, NM & 30 & 23 & Slab & & 0 & $\mathrm{w} / \mathrm{o} \mathrm{T}$ & & \\
\hline Atlanta, GA & 30 & 3 & Slab & & 0 & $\mathrm{w} / \mathrm{o} \mathrm{TB}$ & & \\
\hline Birmingham, AL & 30 & 3 & Slab & & 0 & Double w/o TB & & \\
\hline Bismarck, ND & 30 & 26 & Bsmnt & & 10 to $4 \mathrm{ft}$ & Double Low-E & & \\
\hline Boise, ID & 30 & 3 & Bsmnt & & & Double Low-E & & \\
\hline Boston, MA & 30 & 23 & Bsmnt & & 10 to $4 \mathrm{ft}$ & Double Low-E & & \\
\hline Brownsville, TX & 19 & 11 & Slab & & 0 & Double w/o TB & & \\
\hline uffalo, NY & 30 & 26 & Bsmnt & & $4 \mathrm{ft}$ & Double Low-E & & \\
\hline gton, VT & 30 & 23 & Bsmnt & & & Double Low-E & & \\
\hline harleston, SC & 30 & 23 & Slab & & 0 & Double w/o TB & & \\
\hline ane, WY & 30 & 23 & Bsmnt & & $4 \mathrm{ft}$ & Double Low-E & & \\
\hline hicago, IL & 30 & 23 & Bsmnt & & 10 & Double Low-E & & \\
\hline ati, $\mathrm{OH}$ & 30 & 23 & Bsmnt & & & Double Low-E & & \\
\hline , $\mathrm{CO}$ & 30 & 23 & Bsmnt & & & ble Low-E & & \\
\hline TX & 30 & 11 & Slab & & 0 & Low-E & & \\
\hline orth, TX & 30 & 23 & Slab & & 0 & $\mathrm{w} / \mathrm{o}$ TB & 78 & \\
\hline , CA & 30 & 23 & Slab & & & $\mathrm{w} / \mathrm{o} \mathrm{TB}$ & 78 & \\
\hline alls, MT & 30 & 23 & Bsmnt & & & Low-E & & \\
\hline ille, FL & 30 & 13 & Slab & & 0 & N/o TB & & \\
\hline rles, LA & 30 & 13 & Slab & & 0 & $\mathrm{w} / \mathrm{o} \mathrm{TB}$ & 7 & \\
\hline $\mathrm{NV}$ & 30 & 19 & Slab & & 0 & Low-E & & \\
\hline les, CA & 1 & 13 & Slab & & 0 & $\mathrm{~N} / \mathrm{O}$ & & \\
\hline & 30 & 23 & Crawl & 30 & & $\mathrm{~N} / \mathrm{O}$ & & \\
\hline TN & & 23 & Slab & & 0 & $\mathrm{~V} / \mathrm{O}$ & & \\
\hline lis, 1 & & 23 & Bsmnt & & & 0 & & \\
\hline $\mathrm{TN}$ & & 23 & Slab & & & 1 & & \\
\hline $\mathrm{NY}$ & 30 & 23 & Bsmnt & & & or & & \\
\hline City & 30 & 13 & Slab & & 0 & Lo & & \\
\hline & 00 & 23 & Bsmnt & & & L & & \\
\hline ia, & & & Bsmnt & & & ov & & \\
\hline & & & Slab & & & $\mathrm{V} / \mathrm{O}$ & & \\
\hline $1, \mathrm{PA}$ & & & Bsr & & & or & 7 & \\
\hline IE & & 23 & Bsmnt & & & Low-E & & \\
\hline OR & & 2 & Crawl & 3 & & v/o TB & & \\
\hline $\mathrm{Re}$ & & 23 & Crawl & & & TB & & \\
\hline City & 3 & 23 & Bsmnt & & & Low-E & 7 & \\
\hline iio, TX & 30 & 13 & Slab & & 0 & $\mathrm{w} / \mathrm{o} \mathrm{TB}$ & 7 & \\
\hline CA & 1 & 13 & Slab & & 0 & $\mathrm{~V} / \mathrm{O} \mathrm{TB}$ & & \\
\hline $\mathrm{CA}$ & 30 & 13 & Slab & & & $\mathrm{w} / \mathrm{o} \mathrm{TB}$ & 7 & \\
\hline & 3 & 23 & Bsmnt & & $5 \mathrm{t}$ & Low-E & & \\
\hline & & 11 & Slab & & 0 & Double w/o TB & 7 & \\
\hline & & $2:$ & & & & Low- & & \\
\hline Washington & & & Bsmnt & & 5 to $4 \mathrm{ft}$ & le w/o TB & & \\
\hline
\end{tabular}

See page 19 to identify terms. 
Conservation Guidelines, Houses Heated with Electricity

\begin{tabular}{|c|c|c|c|c|c|c|c|}
\hline City & $\mathrm{Rc}$ & $\mathrm{Rw}$ & Floor & $\mathrm{Rp}$ & Windows & \multicolumn{2}{|c|}{ AFUE SEER } \\
\hline lbuquerque, NM & 38 & 23 & Slab & $0<\pi$ & Double Low-E & ER & \\
\hline Atlanta, GA & 30 & 26 & Slab & to $2 \mathrm{ft}$ & Double Low-E & $\mathrm{ER}$ & \\
\hline Birmingham, $\mathrm{AL}$ & 30 & 26 & Slab & 10 to $2 \mathrm{ft}$ & Double Low-E & $\mathrm{ER}$ & \\
\hline Bismarck, ND & 60 & 26 & Bsmnt & 10 to 8 & Triple Low-E & ER & \\
\hline Boise, ID & 60 & 26 & Bsmint & 10 & Triple Low-E & ER & \\
\hline Boston, MA & 49 & 26 & Bsmnt & 10 & Triple Low-E & ER & \\
\hline Brownsville, TX & 30 & 11 & Slab & 0 & Double w/o TB & $\mathrm{ER}$ & \\
\hline Buffalo, NY & 60 & 26 & Bsmnt & $10 \mathrm{t}$ & Triple Low-E & ER & \\
\hline Burlington, VT & 60 & 26 & Bsmnt & 10 & Double Low-E & ER & \\
\hline Charleston, SC & 30 & 26 & Slab & $\mathrm{ft}$ & Double Low-E & ER & \\
\hline Cheyenne, WY & 60 & 26 & Bsmnt & 10 & Triple Low-E & ER & \\
\hline Chicago, IL & 60 & 26 & Bsmnt & 10 & Triple Low-E & ER & \\
\hline Cincinnati, $\mathrm{OH}$ & 60 & 26 & Bsmnt & 10 & Triple Low-E & ER & \\
\hline Denver, CO & 60 & 26 & Bsmnt & 10 & Triple Low-E & ER & 2 \\
\hline El Paso, TX & 30 & 23 & Slab & $2 \mathrm{ft}$ & Double TB & ER & \\
\hline Fort Worth, TX & 30 & 26 & Slab & & ole Low-E & ER & \\
\hline Fresno, CA & 38 & 23 & Slab & $\mathrm{ft}$ & Double Low-E & ER & \\
\hline Great Falls, MT & 60 & 26 & Bsmnt & 10 & Triple Low-E & ER & \\
\hline Jackonsville, FL & 30 & 23 & Slab & $\mathrm{ft}$ & Double TB & ER & \\
\hline Lake Charles, LA & 30 & 23 & Slab & $2 \mathrm{ft}$ & Double w/o TB & ER & \\
\hline Las Vegas, NV & 49 & 23 & Slab & 5 to $2 \mathrm{ft}$ & Double Low-E & $\mathrm{ER}$ & \\
\hline Los Angeles, CA & 30 & 19 & Slab & 5 to $2 \mathrm{ft}$ & Double TB & ER & \\
\hline Medford, OR & 60 & 26 & Crawl 30 & & Low-E & ER & \\
\hline Memphis, TN & 38 & 23 & Slab & 5 to $2 \mathrm{ft}$ & ble Low-E & ER & \\
\hline Minneapolis, MN & 60 & 26 & Bsmnt & 10 & le Low-E & ER & \\
\hline Nashville, TN & 38 & 23 & Slab & $2 \mathrm{ft}$ & Double Low-E & ER & \\
\hline New York, NY & 49 & 26 & Bsmnt & 10 & Low-E & ER & \\
\hline Oklahoma City, OK & 38 & 23 & Slab & 5 & ble Low-E & ER & 10 \\
\hline Omaha, NE & 60 & 26 & Bsmnt & 10 & le Low-E & ER & 10 \\
\hline Philadelphia, PA & 60 & 26 & Bsmnt & 10 & Triple Low-E & ER & 0 \\
\hline $\mathrm{ix}, \mathrm{AZ}$ & 30 & 23 & Slab & 0 & Double w/o TB & ER & 1 \\
\hline Pittsburgh, PA & 49 & 26 & Bsmnt & 10 & Triple Low-E & ER & 10 \\
\hline Portland, ME & 60 & 26 & Bsmnt & 1 & Low-E & ER & 10 \\
\hline Portland, OR & 38 & 23 & Crawl 30 & & Low-E & ER & 10 \\
\hline Reno, NV & 60 & 26 & Crawl 30 & & Low-E & ER & \\
\hline Salt Lake City, UT & 60 & 26 & Bsmnt & 1 & Low-E & ER & \\
\hline San Antonio, TX & 30 & 13 & Slab & 5 & e Low-E & ER & \\
\hline San Diego, CA & 30 & 19 & Slab & & le w/o TB & ER & \\
\hline San Francisco, CA & 30 & 23 & Slab & & le TB & ER & \\
\hline Seattle, WA & 60 & 26 & Bsmnt & 10 & le Low-E & ER & \\
\hline Tampa, FL & 30 & 19 & Slab & 0 & le w/o TB & ER & \\
\hline Topeka, KS & 60 & 26 & Bsmnt & & Triple Low-E & ER & \\
\hline Washington, DC & ת & 26 & Bsmnt & 10 to & e Low-E & ER & \\
\hline
\end{tabular}

See page 19 to identify terms. 


\section{Mechanical Systems}

The energy-efficient features in the house and the mechanical heating, ventilating, and air-conditioning systems (HVAC) will interact all year round, so the most effective approach will be to design the system as an integrated whole. HVAC design is, of course, a complex subject, but the four areas below are particularly worth noting in energy-efficient houses:

- System Sizing. Mechanical systems are often oversized for the relatively low heating loads in well-insulated energy-efficient houses. Oversized systems will cost more in the first place, and will cycle on and off more often, which wastes energy. The backup systems in energy-efficient houses should be sized to provide $100 \%$ of the heating or cooling load on the design day, but should be no larger. Comparing estimates on system sizes from more than one contractor is probably a good idea.

- Night Setback. Clock thermostats for automatic night setback are usually very effective--but in energy-efficient systems with large amounts of thermal mass (and thus a large capacity for storing energy and releasing it during the night), night setback of the thermostat may not save very much energy.

- Ducts. One area often neglected but of key importance to the house's energy performance is the design and location of the ducts. Both the supply and return ducts should be located within insulated areas (or the ducts should be well insulated where they run through cold areas of the house) and well sealed at the joints. The joints where the ducts turn up into exterior walls or penetrate the ceiling should be particularly tight and caulked.

- System Efficiency. Heating system efficiency is rated by the annual fuel utilization efficiency, AFUE. Cooling system efficiency is rated by the seasonal energy efficiency rating, SEER. Recommended minimum values for these ratings are given in the conservation guideline tables on pages 20 and 21 .

In the National Association of Home Builders' Energy-Efficient House Project, all the rooms were fed with low, central air supplies, as opposed to the usual placement of registers under windows at the end of long runs. This resulted in good comfort and energy performance.

The performance of even the most carefully designed energy-efficient house can easily be undermined by details like uninsulated ducts or by overlooking other basic energy conservation measures. 


\section{South-Facing Glass}

South-facing solar glass is a key component of any passive solar system. The system must include enough solar glazing for good performance in winter, but not so much that cooling performance in summer will be compromised. The amount of solar glazing must also be carefully related to the amount of thermal mass. Suntempered houses require no additional thermal mass beyond that already in the wallboard, framing, and furnishings of a typical house. Passive solar houses must have additional thermal mass.

There are three types of limits on the amount of south-facing glass that can be used effectively in a house. The first is a limit on the amount of glazing for suntempered houses. This limit (without adding thermal mass) is $7 \%$ of the house's total floor area. Above the 7\% limit, mass must be added.

For direct-gain systems in passive solar houses, the maximum amount of south-facing glazing is $12 \%$ of the total floor area, regardless of how much additional thermal mass is provided. Further details about the most effective sizing of south-facing glass and thermal mass for directgain systems are provided in Part Three.

The third limit on south-facing glass is the total of all passive solar systems combined, which should not exceed $20 \%$ of the total floor area. Using more south-facing glass than this limit could lead to overheating even in winter.

The Natural Cooling Guidelines in Part Four include recommendations on the window area that should be operable to allow for natural ventilation.

When the solar glazing is tilted, its winter effectiveness as a solar collector usually increases. However, tilted glazing can cause serious overheating in the summer, and it is very difficult to effectively shade tilted glazing. Ordinary vertical glazing is easier to shade, less likely to overheat, and less susceptible to damage and leaking, so it is almost always a better year-round solution. Even in the winter, with the sun low in the sky and reflecting off snow cover, vertical glazing can often offer energy performance just as effective as can tilted glazing.

Guidelines for the total area of passive solar glazing are listed in the table on page 25 for 43 U.S. locations. The guidelines are given in two ways: (1) total south glazing area as a fraction of house floor area, GF, and (2) recommended load-collector ratio, LCR* Initially, the designer should use the GF guideline, which is easiest to use early in the design process.

\footnotetext{
* LCR is a an intermediate parameter that is used in the BuilderGuide computer program; it is the ratio of net loss coefficient to projected area and has units of $\mathrm{Btu} /{ }^{\circ} \mathrm{Fdayft}{ }^{2}$. LCR is displayed on Line B of Worksheet II.
} 
Later, after the design has progressed and design analysis has started, the LCR guideline can be used as a way to adjust the window area.

For those cases with a recommended glazing fraction of $7 \%$, it is recommended that the house be suntempered. Added mass associated with higher levels of direct gain will not be economical. However, if mass is to be present anyway, then the designer could economically justify increasing the solar glazing area.

Solar savings fractions are also listed in the table. These give a general indication of the solar savings that you should expect to achieve with the LCR values listed; however, this will vary somewhat with the passive system type you are using.

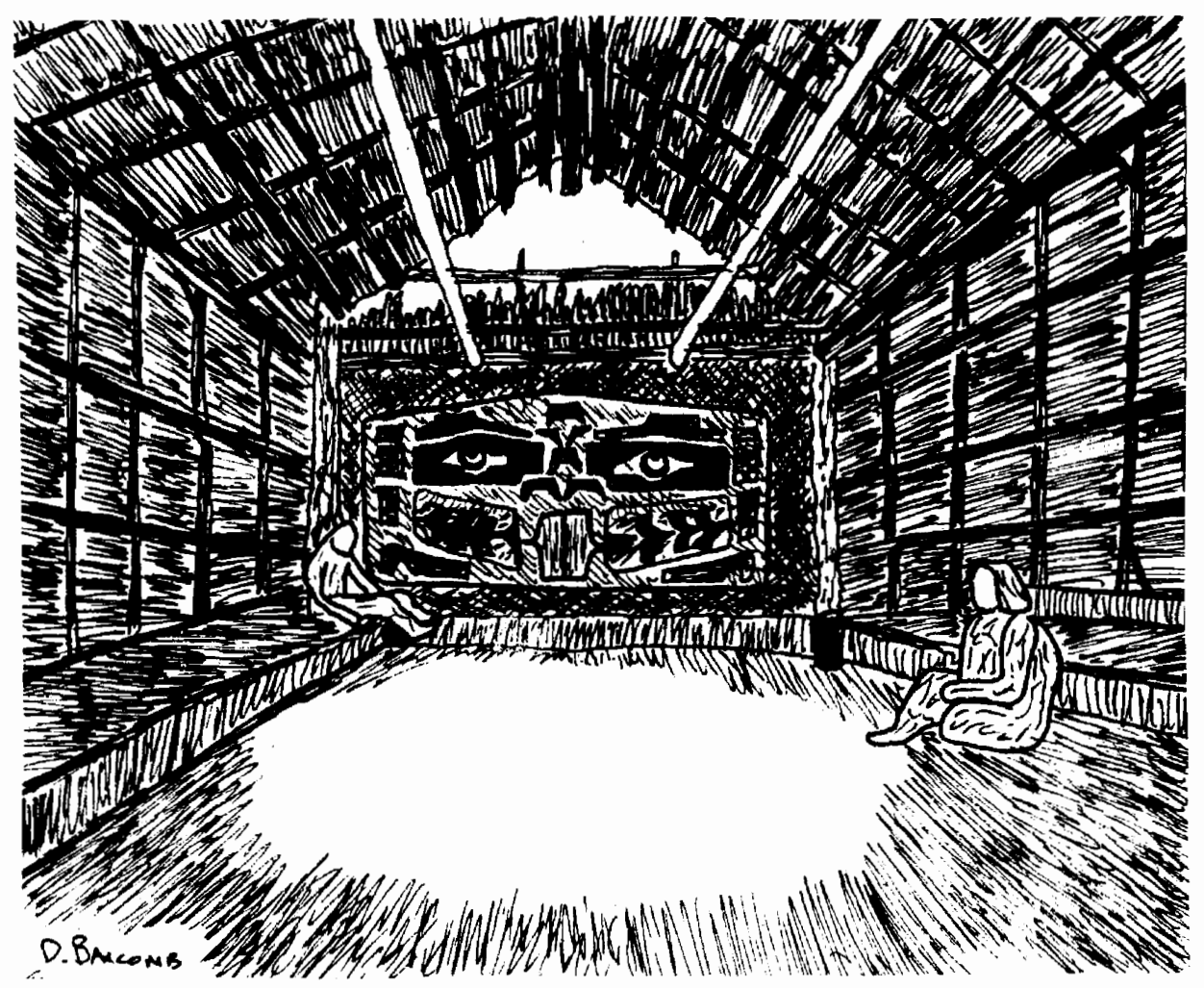

Gable-end roof openings were sometimes used to bring light into the plank houses of the Indians of the Pacific Northwest, but at a sacrifice of comfort. With modern glazing materials, even more light can be admitted while comfort is enhanced. 
Passive Solar Guideline, Total Area of South-Facing Glass of All Passive Systems Combined

GF glazing fraction, south net glass area/floor area, percent LCR load-collector ratio (see BuilderGuide program), Btu $/{ }^{\circ} \mathrm{F}$-day- $\mathrm{ft}^{2}$ SSF solar savings fraction, percent

House heating:

Gas

Electricity

\begin{tabular}{|c|c|c|c|c|}
\hline & $\mathrm{GF}$ & LCR & GF & LCR \\
\hline Albuquerque, NM & 12 & 62 & 16 & \\
\hline Atlanta, GA & 7 & 118 & 13 & \\
\hline Birmingham, AL & 7 & 118 & 11 & \\
\hline Bismarck, ND & 7 & 82 & 13 & \\
\hline Boise, ID & 7 & 89 & 14 & \\
\hline Boston, MA & 7 & 83 & 13 & \\
\hline Brownsville, TX & 7 & 132 & 7 & 12 \\
\hline Buffalo, NY & 7 & 90 & 7 & \\
\hline Burlington, VT & 7 & 91 & 7 & \\
\hline Charleston, SC & 7 & 119 & 7 & \\
\hline Cheyenne, WY & 15 & 40 & 23 & \\
\hline Chicago, IL & 7 & 83 & 12 & \\
\hline Cincinnati, OH & 7 & 98 & 11 & \\
\hline Denver, CO & 13 & 47 & 20 & \\
\hline El Paso, TX & 7 & 107 & 12 & \\
\hline Fort Worth, TX & 7 & 118 & 11 & \\
\hline Fresno, CA & 7 & 104 & 7 & \\
\hline Great Falls, MT & 7 & 88 & 15 & \\
\hline Jackonsville, FL & 7 & 122 & 7 & \\
\hline Lake Charles, LA & 7 & 122 & 7 & 10 \\
\hline Las Vegas, NV & 7 & 106 & 11 & \\
\hline Los Angeles, CA & 7 & 130 & 7 & \\
\hline Medford, OR & 7 & 94 & 11 & 4 \\
\hline Memphis, TN & 7 & 119 & 13 & 4 \\
\hline Minneapolis, MN & 7 & 90 & 7 & \\
\hline Nashville, TN & 7 & 98 & 12 & 5 \\
\hline New York, NY & 7 & 100 & 12 & 4 \\
\hline Oklahoma City, OK & 7 & 106 & 15 & 3 \\
\hline Omaha, NE & 7 & 83 & 18 & 2 \\
\hline Philadelphia, PA & 7 & 100 & 15 & 3 \\
\hline Phoenix, AZ & 7 & 118 & 7 & 11 \\
\hline Pittsburgh, PA & 7 & 90 & 7 & 7 \\
\hline Portland, ME & 7 & 91 & 13 & 4 \\
\hline Portland, OR & 7 & 95 & 7 & 8 \\
\hline Reno, NV & 11 & 49 & 16 & 2 \\
\hline Salt Lake City, UT & 7 & 88 & 17 & \\
\hline San Antonio, TX & 7 & 121 & 7 & \\
\hline San Diego, CA & 7 & 149 & 7 & 10 \\
\hline San Francisco, CA & 7 & 107 & 13 & 5 \\
\hline Seattle, WA & 7 & 91 & 7 & 7 \\
\hline Tampa, FL & 7 & 132 & 7 & 12 \\
\hline Topeka, KS & 7 & 83 & 16 & \\
\hline Washington, DC & 7 & 111 & 16 & \\
\hline
\end{tabular}




\section{Thermal Mass}

Some heat storage capacity, or thermal mass, is present in all houses, in the framing, gypsum wall and ceiling board, typical furnishings and floor coverings. In suntempered houses, this modest amount of mass is sufficient for the modest amount of south-facing glass. But more thermal mass is required in passive solar houses, and the question is not only how much, but what kind and where it should be located.

The thermal mass in a passive solar system is usually a conventional construction material such as brick, adobe, rock, cast concrete, concrete masonry, concrete slabs, or tile, and is usually placed in the floor or interior walls. Water actually has a higher unit thermal storage capacity than concrete or masonry. Water tubes and units called "water walls" are commercially available (general recommendations for these systems are included in the section on Thermal Storage Wall systems).

The thermal storage capabilities of a given material depend on the material's conductivity, specific heat, and density. Most of the concrete and masonry materials typically used in passive solar have similar specific heats. Conductivity tends to increase with increasing density. So the major factor affecting performance is density. Generally, the higher the density, the better.

\begin{tabular}{|c|c|c|}
\hline \multicolumn{3}{|c|}{ Heat Storage Properties of Materials } \\
\hline Material & $\begin{array}{l}\text { Density } \\
\left(\mathrm{lb} / \mathrm{ft}^{3}\right)\end{array}$ & $\begin{array}{l}\text { Heat Capacity } \\
\left.\text { (Btu/in.- } \mathrm{ft}^{2}{ }^{\circ} \mathrm{F}\right)\end{array}$ \\
\hline Poured Concrete & $120-150$ & $2.0-2.5$ \\
\hline \multicolumn{3}{|l|}{ Clay Masonry } \\
\hline Adobe & $100-120$ & $1.6-2.0$ \\
\hline Molded Brick & $120-130$ & $2.0-2.2$ \\
\hline Extruded Brick & $125-135$ & $2.1-2.3$ \\
\hline Pavers & $130-135$ & $2.2-2.3$ \\
\hline \multicolumn{3}{|l|}{ Concrete Masonry } \\
\hline Block & $80-140$ & $1.3-2.3$ \\
\hline Brick & $115-140$ & $1.9-2.3$ \\
\hline Pavers & $130-150$ & $2.2-2.5$ \\
\hline Gypsum Wallboard & 50 & 0.83 \\
\hline Water & 62.4 & 5.2 \\
\hline
\end{tabular}


The possibility of using natural materials that have a cultural significance arises in discussions of Indian housing. Adobe, rock, and wood are the materials that are most often mentioned. Of these, adobe and rock will certainly be effective; however, wood is not very effective beyond a thickness of 2 in. because of its relatively low thermal conductivity, which inhibits heat transfer in and out of the material.

The design issues related to thermal mass depend on the passive system type. For sunspaces and thermal storage wall systems, the required mass of the system is included in the design itself. For direct gain, the added mass must be within the rooms receiving the sunlight." The sections on Direct Gain Systems, Sunspaces, and Thermal Storage Walls contain more information on techniques for sizing and locating thermal mass in those systems.

\section{Orientation}

The ideal orientation for solar glazing is within 5 degrees of true south. This orientation will provide maximum performance. Glazing oriented to within 15 degrees of true south will perform almost as well, and orientations up to 30 degrees off--although less effective--will still provide a substantial level of solar contribution.

Magnetic north as indicated on the compass is actually different than true north, and this correction should be made when planning for orientation of south glazing.

When glazing is oriented more than 15 degrees off true south, not only is winter solar performance reduced, but summer air-conditioning loads also significantly increase, especially as the orientation goes west. The warmer the climate, the more east- and west-facing glass will tend to cause overheating problems. In general, southeast orientations present less of a problem than southwest orientations.

In the ideal situation, the house should be oriented east-west and so have its longest wall facing south. But as a practical matter, if the house's short side has good southern exposure, it will usually accommodate sufficient glazing for an effective passive solar system, provided the heat can be transferred to the northern zones of the house.

\section{Site Planning for Solar Access}

The basic objective of site planning for maximum energy performance is to allow the south side unshaded exposure from 9 am to $3 \mathrm{pm}$ during the winter months.

As discussed above, a good solar orientation is possible within a relatively large southern arc, so the flexibility exists to achieve a workable balance between energy performance and other important factors such as the slope of the site, the individual house plan, the 
direction of prevailing breezes for summer cooling, the views, the street layout, and so on.

But planning for solar access does place some restrictions even on an individual site, and presents even more challenges when planning a complete subdivision. Over the years, developers and builders of many different kinds of projects all over the country have come up with flexible ways to provide adequate solar access.

Once again, there is an ideal situation and then some degree of flexibility to address practical concerns. Ideally, the glazing on the house should be exposed to sunlight with no obstructions within an arc of 60 degrees on either side of true south, but reasonably good solar access will still be guaranteed if the glazing is unshaded within an arc of 45 degrees. The figure shows the optimum situation for providing unshaded southern exposure. See also the figure on page 46 showing landscaping for summer shade. The winter and summer requirements are compatible but do require careful planning.

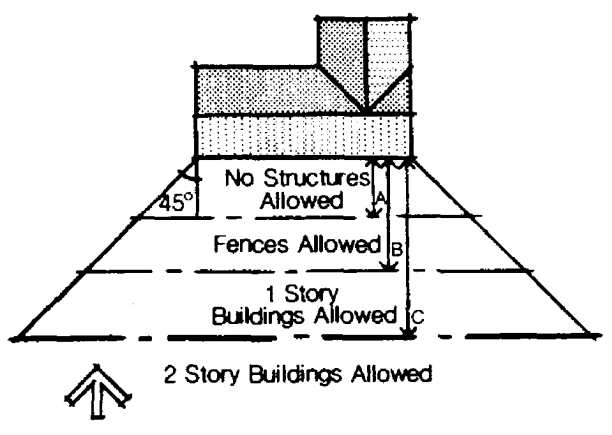

\section{Ideal Solar Access}

Buildings, trees, or other obstructions should not be located so as to shade the south wall of solar buildings. The following setbacks (ft) are recommended.

$\begin{array}{crrr}\text { Latitude } & A & B & C \\ & & & \\ 30 & 7 & 12 & 28 \\ 35 & 10 & 17 & 39 \\ 40 & 12 & 23 & 53 \\ 45 & 19 & 34 & 80 \\ 50 & 24 & 45 & 100\end{array}$

Of course, not all lots are large enough to accommodate this kind of optimum solar access, so it's important to carefully assess shading patterns on smaller lots to make the best compromise.

Protecting solar access is easiest in subdivisions with streets that run within 15 degrees of east-west, because all lots will either face or back up to the south. Where the streets run north-south, creation of east-west cul-de-sacs will help ensure solar access. 

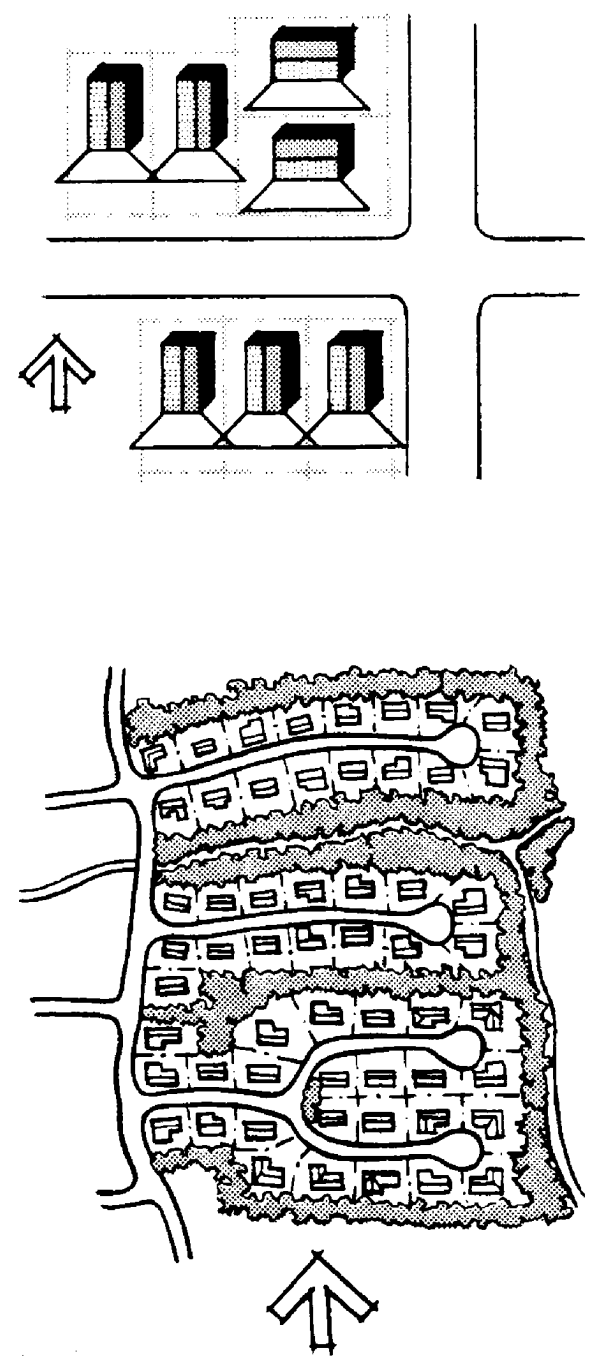

\section{Solar Subdivision Layouts}

Solar access may be provided to the rear yard, the side yard or the front yard of solar homes.

\section{Solar Subdivision Layouts}

A good street pattern for solar access is short east-west culde-sacs tied into north-south collectors.

Two excellent references for ideas about subdivision layout to protect solar access are the Designer's Guide to Passive Solar Home Design and Land Development and Site Planning for Solar Access. (See References 17 and 18.)

\section{Interior Space Planning}

Planning room layout by considering how the rooms will be used in different seasons and at different times of day can save energy and increase comfort. In houses with energy-efficient features, the layout of rooms--and interior zones that may include more than one room--is particularly important.

In general, living areas and other high-activity rooms should be located on the south side to benefit from the solar heat. The closets, storage areas, garage, and other less-used rooms can act as buffers along the north side, but entryways should be located away from the wind. Clustering baths, kitchens, and laundry rooms near the water heater will save the heat that would be lost from longer water lines. 


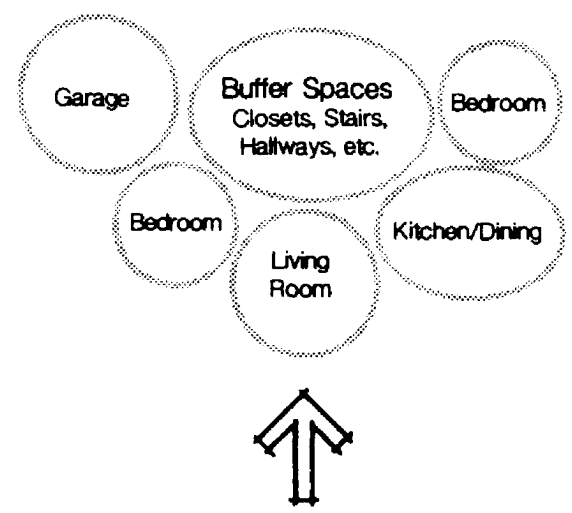

\section{Interior Space Planning}

Living and high activity spaces should be located on the south.

Another general principle is that an open floor plan will allow the collected solar heat to circulate freely through natural convection.

Other ideas from effective energy-efficient houses:

- Orienting internal mass walls as north-south partitions that can be "charged" on both sides, thus making maximum use of the mass.

- Using an east-west partition wall for thermal mass, but making sure the interior space isn't divided into a south zone that may get too warm and a north zone that may get too cold.

- Using thermal storage walls (see page 40); the walls store energy all day and slowly release it at night and can be a good alternative to ensure privacy and to buffer noise when the south side faces the street;

- Collecting the solar energy in one zone of the house and transporting it to another by fans or natural convection through an open floor plan.

- Providing south-facing clerestories to "charge" north zones.

\section{Putting it Together: The House as a System}

Many different factors will affect a house's overall performance, and these factors all interact: the mechanical system, the insulation, the house's tightness, the effects of the energy-efficient features, the appliances, and, very importantly, the actions of the people who live in the house. In each of these areas, changes are possible that would improve the house's energy performance. Some energy savings are relatively easy to get. Others can be more expensive and more difficult to achieve, but may provide benefits over and above good energy performance.

\section{A sensible energy-efficient house uses a combination of techniques.}

In fact, probably the most important thing to remember about designing for energy performance in a way that will also enhance the comfort and 
value of the house is to take an integrated approach, keeping in mind the house as a total system. On the following page is a basic checklist for energy-efficient design.

\section{Checklist for Good Design}

$\checkmark$ 1. Building orientation: A number of innovative techniques can be used to obtain good solar access on less-than-ideal sites (see References 17 and 18). No matter what the house's design, and no matter what the site, some options for orientation will be more energy-efficient than others, and even a very simple review of the site will probably help you choose the best option available.

2. Upgraded levels of insulation: It is possible, of course, to achieve very high energy-efficiency with a "superinsulated" design. But in many cases, one advantage of passive solar design is that energy efficiency can be achieved with more modest increases in insulation. On the other hand, if very high energy performance is a priority--for example, in areas where the cost of fuel is high--the most costeffective way to achieve it is generally through a combination of high levels of insulation and passive solar features.

3. Reduced air infiltration: Air tightness is not only critical to energy performance, but it also makes the house more comfortable. Indoor air quality is an important issue, and too complex for a complete discussion here, but in general, the suntempered and passive solar houses built according to the guidelines provide an alternative approach to achieving improved energy efficiency without requiring air quality controls such as air-to-air heat exchangers, which would be needed if the house were made extremely airtight.

$\checkmark$ 4. Proper window sizing and location: Even if the total amount of glazing is not changed, rearranging the location alone can often lead to significant energy savings at little or no added cost. Some energy-conserving designs minimize window area on all sides of the house--but it's a fact of human nature that people like windows, and windows can be energy producers if located correctly.

$\checkmark \quad 5$. Selection of glazing: Low-emissivity (low-e) glazing types went from revolutionary to commonplace in a very short time, and they can be highly energy-efficient choices. But the range of glazing possibilities is broader than that, and the choice will have a significant impact on energy performance. Using different types of glazing for windows with different orientations is worth considering for maximum energy performance; for example, using heat-rejecting glazing on west windows, high R-value glazing for north and east windows, and clear double glazing on solar glazing.

$\checkmark \quad 6$. Proper shading of windows: If windows are not properly shaded in summer--either with shading devices or by high-performance glazing with a low shading coefficient--the air conditioner will have to work overtime, and the energy savings of the winter may be canceled out. Even more important, unwanted solar gain is uncomfortable.

$\checkmark \quad 7$. Interior design for easy air distribution: If the rooms in the house are planned carefully, the flow of heat in the winter will make the energy-efficient features more effective, and the air movement will also enhance ventilation and comfort during the summer. Often this means the kind of open floor plan that is highly marketable in most areas. Planning the rooms with attention to use patterns and energy needs can save energy in other ways, too--for instance, using less-lived-in areas like storage rooms as buffers on the north side.

$\checkmark \quad$ 8. Addition of thermal mass: Adding effective thermal mass--for example, tiled or paved concrete slab, masonry walls, brick fireplaces, and tile floors--can greatly improve the comfort in the house, holding heat better in winter and keeping rooms cooler in summer. In a passive solar system, of course, properly sized and located thermal mass is essential.

\section{$\checkmark$ 9. Selection and proper sizing of mechanical systems, and selection of energy-efficient}

appliances: High-performance heating, cooling, and hot water systems are extremely energy efficient, and almost always a good investment. Well-insulated energy-efficient homes will have much lower energy loads than conventional homes, and should be sized accordingly. Oversized systems will cost more and reduce the house's performance. For guides to the selection of energy-efficient appliances, see References 13 and 14 


\section{Part Three: Passive Solar Strategies}

\section{Suntempering}

Both suntempered and passive solar houses:

- Begin with good basic energy conservation

- Take maximum advantage of the building site through the right orientation for year-round energy savings

- Have increased south-facing glass to collect solar energy.

Suntempering is the simplest passive solar system and refers to modest increases in windows on the south side.

No additional thermal mass is necessary, only the "free mass" in the house--the framing, gypsum wall-board, and furnishings.

In a "conventional" house, about $25 \%$ of the windows face south, which amounts to about $3 \%$ of the house's total floor area. In a suntempered house, the percentage is increased to a maximum of about $7 \%$ of the houses' total floor area.

The energy savings are more modest with this system, but suntempering is a very low-cost strategy.

Of course, even though the necessity for precise sizing of glazing and thermal mass does not apply to suntempering (as long as the total southfacing glass does not exceed $7 \%$ of the total house floor area), all other recommendations about energy-efficient design, such as the basic energy conservation measures, room layout, siting, and glazing type, are still important for performance and comfort in suntempered homes.

\section{Direct Gain}

The most common passive solar system is called direct gain: sunlight through south-facing glazing penetrates directly into the space to be heated and is stored in thermal mass incorporated into the floor or interior walls. The south window area is increased above the $7 \%$ limit of a suntempered house, and additional thermal mass is added to store the additional solar gains and thus prevent overheating.

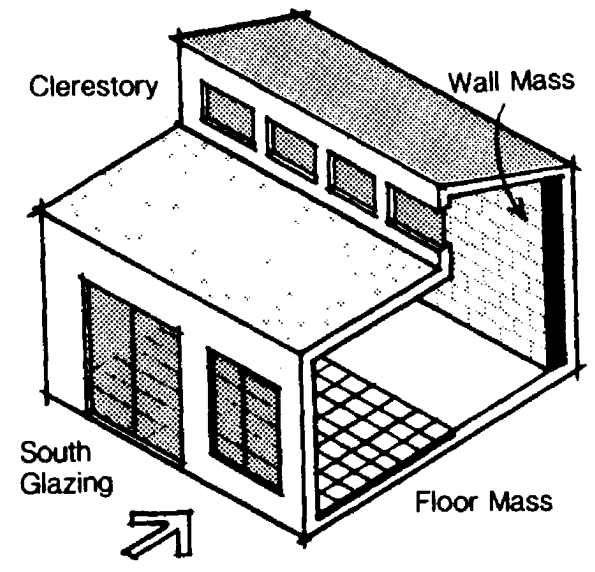

\section{Direct Gain}

Direct gain is the most common passive system. 


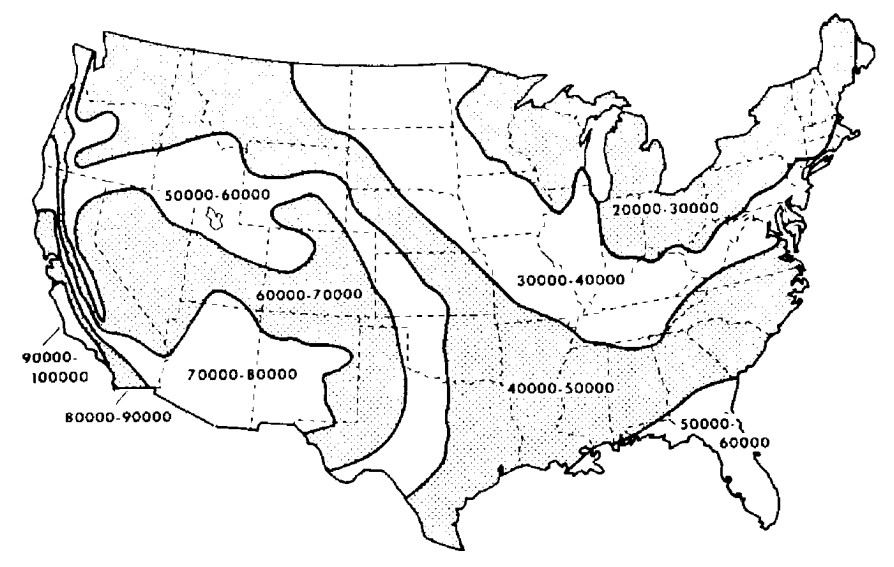

Savings from direct gain

These are the net annual Btus of heat saved per $\mathrm{ft}^{2}$ of directgain glazing, assuming the use of clear double glazing.

\section{Sizing Limit}

Total direct-gain glass area should not exceed about $12 \%$ of the house's floor area. Beyond that, problems with glare or fading of fabrics are more likely to occur, and it becomes more difficult to provide enough thermal mass for year-round comfort.

So the total south-facing glass area in a direct-gain system should be between $7 \%$ (the maximum for suntempered houses) and $12 \%$, depending on how much thermal mass will be used in the design, as discussed below.

\section{Glazing}

Double glazing with a low-e coating is recommended for direct-gain glazing in cold climates or regular double glazing in moderate climates. Generally follow the guidelines on pages 20 and 21 for glazing and window frames. Theoretically, night insulation will improve energy performance dramatically; however, studies have shown that only a relatively few homeowners will be diligent enough about operating their night insulation to achieve those savings. Low-e glazing, on the other hand, needs no operation, and therefore is a more convenient and reliable option.

\section{Thermal Mass}

Thermal mass can be incorporated easily into houses with slab-on-grade floors by exposing the mass. The floor is much more effective if sunlight falls directly on it. Covering the floor with any insulation material, such as carpet, greatly reduces its effectiveness. A good strategy is to expose a narrow strip about 8-ft wide along the south wall next to the windows where the winter sun will fall directly on it.

Effective materials for floors include painted, colored, or vinyl-covered concrete, brick (face brick or pavers have even higher density than 
ordinary building brick), quarry tile, and dark-colored ceramic tile laid directly on the slab.

For houses built with crawlspaces or basements, the incorporation of significant amounts of heavy thermal mass is a little more difficult. Thermal mass floor coverings over basements and crawlspaces would generally be limited to thin-set tile or other thin-mass floors.

When more mass is required, the next best option is interior walls or interior masonry fireplaces. Unlike floor mass, wall or ceiling mass does not have to be in the direct sun to be effective. Any mass that encloses a direct-gain space will be effective as long as there is a line-of-sight connection between the mass and the sunlit area.

When evaluating costs, the dual function of mass walls should be remembered. They often serve as structural elements, serve as fire protection, or provide a cultural connection, as well as providing thermal storage. Another option is to switch to another passive solar system type such as sunspaces or thermal storage walls that have built-in thermal mass.

Sunlit thermal mass floors should be relatively dark in color, to absorb and store energy low in the space. However, mass walls and ceilings should be light in color to help distribute both heat and light more evenly.

Guideline: Ratio of Mass to Glass. The simplest rule of thumb states:

For each added $f^{2}$ of direct-gain glass labove the $7 \%$ suntempering limit), $6 \mathrm{ft}^{2}$ of exposed mass surface should be added within the direct-gain space.

The following procedure can be used to determine a somewhat more accurate estimate. This procedure gives the maximum amount of directgain glazing for a given amount of thermal mass. (If the amount of direct-gain glazing to be used is already known, thermal mass can be added until this procedure produces the desired proportions.)

- Start with a direct-gain glass area equal to $7 \%$ of the house's total floor area. As noted above, the "free mass" in the house will be able to accommodate this much solar energy.

An additional $1.0 \mathrm{ft}^{2}$ of direct-gain glazing may be added for every $5.5 \mathrm{ft}^{2}$ of uncovered, sunlit mass floor. Carpet or area rugs will seriously reduce the effectiveness of the mass. The maximum floor mass that can be considered as "sunlit" may be estimated as about 1.5 times the south window area.

- An additional $1.0 \mathrm{ft}^{2}$ of direct gain glazing may be added for every $40 \mathrm{ft}^{2}$ of thermal mass in the floor of the room, but not in the sun. 
- An additional $1.0 \mathrm{ft}^{2}$ of direct-gain glazing may be added for each 8.3 $\mathrm{ft}^{2}$ of thermal mass placed in the wall or ceiling of the room. Mass in the wall or ceiling does not have to be located directly in the sunlight, as long as it is in the same room, with no obstructions between the mass and the surface where the sunlight is falling. (The 8.3 value is typical, but the true value does depend on mass density and thickness. Refer to the mass thickness graph for more specific values to use.)

More south-facing glazing than the maximum as determined here would tend to overheat the room and to reduce energy performance as well.

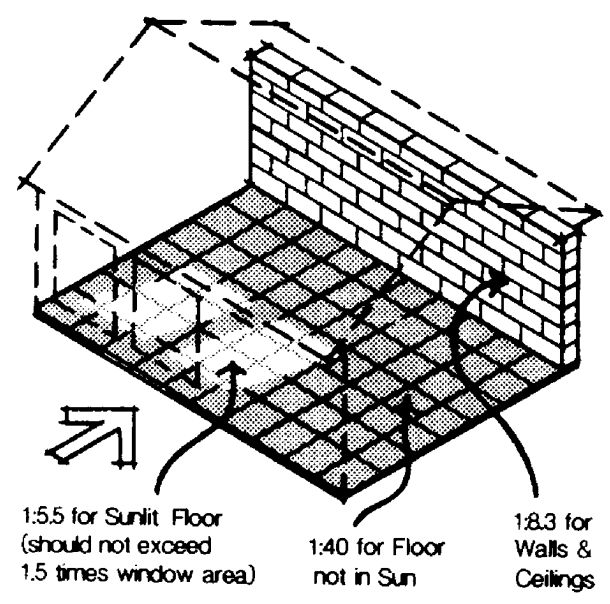

\section{Mass Location and Effectiveness}

Additional mass must be provided for south-facing glass over $7 \%$ of the floor area. The ratio of mass area to additional glass area depends on its location within the direct-gain space.

Thickness. For most materials, the effectiveness of the thermal mass in the floor or interior wall increases proportionally with thickness up to about 4 in. After that, the effectiveness doesn't increase as significantly.

A 2-in. mass floor will be about two-thirds as effective in a direct-gain system as a 4-in. mass floor. But a 6-in. mass floor will only perform about $8 \%$ better than a 4 -in. floor.

The following figure shows the effectiveness of thermal mass in relation to density and thickness. The vertical axis shows how many $\mathrm{ft}^{2}$ of mass area are needed for each added $\mathrm{ft}^{2}$ of direct gain. As you can see, performance increases start leveling off after a few inches of thermal mass. 


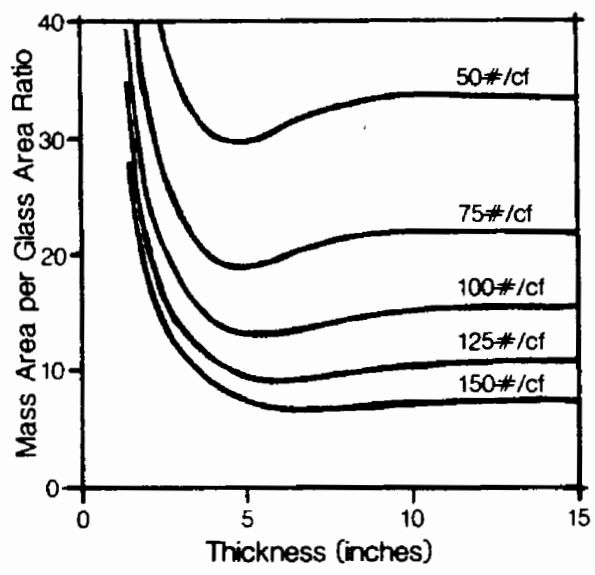

\section{Mass Thickness}

The effectiveness of thermal mass depends on the density of the material and thickness. This graph is for wall or ceiling mass in the direct-gain space, not for floors. The ratio of 8.3 was used earlier as a representative value. More accurate values can be read from this graph and used in the fourth step of the procedure.

In cases in which you are still uncertain if thermal mass is adequate, you can go to BuilderGuide, which includes a more comprehensive procedure.

\section{Sunspaces}

The sunspace is a very popular passive solar feature, adding an attractive living space as well as energy performance. There are many variations on the basic theme of the sunspace, and the possibilities for sunspace design are extraordinarily diverse (References 19 through 22 include specific design ideas).

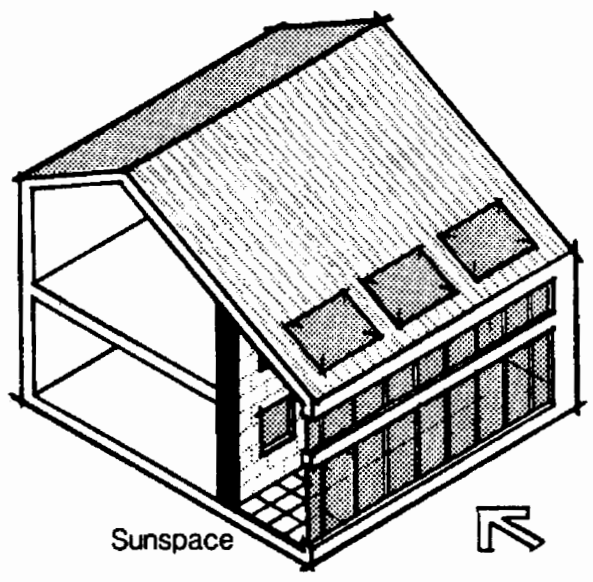

\section{Sunspaces}

Sunspaces provide useful passive solar heating and also provide a valuable amenity to homes. 


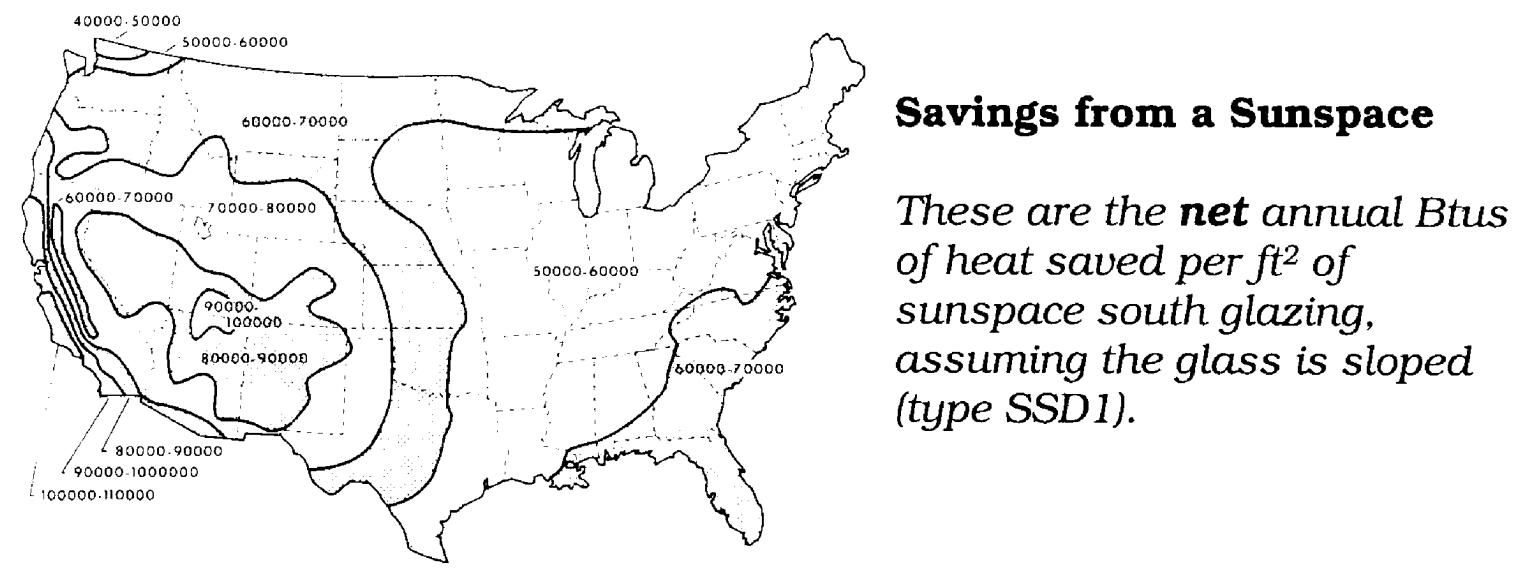

As used in this guide, a sunspace is a separate direct-gain room on the south side of the house that can be thermally isolated from the rest of the house by closing doors between the house and the sunspace. The sunspace provides solar heat to the house but does not drain heat from the house or require additional heat itself. The wall that separates the house from the sunspace is called a common wall.

The sunspace concept, as defined above, adds a room to the house that can be used year-round, that will provide most or all of its own energy needs, and that will contribute to the energy needs of the rest of the house as well.

Sunspaces are sometimes referred to as "isolated gain" passive solar systems, because the solar heat is collected in an area that can be closed off from the rest of the house. During the day, the doors or windows between the sunspace and the house can be opened to circulate collected heat, and then closed at night, and the temperature in the sunspace allowed to drop.

The sunspace should not be on the same heating system as the rest of the house. A well-designed sunspace will probably need no mechanical heating system, but if necessary, a small fan or heater may be used to protect plants on extremely cold winter nights.

Probably the most important factor in controlling the temperature in the sunspace, and thus keeping it as comfortable and efficient as possible, is to make sure the exterior walls are tightly constructed and well insulated. To function properly, the sunspace exterior walls and roof should be just as tightly constructed and insulated as the rest of the house. 


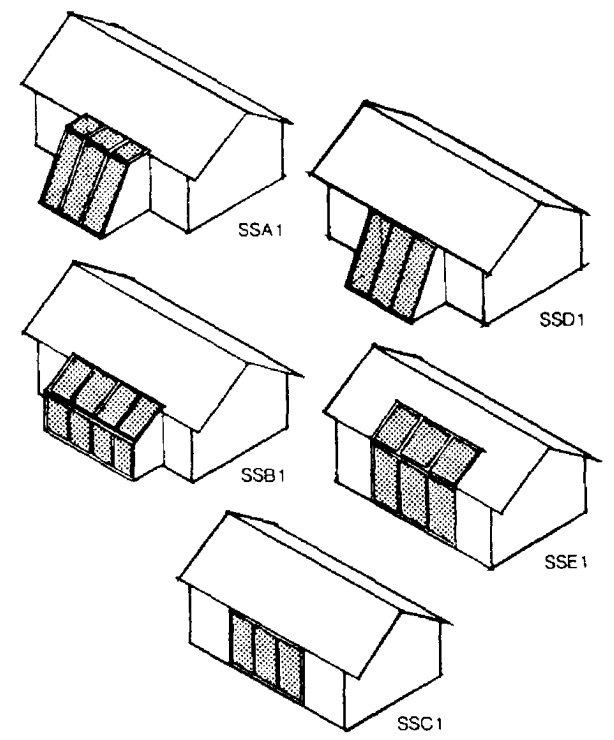

\section{Sunspace geometries that can be evaluated in BuilderGuide}

There are many sunspace configurations.

\section{Thermal Mass}

A sunspace has extensive south-facing glass, so designing in adequate thermal mass is very important. Without it, the sunspace is liable to be uncomfortably hot during the day and too cold for plants or people at night.

However, the temperature in the sunspace can vary more than in the house itself, so about $3 \mathrm{ft}^{2}$ of 4 -in. thick thermal mass for each square foot of sunspace glazing should be adequate. With this glass-to-mass ratio, on a clear winter day, a temperature swing of about $30^{\circ} \mathrm{F}$ should be expected.

The sunspace floor is a good location for thermal mass. The mass floors should be dark in color. No more than $15 \%-25 \%$ of the floor slab should be covered with rugs or plants. The lower edge of the south-facing windows should be no more than 6 in. from the floor or the planter bed to make sure the mass in the floor receives sufficient direct sunlight. If the window sills are higher than that, additional mass will have to be located in the wall.

Another good location for thermal mass is the common wall (the wall separating the sunspace from the rest of the house). Options for the common wall are discussed in more detail below.

Water in various types of containers is another form of energy storage sometimes used in sunspaces.

\section{Glazing}

Clear, double glazing is recommended for sunspaces. Adding the second pane makes a large improvement in energy savings. Triple glazing or low-e coatings, on the other hand, will further improve comfort, but will have little effect on energy savings. 
Windows on the east and west walls should be small (no more than 10\% of the total sunspace floor area), but they are very effective for summer cross-ventilation.

\section{Summer Overheating}

Probably the single biggest problem encountered in sunspaces is summer overheating. Largely, this stems directly from poor design practice and can be avoided. The problem can usually be traced directly to poor glazing orientations--too much non-south glazing. Glass on the roof or on the west walls can create major overheating.

Like any tilted or sloped glazing, a glazed sunspace roof can increase winter solar gain, but it can also present big summer overheating problems. If either glazed roofs or tilted glazing are used in the sunspace, special care should be taken to make sure they can be effectively shaded during the summer. The manufacturers of sunspaces and glazing are developing products with a better ability to control both heat loss and heat gain (for example, roof glazing with low shading coefficients, shading treatments, and shading devices).

Sunspaces with glazed roofs or sloped glazing perform very well. However, if you are not prepared to provide effective shading for the summer months, you should consider using only vertical glazing and accepting somewhat less energy performance in winter.

\section{Common Wall}

There are a number of options for the sunspace common wall--the wall that separates the sunspace from the house. In mild climates, and when the sunspace is very tightly constructed, an uninsulated frame wall is probably adequate. However, insulating the common wall to about R-10 is a good idea, especially in cold climates. An insulated common wall will help guard against house heat loss to the sunspace during prolonged cold, cloudy periods.

The preferred design practice is to make the common wall of masonry so that it also serves for thermal mass. The wall should be solid masonry approximately 4-in. to 8-in. thick and does not need to be insulated. Another option is a frame wall with masonry veneer.

Some solar energy may be transferred from the sunspace to the rest of the house by conduction through the common wall if it is made of thermal mass. But energy is mainly transferred by natural convection through openings in the common wall--doors, windows, and/or vents.

- Doors are the most common opening in the common wall. If only doorways are used, the open area should be at least $15 \%$ of the sunspace south-facing glass area. 
- Windows in the common wall will provide light and views from the house, and will augment natural convection. The window area should be no larger than about $40 \%$ of the entire common wall area. Per unit area, window openings are about one-half as effective for natural convection as are door openings.

\section{Summer Ventilation}

The sunspace must be vented to the outside to avoid overheating in the summer or on warm days in the spring and the fall. A properly vented and shaded sunspace can function much like a screened-in porch.

Operable windows and/or vent openings should be located for effective cross-ventilation, and to take advantage of the prevailing summer wind. Low inlets and high outlets can be used in a "stack effect", because warm air will rise. These ventilation areas should be at least $15 \%$ of the total sunspace south-facing glass areas.

Where natural ventilation is insufficient or access to natural breezes is blocked, a small, thermostat-controlled fan set at about $76^{\circ} \mathrm{F}$ will probably be a useful addition.

\section{Thermal Storage Wall}

The Thermal Storage Wall--also sometimes referred to as a Trombe wall or an indirect-gain system--is a south-facing glazed wall, usually built of heavy masonry, but sometimes using water containers or phase-change materials. The masonry is separated from the glazing only by a small air space. Sunlight is absorbed directly into the wall instead of into the living space. The energy is then released into the living space over a relatively long period. The time lag varies with different materials, thicknesses, and other factors, but typically, energy stored in a Thermal Storage Wall during the day is released during the evening and nighttime hours.

The outside surface of a thermal storage wall should be a very dark color--an absorptance greater than 0.92 is highly recommended. Using a light color will spoil the performance of the wall.

The summer heat gain from a Thermal Storage Wall is much less than that from a comparable area of direct-gain glazing. 


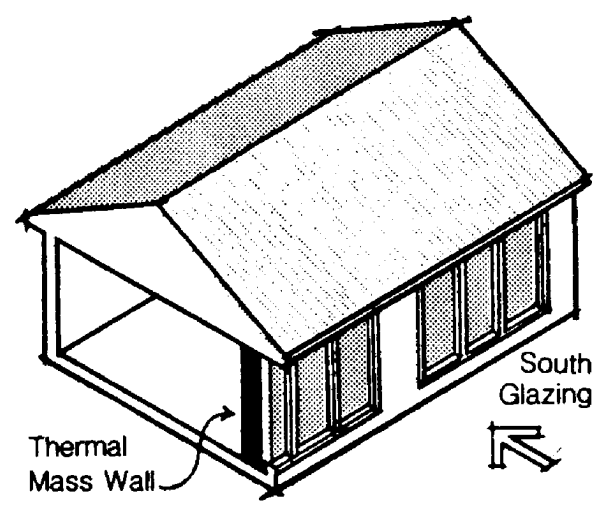

\section{Thermal Storage Wall}

A thermal storage wall is an effective passive solar system, especially to provide nighttime heating.

A masonry Thermal Storage Wall should be solid, and there should be no openings or vents either to the outside or to the living space. Although vents to the living space were once commonly built into Thermal Storage Walls, experience has demonstrated that they are ineffective. Vents between the Thermal Storage Wall and the house tend to reduce the system's nighttime heating capability and to increase the temperature fluctuation in the house. Vents to the outside are similarly ineffective and do little to reduce summer heat gains. 


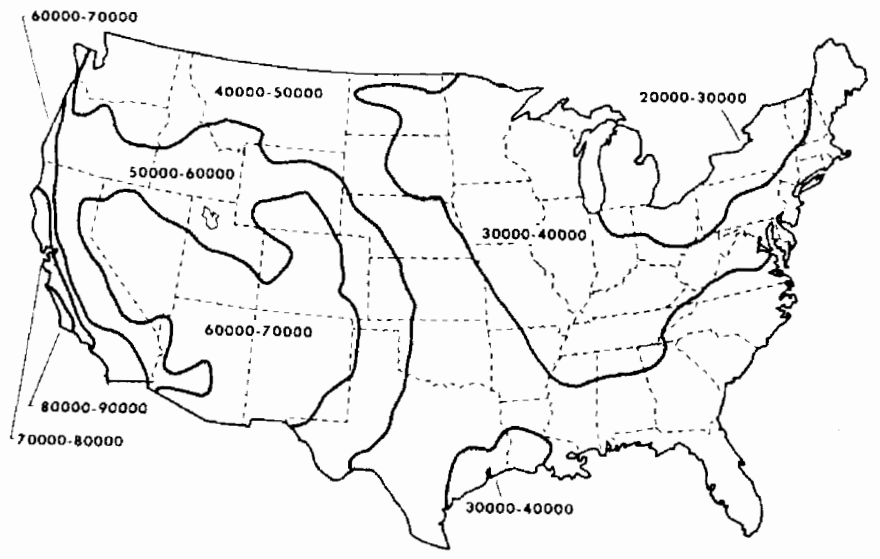

Savings from a Trombe Wall

These are the net annual Btus of heat saved per $\mathrm{ft}^{2}$ Trombe wall south glazing. The wall is high-density concrete block, 12-in. thick, and double glazed. It has a flat-black surface and is unvented.

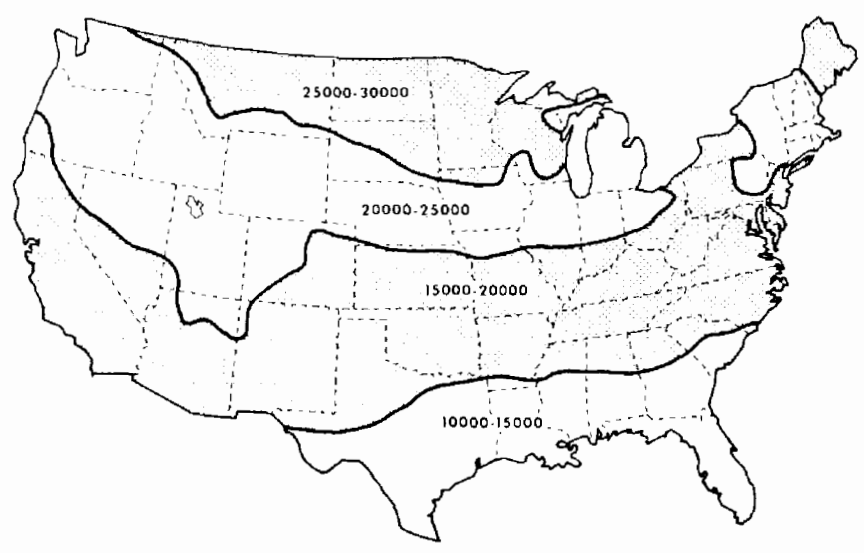

Additional Savings from Using a Selective Surface on a Trombe Wall

Btus of additional heat saved per $f^{2}$ Trombe wall south glazing. Add these values to the values shown on the map above to obtain the total Btu savings of a wall with a selective surface. The wall has a single water-white glazing instead of conventional double glazing.

\section{Glazing}

Double glazing is recommended for Thermal Storage Walls unless a selective surface is used. In that case, single glazing performs about the same as does double glazing in all but the coldest climates.

The space between the glazing and the thermal mass should be between one-half in. and 3 in.

\section{Selective Surfaces}

A selective surface is a special adhesive foil applied to the exterior side of the mass of Thermal Storage Walls. Selective surfaces absorb a large 
percentage of solar radiation but radiate very little heat back to the outof-doors (low emittance).

To be effective, selective surfaces must be applied carefully for $100 \%$ adhesion to the mass surface.

\section{Mass Material and Thickness}

In general, the effectiveness of the Thermal Storage Wall will increase as the density of the material increases. Low-density materials are not recommended. Block filled with sand, for example, will perform poorly.

The optimum thickness of the wall depends on the density of the material chosen, but performance is not very sensitive to thickness. The following chart indicates the recommended thicknesses of Thermal Storage Walls made of various materials. As thickness is increased, the time delay of heat flow through the wall is increased, and the temperature variation on the inside surface is decreased.

\begin{tabular}{|lcc|}
\hline \multicolumn{2}{|l|}{ Mass Wall Thickness } & \\
Material & $\begin{array}{c}\text { Density } \\
\left(\mathrm{lb} / \mathrm{ft}^{3}\right)\end{array}$ & $\begin{array}{c}\text { Thickness } \\
\text { (in.) }\end{array}$ \\
Concrete & 140 & $8-24$ \\
Concrete Block & 130 & $7-18$ \\
$\begin{array}{l}\text { Clay Brick } \\
\text { Ltwt. Concrete }\end{array}$ & 120 & $7-16$ \\
$\begin{array}{l}\text { Block } \\
\text { Adobe }\end{array}$ & 110 & $6-12$ \\
& 100 & $6-12$ \\
\hline
\end{tabular}

\section{Water Walls}

Water provides about twice the heat storage per unit volume as masonry, so a smaller volume of mass can be used. In "water walls", the water is in light, rigid containers. The containers are shipped empty and are easily installed. Manufacturers can provide information about durability, installation, protection against leakage, and other characteristics. At least $30 \mathrm{lb}$ ( 3.5 gal.) of water should be provided for each $\mathrm{ft}^{2}$ of glazing. This is equivalent to a water container about 6 -in. thick, having the same area as the glazing. 


\section{Combined Systems}

Although the previous sections have presented separate discussions of four different systems, it isn't necessary to choose one and only one system. In fact, passive solar features work best in combination.

For example, direct gain works very well in conjunction with a sunspace or thermal storage wall. Because thermal storage walls release energy more slowly than direct-gain systems, they are useful for supplying heat in the evening and at night, whereas the direct-gain system works best during the day. Although using a sunspace, a thermal storage wall, and a direct-gain system in the same house may result in excellent performance, such combinations do require a large south-facing area and careful design to make sure the systems are well integrated with each other and with the house's mechanical system.

\section{Part Four: Natural Cooling Guidelines}

The term "natural cooling" is used here to describe techniques that help a house stay cool in summer but require little or no energy. Natural cooling techniques work to help reduce air conditioning, not to replace it.

These techniques are useful not only in passive solar houses, but in "conventional" houses as well. The strategies outlined below--attention to the location, size, and shading of glazing; using the opportunities on the site for shading and natural ventilation; and using fans--can reduce air-conditioning needs and increase comfort even if the house has no passive solar heating features.

But shading is particularly important in passive solar houses, because the same features that collect sunlight so effectively in winter will go right on collecting it in summer--resulting in uncomfortably hot rooms and big air-conditioning bills--unless those features are properly shaded and the house is designed to help cool itself.

Fortunately, many of the features that help maintain comfort and reduce energy needs in winter also work well in summer. For instance, additional thermal mass performs well year-round. Masonry materials are equally effective in staying cool and storing heat. If mass surfaces can be exposed to cool nighttime temperatures--a technique referred to as "night ventilation"--they will help the house stay cooler the next day. A California utility found during studies of small test buildings that on hot summer days, the workmen at the facility always ate lunch in the masonry test building because it stayed much cooler than any of the others. (See Reference 9.)

The additional insulation that increases winter performance will also work to improve summer performance by conserving the conditioned air inside the house. And some low-e windows and other glazing with high R-values can help shield against unwanted heat gain in summer. 


\section{Glazing}

As mentioned earlier, poorly placed windows can increase airconditioning loads dramatically. It is generally best in terms of energy performance to carefully size nonsolar glazing as indicated in the following table.

\begin{tabular}{|lc|}
\hline $\begin{array}{l}\text { Recommended Non-South Net } \\
\text { Glass Area }\end{array}$ & $\begin{array}{r}\text { Percent } \\
\text { of Total } \\
\text { Floor Area }\end{array}$ \\
Orientation & $4 \%$ \\
East & $4 \%$ \\
North & $2 \%$ \\
West & \\
\hline
\end{tabular}

As mentioned earlier, west-facing windows present particularly difficult shading problems. If glazing is added above the recommended $2 \%$ of the floor area, the need for shading will become even more critical.

Using special glazing or window films that block solar transmission (low shading coefficient) is an option often used in particularly hot climates, but the more effective they are at blocking sunlight, the less clear they are, as a rule, and so they may interfere with desirable views. It is important to note, however, that some types of low-e windows block solar transmission but also allow clear views. These treatments are not recommended for south windows because the winter solar gain is so desirable.

Skylights present a high potential for overheating because the summer sun passes nearly overhead, and because they are especially difficult to shade properly. But skylights are a very popular feature, and they save electricity by providing good natural daylight to the house. In some parts of the country, almost every new house has at least one skylight. A good working compromise can usually be achieved if the skylight area is limited, and if careful attention is paid to shading, either by using a low shading coefficient glass or by devices such as roller shades or blinds. The manufacturer can usually give guidance on shading options for a particular skylight design.

\section{Shading}

Shading strategies generally fall into three categories: landscaping, roof overhangs, and exterior or interior shading devices.

Landscaping. The ideal site for summer shading has deciduous trees to shade the east and west windows. Even small trees such as fruit trees can help block sun hitting the first story of a house. 
Trees on the south side can present a difficult choice. Even deciduous trees will shadow the solar glazing during the winter and interfere with solar gain. In fact, trees on the south side can all but eliminate passive solar performance, unless they are very close to the house and the low branches can be removed, allowing the winter sun to penetrate under the tree canopy. However, in many cases, the trees around the house are bigger selling points than the energy efficiency, and the designer must make a choice.

If a careful study of the shading patterns is done before construction, it should be possible to accommodate the south-facing glazing while leaving in as many trees as possible (see page 27, Site Planning for Solar Access).

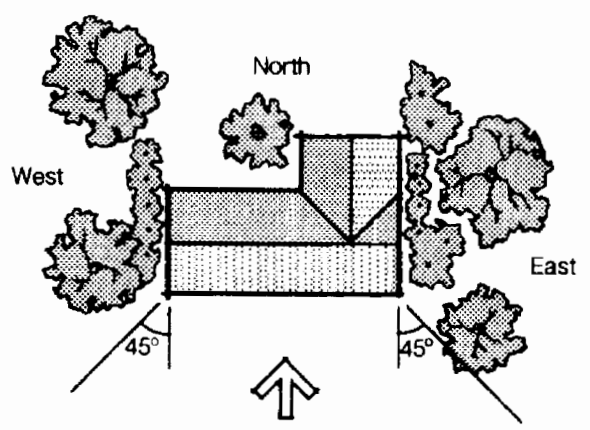

\section{Landscaping for Summer Shade}

Trees and other landscaping features may be effectively used to shade east and west windows from summer solar gains.

Other landscaping ideas for summer shade:

- Trellises covered with vines on the east and west and west sides of the house

- Shrubbery or other plantings to shade paved areas

- Ground cover to prevent glare and heat absorption

- Trees, fences, shrubbery or other plantings to "channel". summer breezes into the house

- Deciduous trees on the east and west sides of the house, as shown above, to balance solar gains in all seasons.

Roof Overhangs. Fixed overhangs are an inexpensive feature and require no operation by the homeowner. They must be carefully designed, however. Otherwise, an overhang that blocks summer sun may also block sun in the spring, when solar heating is desired, and, by the same token, an overhang sized for maximum solar gain in winter will allow solar gain in the fall on hot days. The following figure may be used to determine the optimum overhang size. 


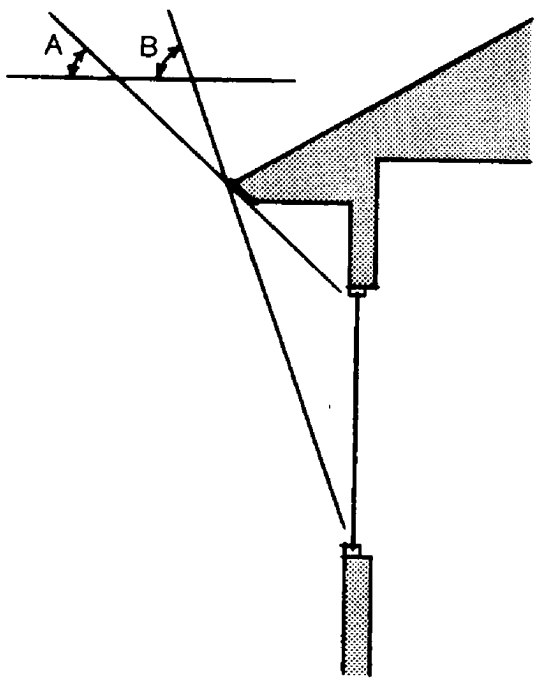

\section{South Overhang Sizing}

An ideally sized south overhang should allow full exposure of the window when the sun has a noon altitude angle $A$ and fully shade the window when the sun has a noon altitude angle $B$.

$\begin{array}{ccc}\text { Latitude } & A & B \\ & & \\ 30 & 41 & 78 \\ 35 & 36 & 73 \\ 40 & 31 & 68 \\ 45 & 26 & 63 \\ 50 & 21 & 58\end{array}$

A combination of carefully sized overhangs on the south windows and shading devices on the other windows will probably be an effective solution. Adjustable overhangs that can be seasonally regulated are another option.

Shading Devices. External shades are the most effective because they stop solar gain before the sun hits the building. A wide range of products is available, from canvas awnings to solar screens to roll-down blinds to shutters to vertical louvers. They are adjustable and perform very well, but their limitation is that they require the homeowner's cooperation. Usually external screens that can be put up and taken down once a year like storm windows are more acceptable to homeowners than those requiring more frequent operation.

Interior shades must be operated, too, and have the further disadvantage of permitting the sun to enter the house and be trapped between the window and the shading device. But highly reflective interior blinds and curtains are relatively low cost and easy to operate.

Another shading "device" well worth considering is a porch. Especially on the east and west sides, porches add pleasant spaces to houses and are excellent for providing shade to windows. Carports located on the east or west are another option.

\section{Ceiling Fans}

Ceiling fans will probably save more energy than any other single cooling strategy. Studies show that air movement can make people feel comfortable at higher temperatures. As a general rule, the thermostat can be set 4 degrees higher without affecting comfort if the air is moving at $100-150 \mathrm{ft}$ per minute. This is enough air movement to greatly improve comfort but not enough to disturb loose papers. 


\begin{tabular}{|lc|}
\hline Ceiling Fan Sizes & \\
Largest Room & $\begin{array}{c}\text { Minimum Fan } \\
\text { Diameter } \\
\text { (in.) }\end{array}$ \\
& \\
$12 \mathrm{ft}$ or less & 36 \\
$12-16 \mathrm{ft}$ & 48 \\
$16-17.5 \mathrm{ft}$ & 52 \\
$17.5-18.5 \mathrm{ft}$ & 56 \\
18.5 or more $\mathrm{ft}$ & 2 fans \\
\hline
\end{tabular}

A ceiling fan should have a minimum clearance of $10 \mathrm{in}$. between ceiling and fan to provide adequate ventilation in a standard room with 8-ft ceilings. In rooms with higher ceilings, fans should be mounted 7.5 to $8 \mathrm{ft}$ above the floor.

\section{Ventilation}

When possible, the house should be positioned on the site to take advantage of prevailing winds. Windows, stairwells, transoms, and other elements should be located for maximum cross-ventilation in each room. The free vent area (unobstructed openings like open windows) should be between $6 \%$ and $7.5 \%$ of total floor area, half located on the leeward side and half located on the windward side of the building. Insect screens can reduce the effective free vent area by as much as $50 \%$. Casement or awning windows have a $90 \%$ open area; double hung windows have only $50 \%$. Casement windows extend outward from the house, tending to channel breezes through the opening; double-hung windows do not have this advantage.

Natural ventilation can help keep houses cool and comfortable at the beginning and end of the cooling season and thus shorten the time when air conditioning is required. But natural ventilation can seldom do the entire cooling job, especially for less than ideal sites with little natural air movement. 


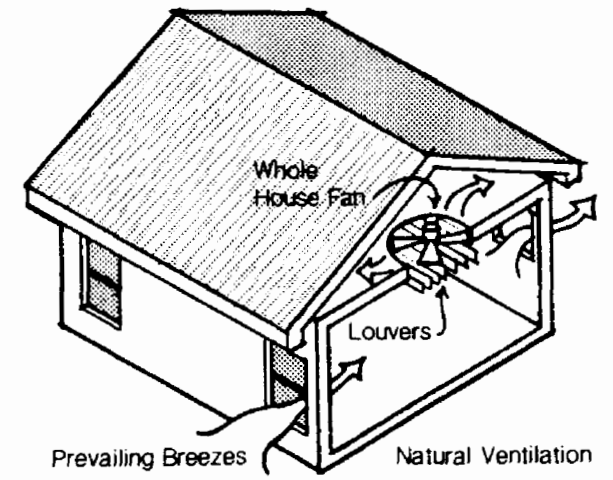

\section{Ventilation for Summer Cooling}

Natural ventilation is often impaired by vegetation and topography. Ventilation fans do not depend on surroundings to be effective.

In cooling climates, a whole-house fan is a good idea for assisting ventilation, especially in houses with sites or designs that make natural ventilation difficult. On the other hand, when the temperature is higher than about $76^{\circ} \mathrm{F}$, a whole-house fan will not be very effective.

Research indicates that a whole-house fan should pull approximately $10 \mathrm{ACH}$. A rule of thumb: for rooms with 8-ft ceilings, the total floor area multiplied by 1.34 will equal the necessary CFM of the fan. For 10-ft ceilings, multiply the floor area by 1.67 .

Natural ventilation and whole-house fans are effective at removing heat, but not at moving air. Ceiling fans, on the other hand, can often create enough of a breeze to maintain comfort at higher temperatures and still use less power than required by air conditioning. The days when air conditioning is needed can be reduced substantially by using natural cooling strategies and low-energy fans. 


\section{SECTION II. BuilderGuide}

\section{Part One: Description of BuilderGuide}

BuilderGuide is a PC program that is easy to use. Calculations that you will make with this program are a very important part of the energyefficient design process because they allow you to quickly evaluate different energy-efficient strategies or combinations of strategies, and the effect that design changes will have on the overall performance of the house.

The results that you get from BuilderGuide can be compared with values that you expect from conventional nonsolar construction. This way you can see how your house will perform in comparison with other houses in the area. You will be surprised at how much energy you will save if you follow the recommendations in this guide.

BuilderGuide results can also be compared with performance goal values that are listed in Section III. If your numbers meet or beat these performance goals, then you can be confident that your design is okay. Two sets of goals are given, one for houses heated with gas and one for houses heated with electricity. The goals for electrically heated houses are much more stringent because of the higher assumed cost of electricity.

BuilderGuide is supported by "look-up" tables containing precalculated factors and numbers for the local area. These files are available for 208 locations in the United States. Some of the blanks in BuilderGuide call for information about the house--for example, floor area, projected area of passive solar glazing, and so forth. These are taken from the house plans. The look-up tables are automatic in the program operation.

BuilderGuide contains four worksheets to calculate four key performance indicators, as follows:

- Worksheet I: Conservation Performance Level--determines how well the house's basic energy conservation measures (insulation, sealing, caulking, etc.) are working to prevent unwanted heat loss in the winter. The bottom line of this Worksheet is a number measuring heat loss in British thermal units per square foot per year (Btu/ $\mathrm{ft}^{2}$-yr)--the lower the heat loss, the better.

- Worksheet II: Auxiliary Heat Performance Level--determines how much heat has to be supplied (that is, provided by the heating system) after taking into account the heat contributed by passive solar. This worksheet arrives at a number estimating the amount of heating energy the house's nonsolar heating system has to provide in Btu $/ \mathrm{ft}^{2}-\mathrm{yr}$. Again, the lower, the better.

Worksheet III: Thermal Mass/Comfort--determines whether the house has adequate thermal mass to assure comfort and good 
thermal performance. Worksheet III calculates the number of degrees the temperature inside the house is likely to vary, or "swing", during a sunny winter day without the heating system operating. A well-designed house should have a temperature swing of no more than 13 degrees, and the less the better. The temperature swing not only measures potential discomfort, it serves as an indicator of adequate thermal mass in the house. If the temperature swing exceeds $13^{\circ} \mathrm{F}$, there is too little thermal mass. The smaller the temperature swing, the better.

- Worksheet IV: Summer Cooling Performance Level--indicates how much air conditioning the house will need in the summer (it is not, however, intended for use in sizing equipment, but as an indication of the reductions in annual cooling load made possible by the use of natural cooling). The natural cooling guidelines should make the house's total cooling load--the bottom line of this Worksheet, in $\mathrm{Btu} / \mathrm{ft}^{2}-\mathrm{yr}-$-smaller than in a conventional house.

\section{Availability of BuilderGuide}

BuilderGuide and city files for 208 U.S. locations are available at a very reasonable price from the Passive Solar Industries Council (PSIC). The program is essential if you are to make full use of these guidelines and wish to compare the performance of your design with the performance goals in Section III. The PSIC address is:

Passive Solar Industries Council

1511 K St. NW, Suite 600

Washington, DC 20005

\section{Part Two: The Basecase House}

Even before you start to design, we strongly recommend that you set up a basecase house using BuilderGuide. This basecase serves as a reference point--it gives you numbers that you can compare with the numbers for your energy-efficient design. It also gives you a quick feeling for the magnitudes of the heating and cooling loads.

To set up a basecase house, you have three choices: (1) You can use the automatic basecase generation feature in BuilderGuide, (2) you can enter a house design of your choosing, or (3) you can use suggested values in this guide. The three options are described in the following paragraphs.

(1) Automatic basecase generation. You specify the house floor area, the number of stories, and the floor type. These should be the same as those for the house that you plan to design. BuilderGuide then calculates all the input data, including house takeoffs and insulation levels, evaluates this house design, and saves the results for later comparison with numbers corresponding to your design. The insulation levels that are assigned may be somewhat better than standard practice. 
(2) Custom basecase. You fill out the worksheets, using any values you think are representative. These might correspond to your last house design, to energy regulations in force in your area, or to conventional practice. You can start with blank worksheets or, better yet, start with the worksheets filled out by the automatic basecase generation feature. You can then change only those values that you feel are inappropriate.

(3) Suggested Values. The National Association of Home Builders (NAHB) conducted a national survey in 1980 to determine conservation levels that were being used in conventional houses. These results are listed on page 53 for 43 cities in the United States. We entered these values into BuilderGuide and used the program to calculate the bottom-line conservation, heating, and cooling numbers for the same 43 cities. The house takeoffs used are for a one-story, $1500-\mathrm{ft}^{2}$ house, as calculated by BuilderGuide. The results are given on page 54 . These numbers should be reasonable choices for a basecase. 
NAHB 1980 Housing Construction Practice (Basecase House)

\begin{tabular}{|c|c|c|c|c|c|c|}
\hline ity & $\mathrm{Rc}$ & $\mathrm{Rw}$ & Floor & $\mathrm{Rf}$ & $\mathrm{Rp}$ & Windows \\
\hline Albuquerque, NM & 30 & 13 & Slab & & 0 & Single/Al/Reg \\
\hline Atlanta, GA & 19 & 13 & Slab & & 0 & Single/Al/Reg \\
\hline Birmingham, AL & 19 & 11 & Slab & & 0 & Double/Al/Reg \\
\hline Bismarck, ND & 30 & 13 & Bsmnt & & 0 & Double/Wood/Reg \\
\hline Boise, ID & 19 & 11 & Bsmnt & & 0 & Double/Al/Reg \\
\hline Boston, MA & 19 & 11 & Bsmnt & & 0 & Double/Wood/Reg \\
\hline Brownsville, TX & 19 & 11 & Slab & & 0 & Single/Al/Reg \\
\hline Buffalo, NY & 19 & 11 & Bsmnt & & 0 & Double/Wood/Reg \\
\hline Burlington, VT & 19 & 11 & Bsmnt & & 0 & Double/Wood/Reg \\
\hline Charleston, SC & 19 & 13 & Slab & & 0 & Single/Al/Reg \\
\hline Cheyenne, WY & 19 & 11 & Bsmnt & & 0 & Double/Al/Reg \\
\hline Chicago, IL & 30 & 13 & Bsmnt & & 0 & Double/Wood/Reg \\
\hline Cincinnati, $\mathrm{OH}$ & 30 & 13 & Bsmnt & & 0 & Double/Wood/Reg \\
\hline Denver, $\mathrm{CO}$ & 19 & 11 & Bsmnt & & 0 & Double/Al/Reg \\
\hline El Paso, TX & 19 & 11 & Slab & & 0 & Single/Al/Reg \\
\hline Fort Worth, TX & 19 & 11 & Slab & & 0 & Single/Al/Reg \\
\hline Fresno, CA & 19 & 11 & Slab & & 0 & Single/Al/Reg \\
\hline Great Falls, MT & 19 & 11 & Bsmnt & & 0 & Double/Al/Reg \\
\hline Jackonsville, FL & 19 & 13 & Slab & & 0 & Single/Al/Reg \\
\hline Lake Charles, LA & 19 & 11 & Slab & & 0 & Single/Al/Reg \\
\hline Las Vegas, NV & 30 & 13 & Slab & & 0 & Single/Al/Reg \\
\hline Los Angeles, CA & 19 & 11 & Slab & & 0 & Single/Al/Reg \\
\hline Medford, OR & 30 & 11 & Crawl & 19 & & Double/Al/Reg \\
\hline Memphis, TN & 19 & 11 & Slab & & 0 & Double/Al/Reg \\
\hline Minneapolis, MN & 30 & 13 & Bsmnt & & 0 & Double/Wood/Reg \\
\hline Nashville, TN & 19 & 11 & Slab & & 0 & Double/Al/Reg \\
\hline New York, NY & 19 & 11 & Bsmnt & & 0 & Double/Wood/Reg \\
\hline Oklahoma City, OK & 19 & 11 & Slab & & 0 & Single/Al/Reg \\
\hline Omaha, NE & 30 & 13 & Bsmnt & & 0 & Double/Wood/Reg \\
\hline Philadelphia, PA & 19 & 11 & Bsmnt & & 0 & Double/Wood/Reg \\
\hline Phoenix, AZ & 30 & 13 & Slab & & 0 & Single/Al/Reg \\
\hline Pittsburgh, PA & 19 & 11 & Bsmnt & & 0 & Double/Wood/Reg \\
\hline Portland, ME & 19 & 11 & Bsmnt & & 0 & Double/Wood/Reg \\
\hline Portland, OR & 30 & 11 & Crawl & 19 & & Double/Al/Reg \\
\hline Reno, NV & 30 & 11 & Crawl & 19 & & Double/Al/Reg \\
\hline Salt Lake City, UT & 19 & 11 & Bsmnt & & 0 & Double/Al/Reg \\
\hline San Antonio, TX & 19 & 11 & Slab & & 0 & Single/Al/Reg \\
\hline San Diego, CA & 19 & 11 & Slab & & 0 & Single/Al/Reg \\
\hline San Francisco, CA & 19 & 11 & Slab & & 0 & Single/Al/Reg \\
\hline Seattle, WA & 19 & 11 & Bsmnt & & 0 & le/Al/Reg \\
\hline Tampa, FL & 19 & 13 & Slab & & 0 & Single/Al/Reg \\
\hline Topeka, KS & 30 & 13 & Bsmnt & & 0 & e/Wood/Reg \\
\hline Washington & 19 & 11 & Bsmnt & & 0 & Double/Wood/Reg \\
\hline
\end{tabular}

See page 19 to identify terms. 


\section{Performance of the Basecase Houses, Btu/ft ${ }^{2}$ per year}

BuilderGuide Worksheet I, II, and IV results for a $1500-\mathrm{ft}^{2}$ house with conservation values according the NAHB survey of standard housing construction practice. The house has $45 \mathrm{ft}^{2}$ of windows on each side, no shading, no night ventilation, and no ceiling fan. These values are suitable numbers to use as a basecase comparison with your results.

\begin{tabular}{|c|c|c|c|}
\hline Albuquerque, NM & 42039 & 37835 & 13813 \\
\hline Atlanta, GA & 34142 & 31342 & 14243 \\
\hline Birmingham, AL & 30747 & 28134 & 13680 \\
\hline Bismarck, ND & 79769 & 77216 & 7259 \\
\hline Boise, ID & 56203 & 52887 & 10880 \\
\hline Boston, MA & 55879 & 53700 & 7886 \\
\hline Brownsville, TX & 8077 & 6122 & 19611 \\
\hline Buffalo, NY & 66808 & 65472 & 6571 \\
\hline Burlington, VT & 78263 & 75993 & 6004 \\
\hline Charleston, SC & 25085 & 22275 & 16699 \\
\hline Cheyenne, WY & 69150 & 65001 & 4561 \\
\hline Chicago, IL & 57636 & 55849 & 10330 \\
\hline Cincinnati, $\mathrm{OH}$ & 48070 & 46195 & 8965 \\
\hline Denver, CO & 57329 & 53316 & 6246 \\
\hline El Paso, TX & 29564 & 25721 & 17264 \\
\hline Fort Worth, TX & 27203 & 24564 & 17427 \\
\hline Fresno, CA & 30814 & 27394 & 19209 \\
\hline Great Falls, MT & 74399 & 71497 & 5907 \\
\hline Jackonsville, FL & 16753 & 14441 & 17686 \\
\hline Lake Charles, LA & 18989 & 16786 & 17341 \\
\hline Las Vegas, NV & 26383 & 22610 & 19893 \\
\hline Los Angeles, CA & 20856 & 16539 & 9134 \\
\hline Medford, OR & 35864 & 32959 & 8999 \\
\hline Memphis, TN & 34555 & 32343 & 14795 \\
\hline Minneapolis, MN & 71080 & 68877 & 7742 \\
\hline Nashville, TN & 38808 & 36596 & 13157 \\
\hline New York, NY & 52844 & 51259 & 9657 \\
\hline Oklahoma City, OK & 40762 & 37786 & 15092 \\
\hline Omaha, NE & 55305 & 52927 & 12484 \\
\hline Philadelphia, PA & 53113 & 50617 & 11353 \\
\hline Phoenix, AZ & 15226 & 11876 & 18404 \\
\hline Pittsburgh, PA & 58475 & 56779 & 7512 \\
\hline Portland, ME & 73886 & 71743 & 5009 \\
\hline Portland, OR & 35570 & 33222 & 4981 \\
\hline Reno, NV & 39356 & 34948 & 8845 \\
\hline Salt Lake City, UT & 55690 & 52404 & 13287 \\
\hline San Antonio, TX & 18573 & 16121 & 17390 \\
\hline San Diego, CA & 16923 & 13251 & 9732 \\
\hline San Francisco, CA & 37751 & 33372 & 4139 \\
\hline Seattle, WA & 52029 & 49584 & 2931 \\
\hline Tampa, FL & 9631 & 7175 & 19497 \\
\hline Topeka, KS & 47676 & 45149 & 14309 \\
\hline Washington, DC & 44625 & 42081 & 10898 \\
\hline
\end{tabular}




\section{Part Three: Worked Examples: The Method in Practice}

Two worked examples are included to help you understand how BuilderGuide works and to demonstrate how useful the program can be in meeting your energy-efficiency goals as you work through the design process.

\section{Example One--Bob's House}

The first example is a design that came out of one of four special workshops held by the American Indian Council of Architects and Engineers (AICAE). The original design was drawn by Bob Gachupin, who attended the workshop in Albuquerque. Bob's sketch was originally converted into a house plan by David Sloan, an architect working on the AICAE team. It was then adapted and redrawn at NREL.

The house plan provides a communal area in a circular living room. The front door is on the east, facing the rising sun. A corridor runs across the south side of the main house. The plan was flipped and rotated so that main windows and the main outdoor area are on the south and east of the house, providing good warmth in the winter and shelter from the west sun in the summer. Windows along the corridor provide winter solar gain and the tiled-slab floor of the corridor and adobe back wall provide thermal mass. Although this hallway works somewhat like a sunspace, it is open to the house and was therefore analyzed as a direct gain feature.

The following is a summary of the BuilderGuide results:

\begin{tabular}{|c|c|c|c|c|}
\hline & & Basecase & Design & Goal \\
\hline I. & $\begin{array}{l}\text { Conservation Performance } \\
\text { Btu/ } \mathrm{ft}^{2} \text {-year }\end{array}$ & 42039 & 18049 & 22213 \\
\hline II. & $\begin{array}{l}\text { Auxiliary Heat } \\
\mathrm{Btu} / \mathrm{ft}^{2} \text {-year }\end{array}$ & 37835 & 7581 & 11849 \\
\hline III. & $\begin{array}{l}\text { Temperature Swing } \\
{ }^{\circ} \mathrm{F}\end{array}$ & - & 8.2 & $<13^{\circ} \mathrm{F}$ \\
\hline IV. & $\begin{array}{l}\text { Auxiliary Cooling } \\
\text { Btu/ } \mathrm{ft}^{2} \text {-year }\end{array}$ & 13813 & 5482 & 10548 \\
\hline
\end{tabular}

Note that the design reduces the required annual auxiliary heat by $80 \%$ and the required annual auxiliary cooling by $60 \%$, compared with the basecase. The design is well within the performance goals. The temperature swing is well within the $13^{\circ} \mathrm{F}$ limit recommended, indicating that there is adequate thermal mass. The basecase numbers shown are 
from the table on page 54, and the goals are from Section III (multiplied by 0.96 to account for the $2000-\mathrm{ft}^{2}$ floor area).

The $57 \%$ reduction in conservation performance is a measure of the improvement in the thermal tightness of the envelope. The solar savings fraction of $58 \%$ is a measure of the fraction of the heat required by the nonsolar elements of the house that is saved by the solar elements. In this example, you can see that both conservation and solar contribute to the good performance, without adversely affecting the summer cooling requirements. The resulting low level of cooling that remains indicates that the house may well get by just fine without any auxiliary air conditioning. A small evaporative cooler may be warranted for the occasional hot spell.

Floor plan of Bob's house.

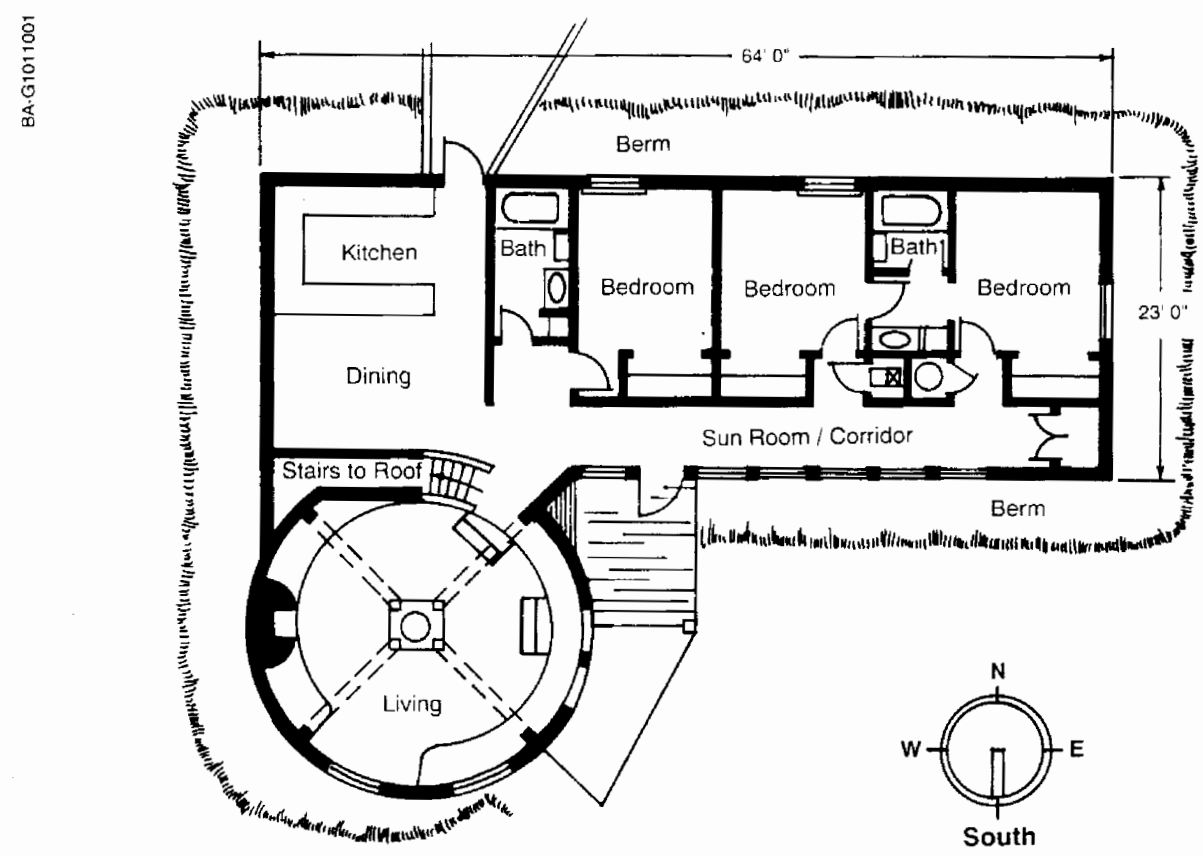

Floor Pian

North-south section of Bob's house through the kiva room.

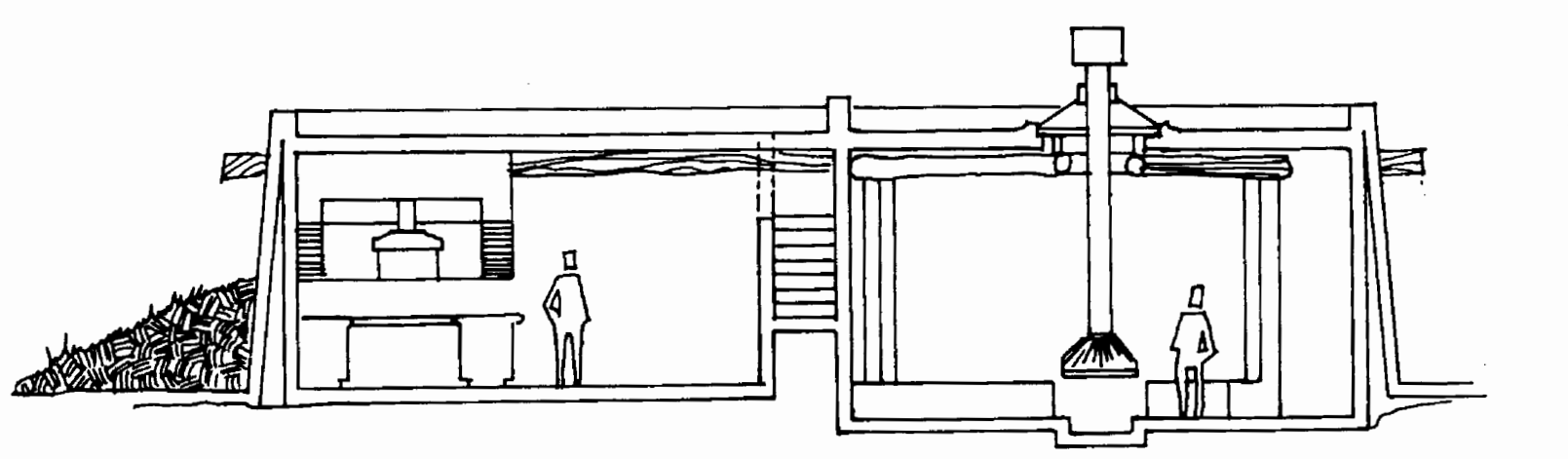

Section 


\section{Example Two--Ernie's House}

The second example also came out of one of the workshops held by the AICAE. No one person originated the design, but it came from marrying the general plan of a passive solar house (rectangular, elongated eastwest) with the octagonal form of the Navajo hogan. The plan was developed by David Sloan of the AICAE and was redrawn without modification at NREL. We arbitrarily located the house in Window Rock, Arizona, which is on the Navajo Indian Reservation. This is a cold, sunny climate (6416 heating degree days), and summer cooling is not a major concern. We assumed that the house is of adobe construction, insulated on the exterior, providing ample thermal mass.

The BuilderGuide printout is shown following the design drawings. Various area takeoffs were determined from the plans. Insulation levels are the guideline values given in Section I.

The following is a summary of the results:

$\begin{array}{llrrr} & \text { Basecase } & \text { Design } & \text { Goal } \\ \text { I. } \quad \begin{array}{l}\text { Conservation Performance } \\ \text { Btu } / \mathrm{ft}^{2} \text {-year }\end{array} & 61161 & 23061 & 28813 \\ \text { II. } \quad \begin{array}{l}\text { Auxiliary Heat } \\ \text { Btu } / \mathrm{ft}^{2} \text {-year }\end{array} & 56888 & 10793 & 15530 \\ \text { III. } \quad \begin{array}{l}\text { Temperature Swing } \\ { }^{\circ} \mathrm{F}\end{array} & 3683 & 2399 & 1746 \\ \text { IV. } & \begin{array}{l}\text { Auxiliary Cooling } \\ \text { Btu } / \mathrm{ft}^{2} \text {-year }\end{array} & & & \\ \end{array}$

Note that the design reduces the required annual auxiliary heat by $81 \%$ and the required annual auxiliary cooling by $35 \%$, compared with the basecase. The design is within the heating performance goals. The temperature swing is well within the $13^{\circ} \mathrm{F}$ limit recommended, indicating that there is adequate thermal mass. The basecase numbers shown are from the table on page 54 and the goals are from Section III. The basecase values and performance goals for Denver were used because the climates are quite similar; the numbers were adjusted by the ratio of heating or cooling degree days, as recommended (see page 74).

The $62 \%$ reduction in conservation performance is a measure of the improvement in the thermal tightness of the envelope. The solar savings fraction of $53 \%$ is a measure of the fraction of the heat required by the nonsolar elements of the house that is saved by the solar elements. In this example, you can see that both conservation and passive solar heat contribute to the good performance. The cooling performance does not meet the target, but the number, $2399 \mathrm{Btu} / \mathrm{ft}^{2}$-yr, is still relatively small. 
If cooling did prove to be a problem, an inexpensive solution would be to apply shade screen to some of the south-facing windows during the summer months only. 
Schematic showing the marriage of two house footprints, a conventional passive-solar rectangle and a hogan octagon.

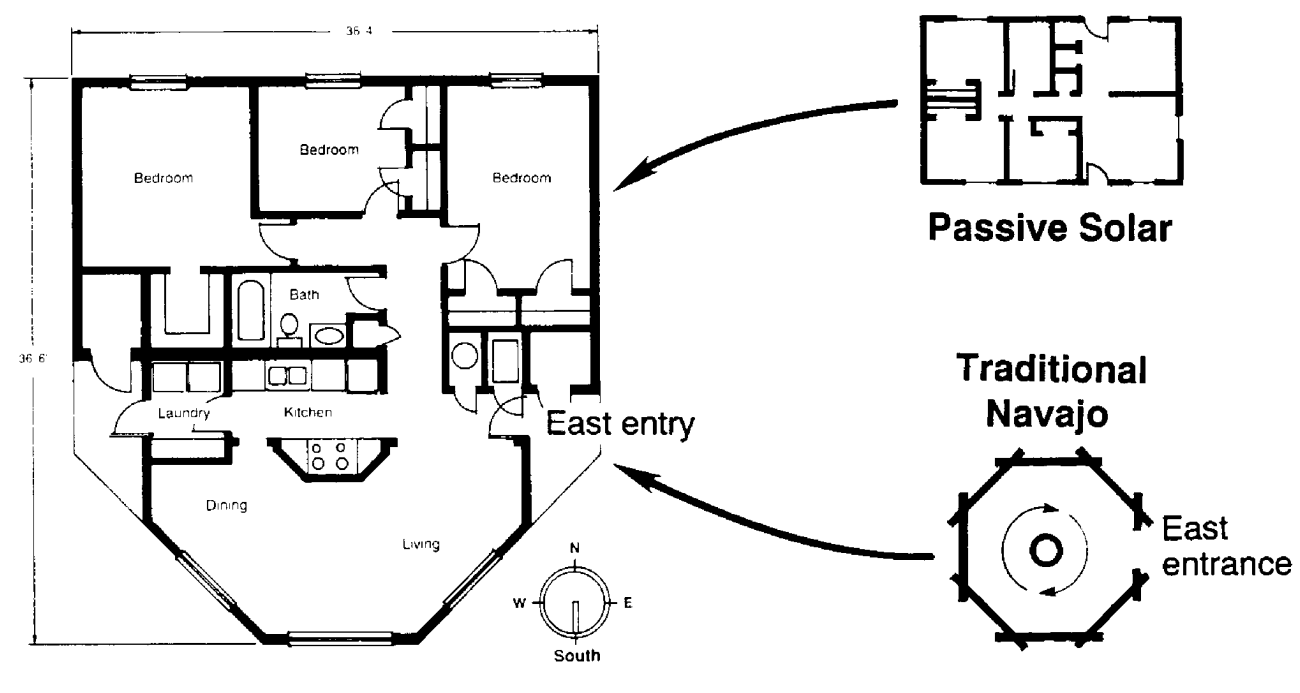

Ernie's House

Perspective view of Ernie' house from the southwest.

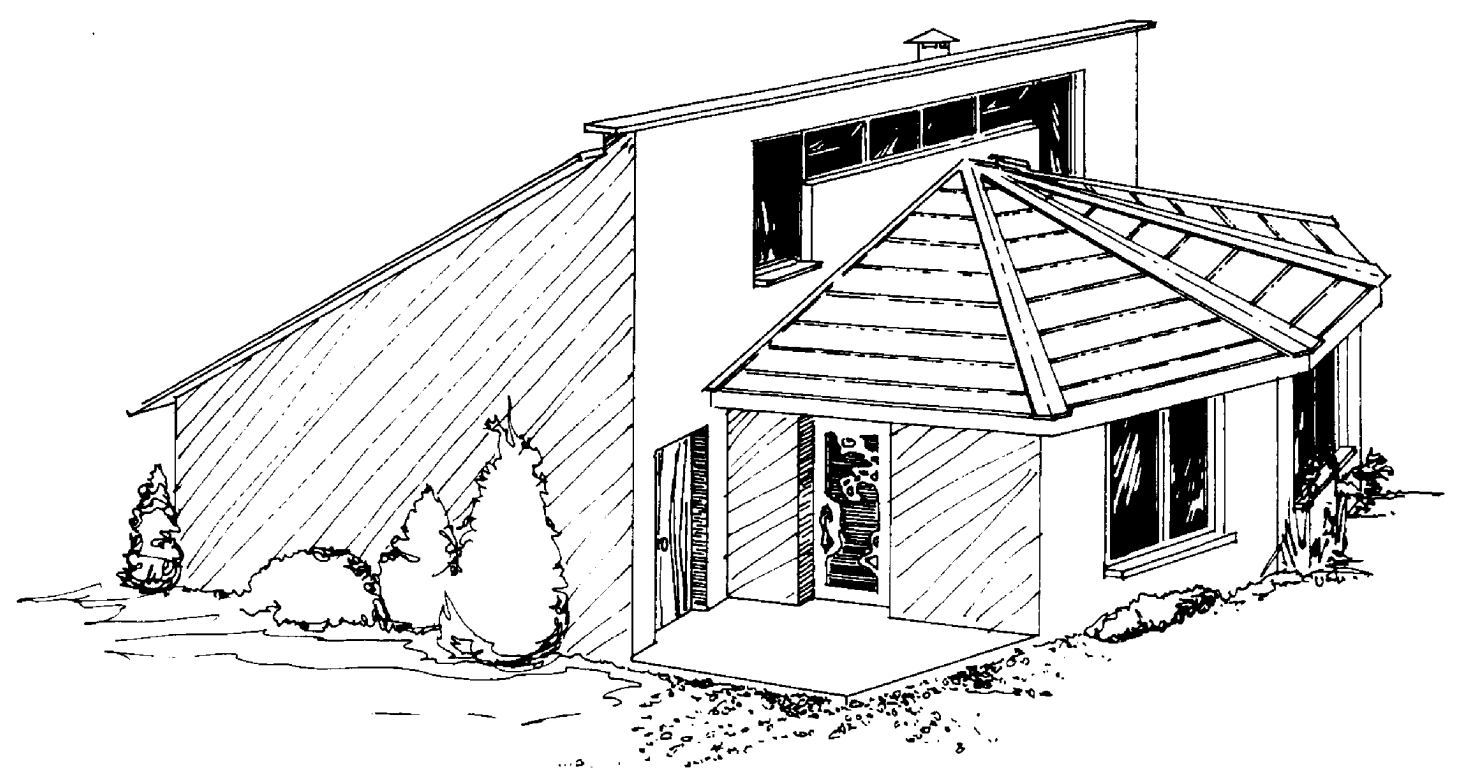


Floor plan of Ernie's house.

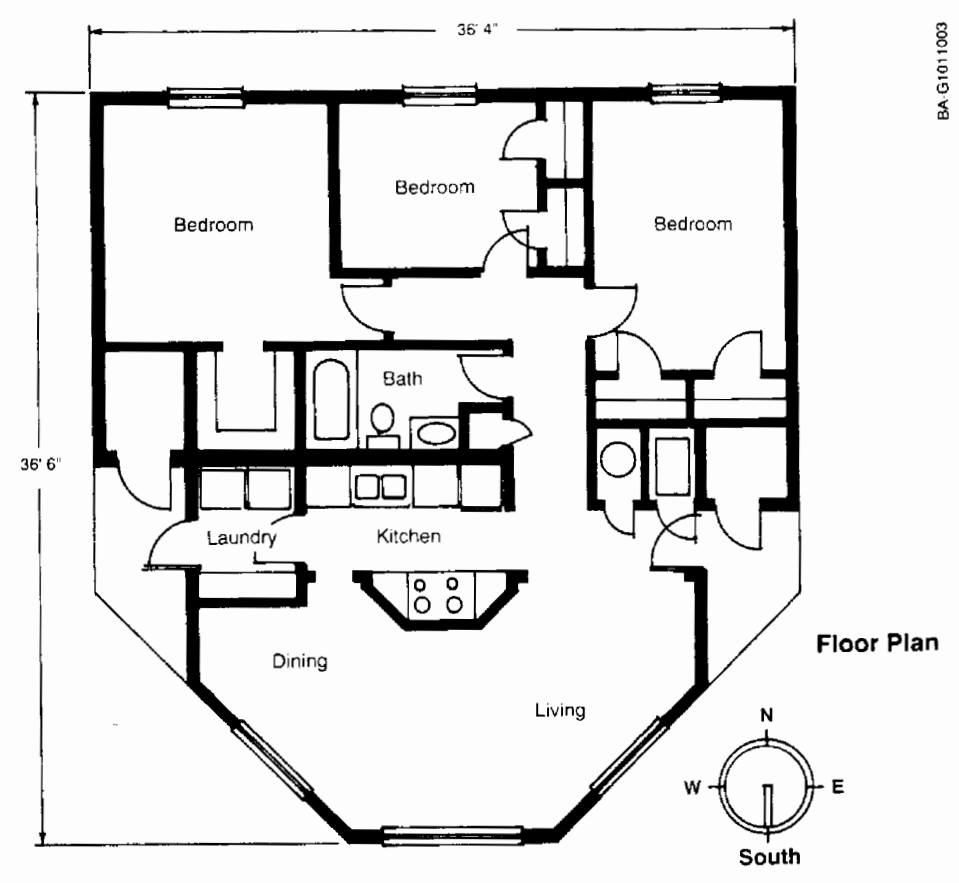

North-south section of Ernie's house.

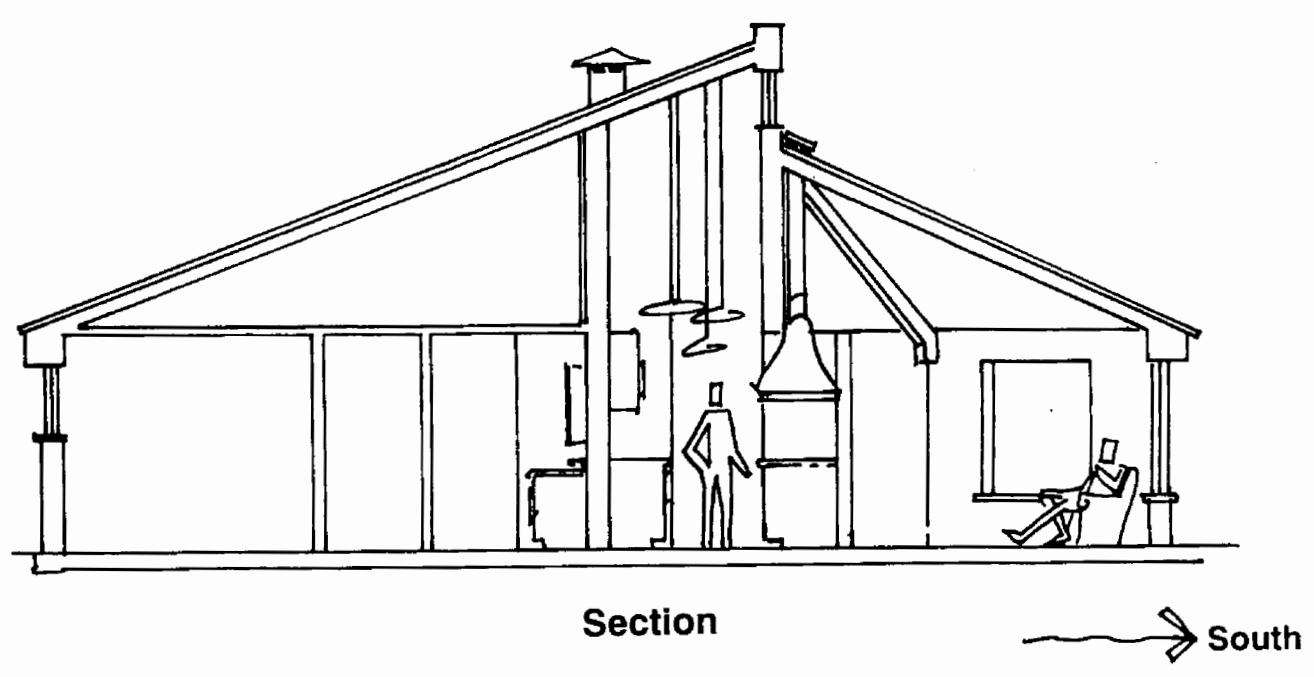




\section{Comment on the Examples}

These examples show very large savings, in the range of $70 \%$ to $80 \%$, compared with the basecase. This is quite realistic. To some extent, this is because both examples are located in the sunny southwest, where good solar performance can be achieved. However, even in cloudy climates, very substantial savings, in the range of $30 \%$ to $50 \%$, will result just from meeting the performance goals. To see this, refer again to the numbers in the table on page 10 . In cloudy climates, the savings are mostly because of improved levels of conservation, although even in these cases, solar savings fractions of $10 \%$ to $20 \%$ are achieved.

\section{BuilderGuide Printouts}

The printouts from BuilderGuide are reproduced on the following pages. Various area takeoffs were determined from the plans. Insulation levels used are the guideline values for electrically heated homes in the locality, as given in Section I.

The reference cases listed are computed using the automatic basecase generation feature of BuilderGuide. The numbers are somewhat different than those listed in the previous summary table. The differences are caused by different assumptions for typical insulation levels for the two localities. 


\section{BuilderGuide Results for Bob's House}

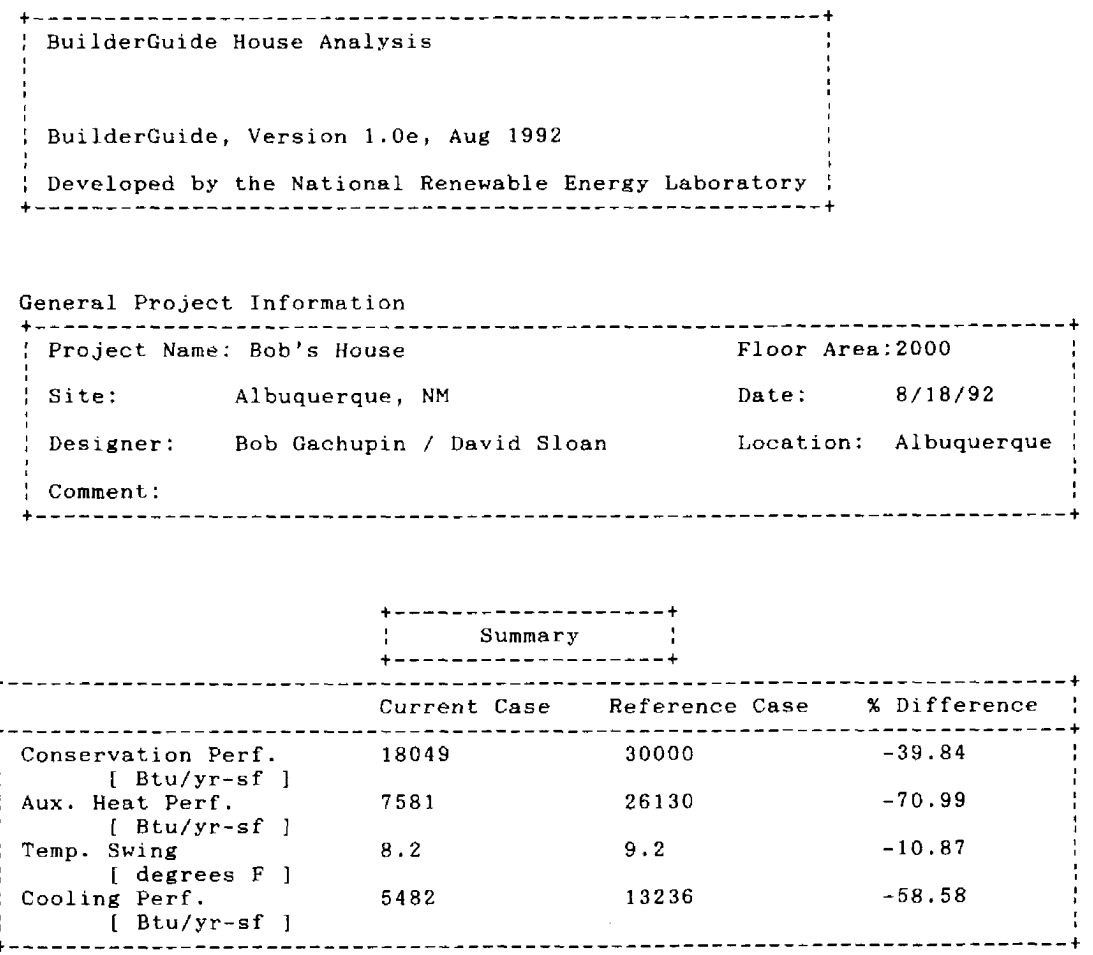

In BuilderGuide, the user fills in fields on the computer screen, such as the Area and $R$-value, and the program calculates other numbers, such as Heat Loss. The program also performs table lookups, such as Heating Degree-Day Multiplier. Pop-up help screens provide useful information, such as definitions of terms and tables of R-values for typical construction. There is an initial summary of results, followed by one page each for the four worksheets. Two numbers show at the bottom of each worksheet, the value for the house being designed and a comparison value for the basecase house. These pairs of numbers also show on the summary. Thus the user has a benchmark for comparison, with percentage improvements shown on the summary. The notations on these printouts are fairly self-explanatory; however, the reader should refer to the user manual and the help text in the program for complete descriptions. As with any engineering evaluation, the results depend on good, informed judgment being applied by the user at each step.

The DGC2 solar system reference code shown on Worksheet II refers to direct gain with low-e glass. In Bob's house, adobe walls are shown on Worksheet III. These add significantly to the heat capacity of the house and reduce the temperature swing to a very comfortable level. The use of night vent with ceiling fan and no west windows on Worksheet IV decreases the cooling loads markedly. The large south glazing area combines with Albuquerque's favorable climate to produce a very respectable $58 \%$ solar savings fraction. 


\section{Bob's Worksheet I}

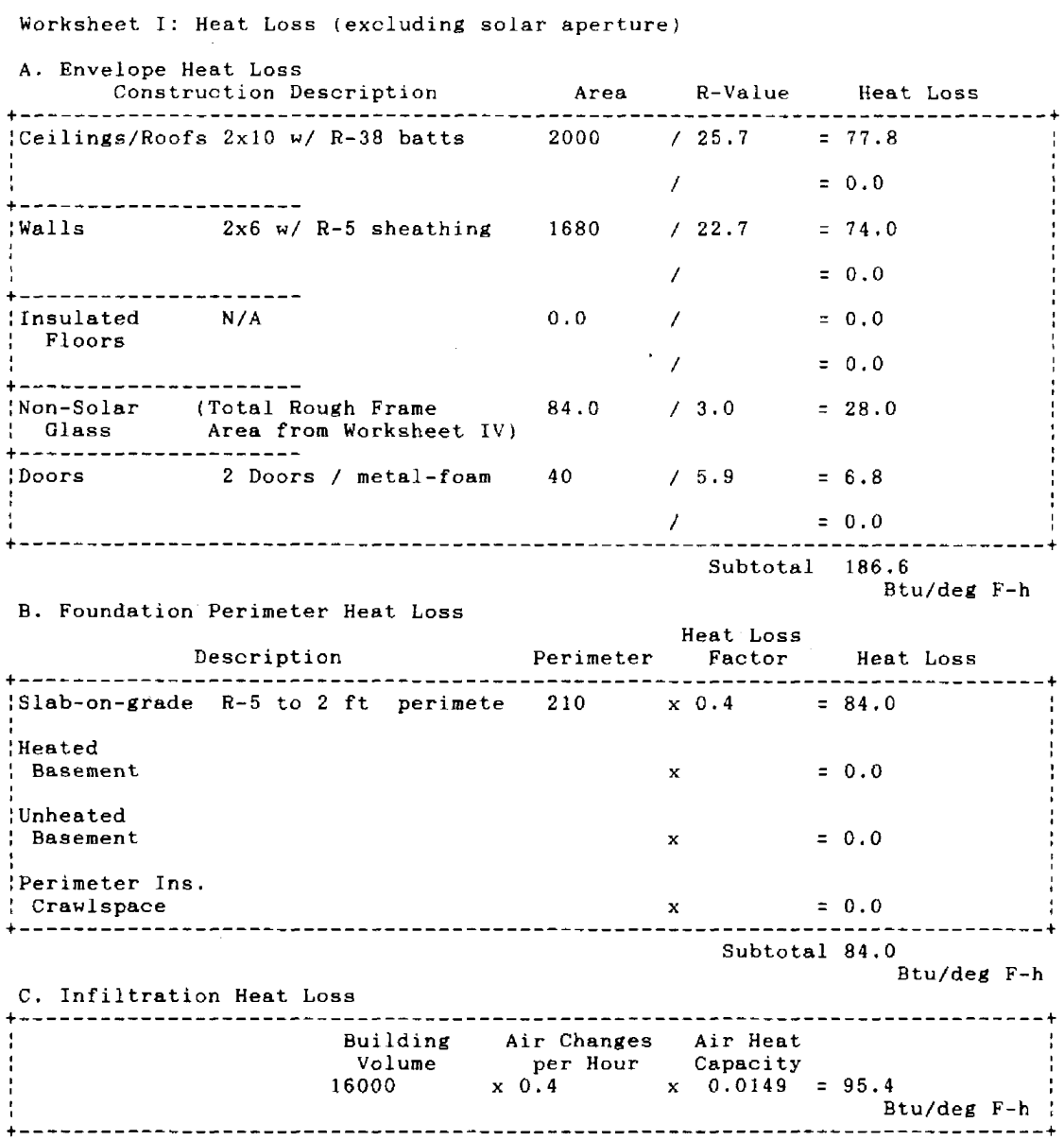

D. Total Heat Loss per Square Foot

D. Total Heat Loss per Square Foot
24

E. Annual Heat Loss (excluding solar aperture)

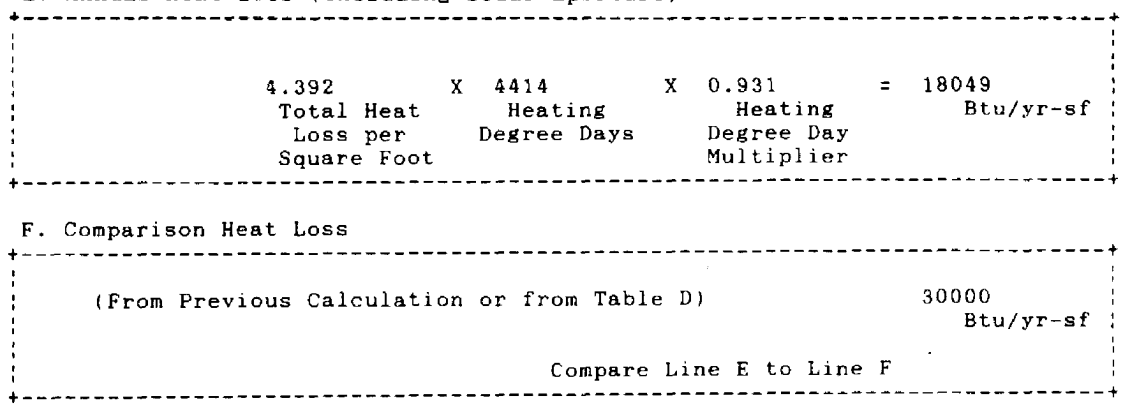

- End of worksheet I -- 


\section{Bob's Worksheet II}

Worksheet II: Auxiliary Heat

A. Projected Area of Passive Solar Glazing

\begin{tabular}{|c|c|c|c|c|c|c|c|c|}
\hline $\begin{array}{l}\text { Solar System } \\
\text { Reference Code }\end{array}$ & $\begin{array}{r}\text { Rough } \\
\text { Area }\end{array}$ & $\begin{array}{l}\text { Frame } \\
\text { (sf) }\end{array}$ & & $\begin{array}{l}\text { Net Area } \\
\text { Factor }\end{array}$ & & $\begin{array}{l}\text { Adjustment } \\
\text { Factor }\end{array}$ & & $\begin{array}{c}\text { Projected } \\
\text { Area (sf) }\end{array}$ \\
\hline \multirow[t]{6}{*}{ DGC2 } & 279 & & $\mathrm{x}$ & 0.8 & $\mathrm{x}$ & 1.0 & $=$ & 223.2 \\
\hline & 0.0 & & $\mathrm{x}$ & 0.8 & $\mathrm{x}$ & 1.0 & $=$ & 0.0 \\
\hline & 0.0 & & $\mathrm{x}$ & 0.8 & $\mathrm{x}$ & 1.0 & $=$ & 0.0 \\
\hline & 0.0 & & $\mathrm{X}$ & 0.8 & $\mathrm{x}$ & 1.0 & $=$ & 0.0 \\
\hline & 279.0 & Area & & & & Total & Proj & $\begin{array}{l}223.2 \\
\text { ected Area }\end{array}$ \\
\hline & & & & $\begin{array}{l}3.2 \\
\text { Total } \\
\text { rojected } \\
\text { Area }\end{array}$ & 1 & $\begin{array}{l}2000 \\
\text { Floor } \\
\text { Area }\end{array}$ & $=$ & $\begin{array}{l}0.112 \\
\text { Total } \\
\text { Projected } \\
\text { Area per } \\
\text { Square Foot }\end{array}$ \\
\hline
\end{tabular}

B. Load Collector Ratio

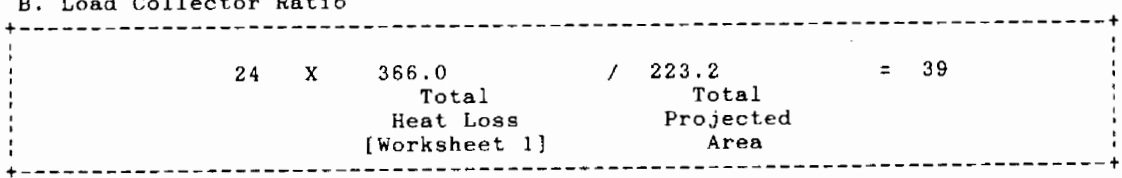

C. Solar Savings Fraction

\begin{tabular}{|c|c|c|c|c|c|c|}
\hline $\begin{array}{l}\text { Solar system } \\
\text { Reference } \\
\text { Code }\end{array}$ & $\begin{array}{c}\text { Projected } \\
\text { Area }\end{array}$ & & $\begin{array}{l}\text { Sys } \\
\text { Solar } \\
\text { Frao }\end{array}$ & $\begin{array}{l}\text { em } \\
\text { avings } \\
\text { ion }\end{array}$ & & \\
\hline \multirow[t]{6}{*}{ DGC2 } & 223.2 & $\mathrm{x}$ & 0.580 & $=$ & 129.46 & \\
\hline & 0.0 & $\mathrm{x}$ & & $=$ & 0.00 & \\
\hline & 0.0 & $\mathrm{x}$ & & $=$ & 0.00 & \\
\hline & 0.0 & $\mathrm{x}$ & & $=$ & 0.00 & \\
\hline & & & & Total & 129.46 & \\
\hline & & & & & $\begin{array}{c}223.2 \\
\text { Total } \\
\text { Projected } \\
\text { Area }\end{array}$ & $\begin{array}{l}=0.580 \\
\quad \text { Solar } \\
\text { Savings } \\
\text { Fraction }\end{array}$ \\
\hline
\end{tabular}

D. Annual Auxiliary Heat Required

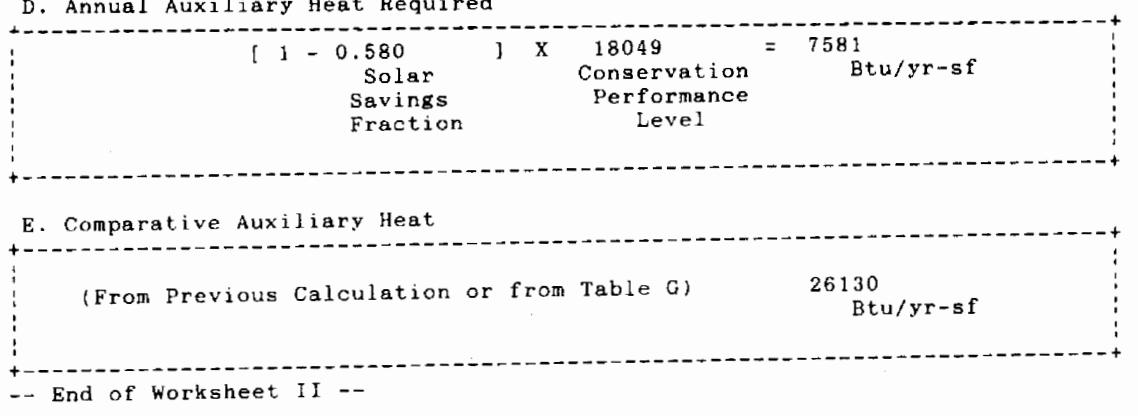


Bob's Worksheel III

Worksheet III: Thermal Mass / Comfort

A. Heat Capacity of Sheetrock and Interior Furnishings

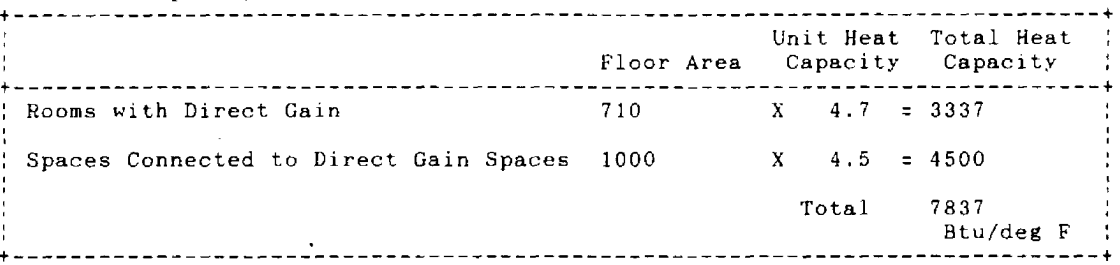

B. Heat Capacity of Mass Surfaces Enclosing Direct Gain Spaces

\begin{tabular}{|c|c|c|c|c|c|c|}
\hline $\begin{array}{l}\text { Mass Descr } \\
\text { linclude t }\end{array}$ & $\begin{array}{l}\text { iption } \\
\text { hickness) }\end{array}$ & Area & & $\begin{array}{l}\text { Init Heat } \\
\text { Capacity }\end{array}$ & & $\begin{array}{c}\text { Total Heat } \\
\text { Capacity }\end{array}$ \\
\hline Trombe walls & & & $X$ & 8.8 & $=$ & 0 \\
\hline Water Walls & & & $\mathrm{x}$ & 10.4 & $=$ & 0 \\
\hline $\begin{array}{c}\text { Exposed Slab } \\
\text { in Sun }\end{array}$ & $580 * .6$ & 348 & $\mathrm{x}$ & 13.4 & $=$ & 4663 \\
\hline $\begin{array}{l}\text { Exposed Slab } \\
\text { not in Sun }\end{array}$ & remainder & 232 & $x$ & 1.8 & $=$ & 418 \\
\hline Other Mass & adobe walls & 1184 & $\mathrm{x}$ & 4.9 & $=$ & 5802 \\
\hline Other Mass & & & $x$ & & $=$ & 0 \\
\hline Other Mass & & & $\mathrm{x}$ & & $=$ & 0 \\
\hline \multicolumn{6}{|c|}{ Total } & $\begin{array}{l}10883 \\
\text { Btu/deg F }\end{array}$ \\
\hline
\end{tabular}

C. Heat Capacity of Mass Surfaces

Enclosing Spaces Connected to Direct Gain Spaces

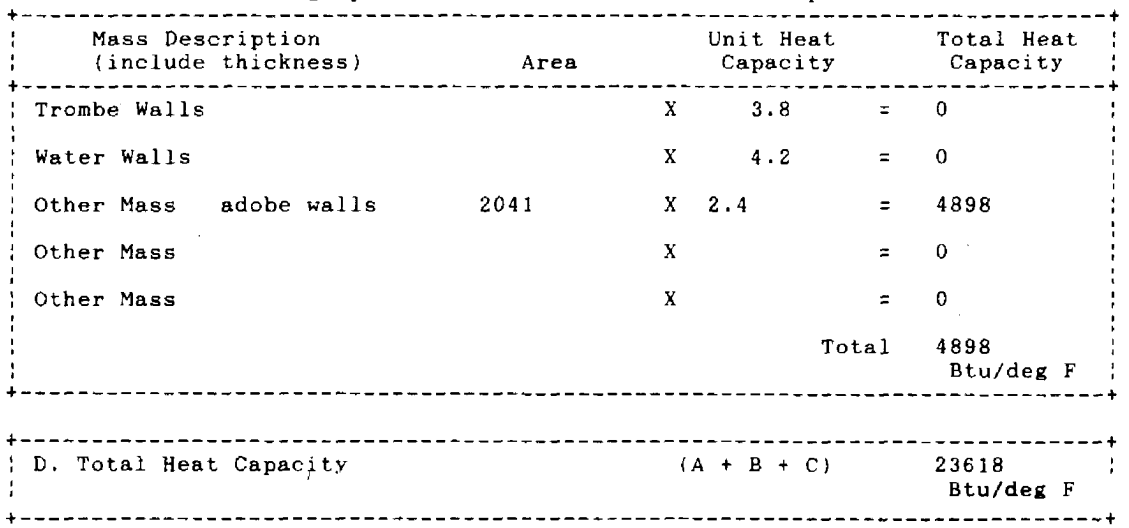

E. Total Heat Capacity per Square Foot

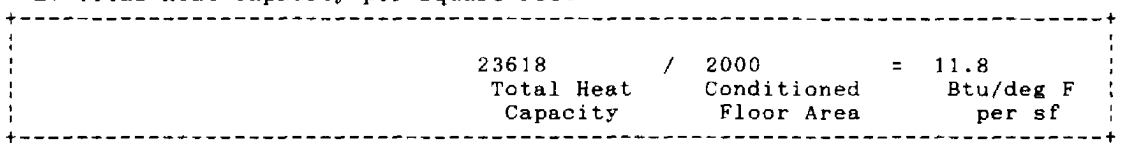

F. Clear Winter Day Temperature Swing

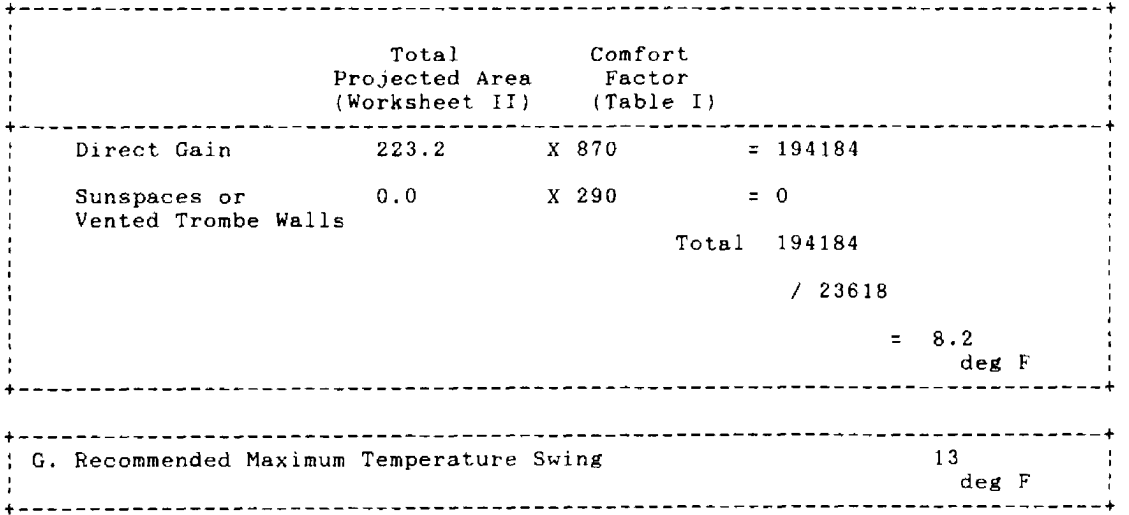

End of worksheet II - 


\section{Bob's Worksheet IV}

Worksheet IV: Auxiliary Cooling

\begin{tabular}{|c|c|c|c|c|c|c|c|c|}
\hline Description & $\begin{array}{l}\text { Heat } \\
\text { Loss }\end{array}$ & & $\begin{array}{l}\text { Radiant } \\
\text { Barrier } \\
\text { Factor }\end{array}$ & & $\begin{array}{l}\text { Absorp- } \\
\text { tance }\end{array}$ & & $\begin{array}{l}\text { Heat } \\
\text { Gain } \\
\text { Factor }\end{array}$ & Load \\
\hline Ceilings/Roofs & 77.8 & $\mathrm{x}$ & 1.0 & $x$ & 0.60 & $\mathrm{x}$ & 62.3 & $=2908$ \\
\hline$---2--$ & 0.0 & $\mathrm{x}$ & & $\mathrm{x}$ & & $\mathrm{x}$ & 62.3 & $=0$ \\
\hline Walls & 74.0 & & & $\mathrm{x}$ & 0.70 & $\mathrm{x}$ & 28.5 & $=1476$ \\
\hline$i$ & 0.0 & & & $\mathrm{x}$ & & $x$ & 28.5 & $=0$ \\
\hline Doors & 6.8 & & & $x$ & 0.84 & $\mathrm{x}$ & 28.5 & $=163$ \\
\hline & & & & & & & Tota & $\begin{array}{l}4547 \\
\quad k B t u / y r\end{array}$ \\
\hline
\end{tabular}

B. Non-solar Glazing

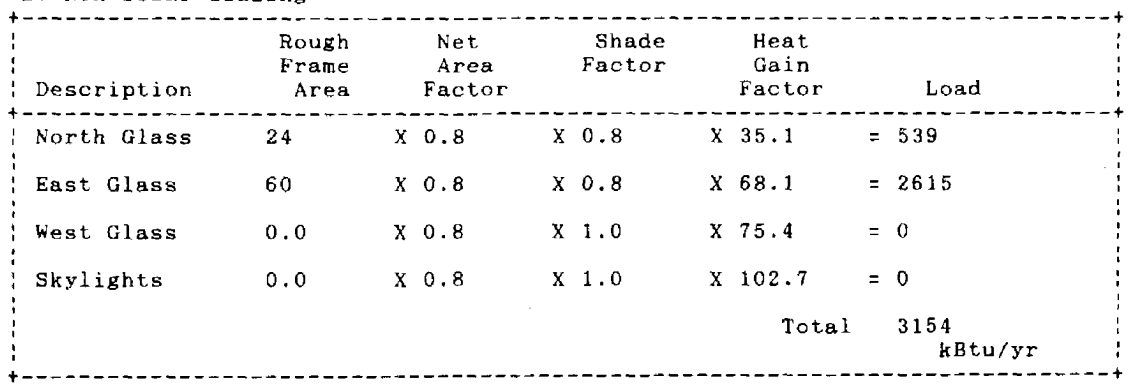

c. Solar Glazing

\begin{tabular}{|c|c|c|c|c|c|c|c|c|}
\hline & $\begin{array}{r}\text { Rough } \\
\text { Frame } \\
\text { Area }\end{array}$ & & $\begin{array}{l}\text { Net } \\
\text { Area } \\
\text { Factor }\end{array}$ & & $\begin{array}{r}\text { Shade } \\
\text { Factor }\end{array}$ & & $\begin{array}{c}\text { Heat } \\
\text { Gain } \\
\text { Factor }\end{array}$ & Load \\
\hline Direct Gain & 279.0 & $\mathrm{x}$ & 0.8 & $\mathrm{x}$ & 0.8 & $\mathrm{x}$ & 47.1 & $=8410$ \\
\hline Storage Walls & 0.0 & $\mathrm{x}$ & 0.8 & $\mathrm{x}$ & 1.0 & $\mathrm{x}$ & 11 & $=0^{-}$ \\
\hline Sunspace & 0.0 & $\mathrm{x}$ & 0.8 & $\mathrm{x}$ & 1.0 & $\mathrm{x}$ & 36.7 & $=0$ \\
\hline & & & & & & & Total & $\begin{array}{l}8410 \\
\mathrm{kBtu} / \mathrm{yr}\end{array}$ \\
\hline
\end{tabular}

D. Internal Gain

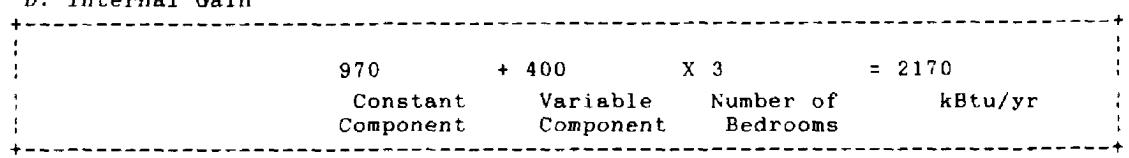

E. Cooling Load per Square Foot

$\begin{array}{rrr}1000 & x 18281 \\ (A+B+C+D) & / 2000 & \text { Floor Area }=9140 \\ B t u / y r-s f\end{array}$

F. Adjustment for Thermal Mass and Ventilation

F. Adjustment for Thermal Mass and Ventilation
Strategy: Night Vent with Ceiling Fan
(Table o)

G. Annual Auxiljary Cooling Required

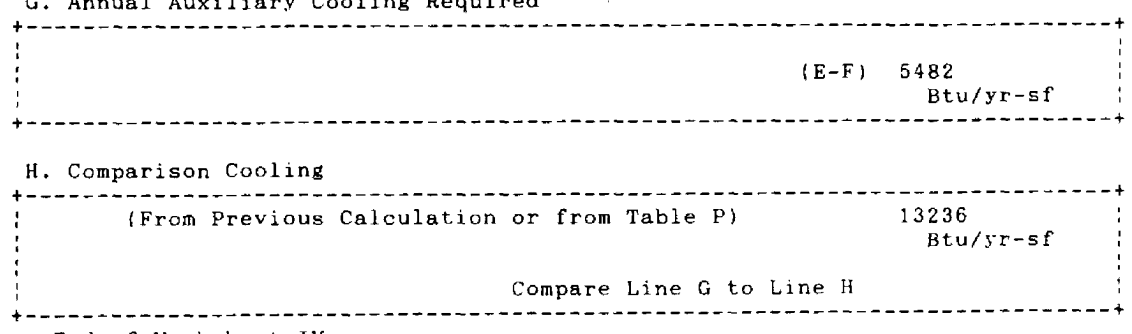

-- End of Worksheet IV -- 
BuilderGuide Results for Ernie's House
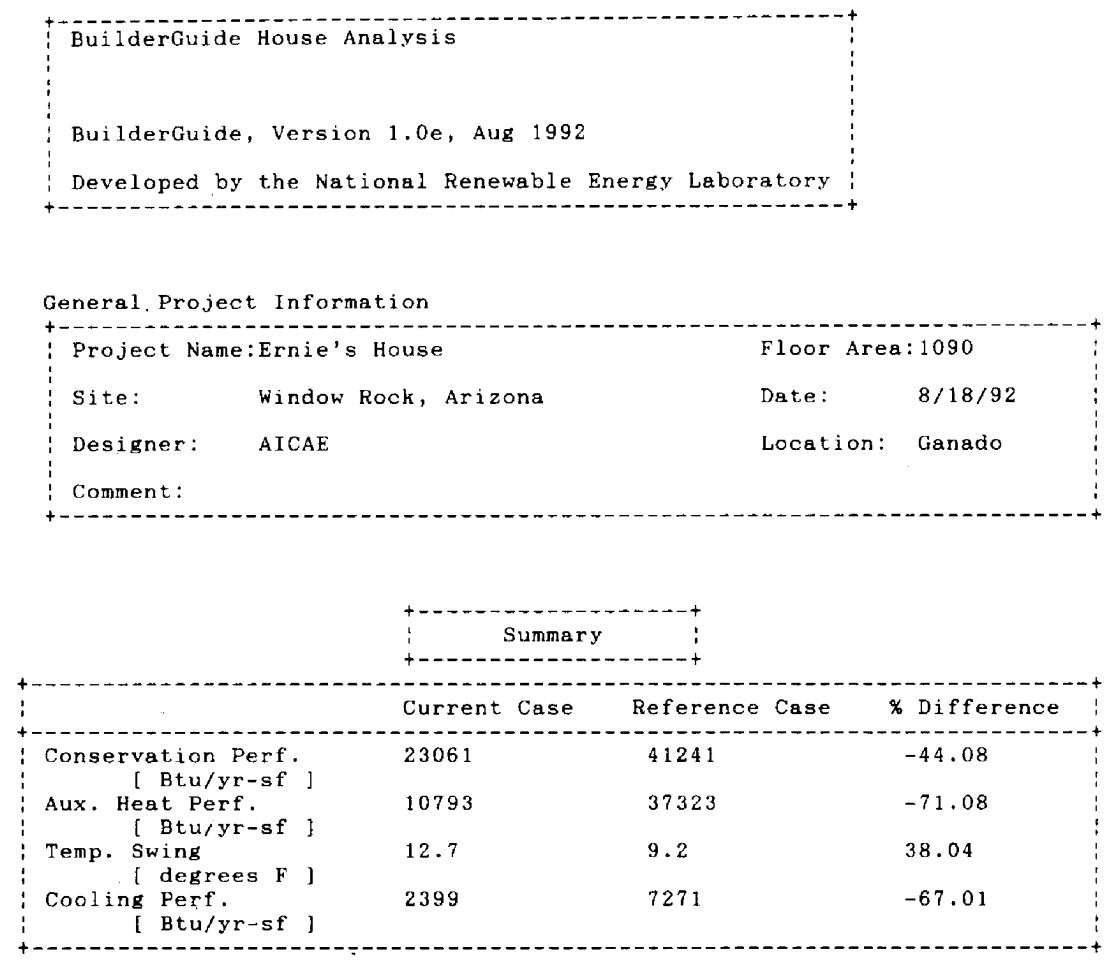

At $1090 \mathrm{ft}^{2}$, Ernie's house is more modest. Because it uses frame construction, rather than adobe, the solar glazing area has been scaled down to avoid excessive temperature swings. The energy solution is primarily to use high levels of insulation, as is appropriate in this cold and windswept location. The walls are built with $2 \times 6$ studs on 24-in. centers covered over with $11 / 2$ inches of expanded-polystyrene-foam exterior sheathing (no CFCs!). Good airtightness is essential to avoid high infiltration losses. The plan also benefits from being quite compact, thus presenting a minimum exterior surface area for heat loss.

The solar savings fraction is a respectable $53 \%$. Worksheet III results indicate that the south window area is at the maximum permissible without exceeding the $13^{\circ} \mathrm{F}$ temperature-swing limit.

Summer cooling is not a big issue at Window Rock's $6750 \mathrm{ft}$ elevation; however, the intense sun invites one to seek shade, especially in the afternoon. One attractive addition to the plan would be a long covered porch along the east wall connecting to the small existing entry porch. This would be a popular place for people and dogs to hang out on summer afternoons. 


\section{Ernie's Worksheet I}

Worksheet I: Heat Loss (excluding solar aperture)

A. Envelope Heat Loss

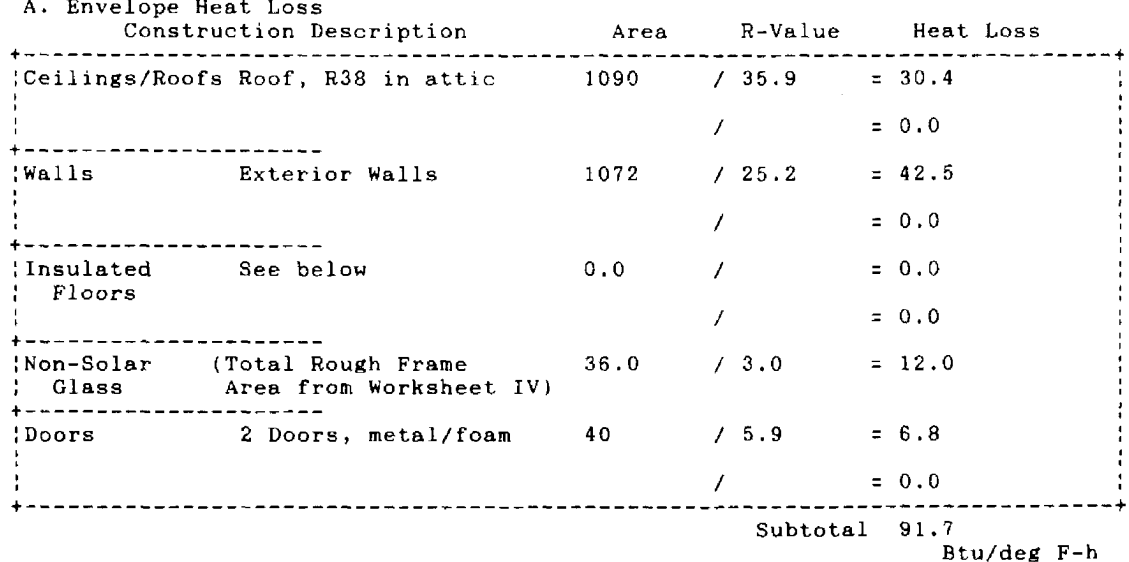

B. Foundation Perimeter Heat Loss

Heat Loss

Btu/deg F-h

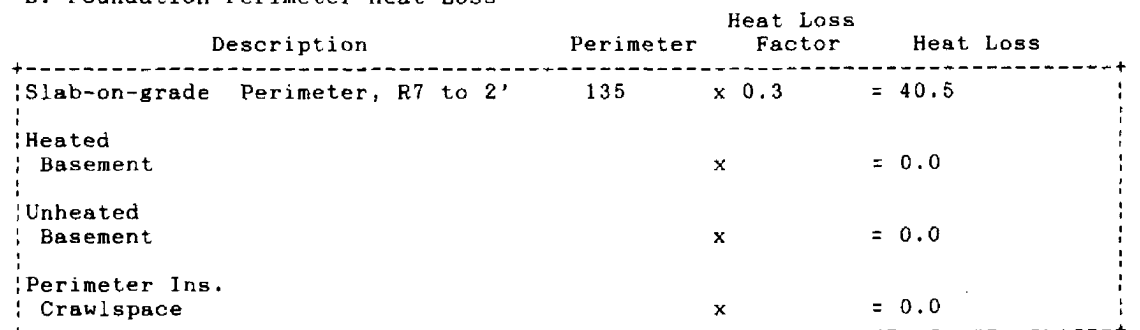

Subtotal 40.5

Btu/deg F-h

C. Infiltration Heat Loss

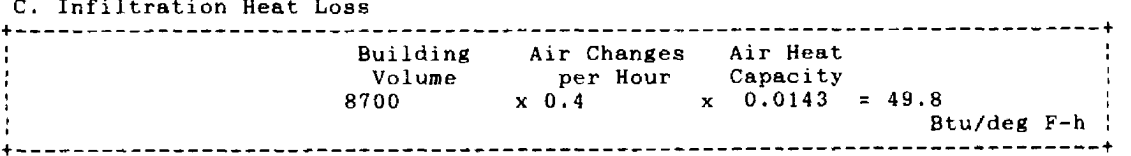

D. Total Heat Loss per Square Foot

182.0
24 $\quad x \quad \begin{aligned} & 1090 \\ & \text { Total Heat Loss Floor Area } \\ & \text { (A+B+C) }\end{aligned}$

E. Annual Heat Loss (excluding solar aperture)

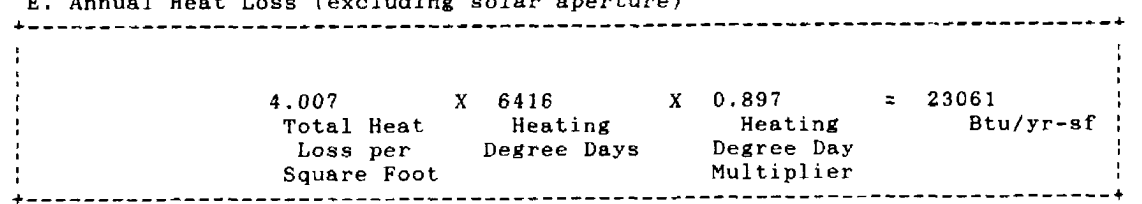

F. Comparison Heat Loss

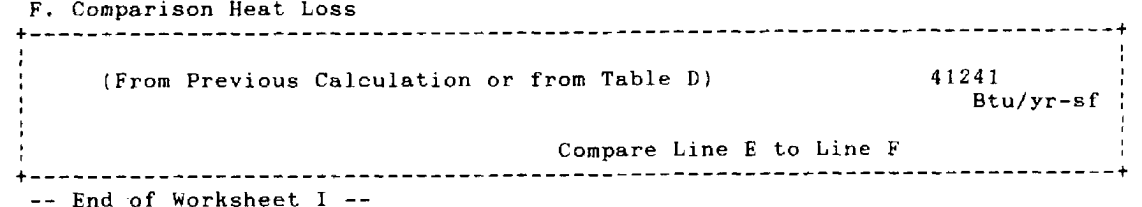




\section{Ernie's Worksheet II}

Worksheet II: Auxiliary Heat

A. Projected Area of Passive Solar Glazing

\begin{tabular}{|c|c|c|c|c|c|c|c|c|}
\hline $\begin{array}{l}\text { Solar System } \\
\text { Reference Code }\end{array}$ & $\begin{array}{r}\text { Rough } \\
\text { Area }\end{array}$ & $\begin{array}{l}\text { Frame } \\
\text { (sf })\end{array}$ & & $\begin{array}{l}\text { Net Area } \\
\text { Factor }\end{array}$ & & $\begin{array}{l}\text { Adjustment } \\
\text { Factor }\end{array}$ & & $\begin{array}{l}\text { Projected } \\
\text { Area (sf): }\end{array}$ \\
\hline \multirow[t]{6}{*}{ DGC2 } & 159 & & $\mathrm{x}$ & 0.8 & $\mathrm{x}$ & 1.0 & $=$ & 127.2 \\
\hline & 0.0 & & $\mathrm{x}$ & 0.8 & $\mathrm{x}$ & 1.0 & $=$ & 0.0 \\
\hline & 0.0 & & $\mathrm{X}$ & 0.8 & $\mathrm{X}$ & 1.0 & $=$ & 0.0 \\
\hline & 0.0 & & $\mathrm{x}$ & 0.8 & $\mathrm{X}$ & 1.0 & $=$ & 0.0 \\
\hline & $\begin{array}{l}159.0 \\
\text { Total }\end{array}$ & Area & & & & Total & Pro & 127.2 \\
\hline & \multicolumn{4}{|c|}{$\begin{array}{c}127.2 \\
\text { Total } \\
\text { Projected } \\
\text { Area }\end{array}$} & I & $\begin{array}{r}1090 \\
\text { Floor } \\
\text { Area }\end{array}$ & $=$ & $\begin{array}{c}0.117 \\
\text { Total } \\
\text { Projected } \\
\text { Area per } \\
\text { Square Foot }\end{array}$ \\
\hline
\end{tabular}

B. Load Collector Ratio

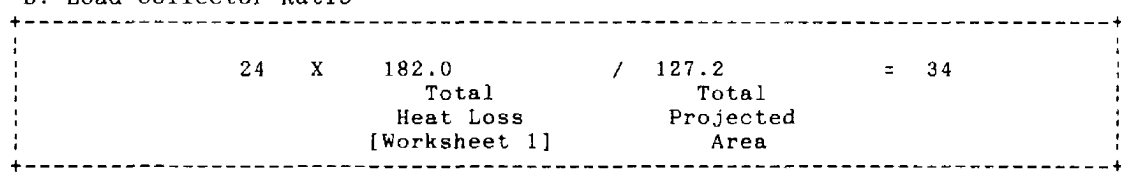

C. Solar Savings Fraction

\begin{tabular}{|c|c|c|c|c|c|c|}
\hline $\begin{array}{c}\text { Solar System } \\
\text { Reference } \\
\text { Code }\end{array}$ & $\begin{array}{c}\text { Projected } \\
\text { Area }\end{array}$ & & $\begin{array}{l}\text { Sys } \\
\text { Solar } \\
\text { Frac }\end{array}$ & $\begin{array}{l}\text { em } \\
\text { avings } \\
\text { ion }\end{array}$ & & . \\
\hline \multirow[t]{6}{*}{ DGC2 } & 127.2 & $\mathrm{x}$ & 0.532 & $=$ & 67.67 & \\
\hline & 0.0 & $x$ & & $=$ & 0.00 & \\
\hline & 0.0 & $\mathrm{x}$ & & $=$ & 0.00 & \\
\hline & 0.0 & $\mathrm{x}$ & & $=$ & 0.00 & \\
\hline & & & & Total & 67.67 & \\
\hline & & & & & $\begin{array}{c}127.2 \\
\text { Total } \\
\text { Projected } \\
\text { Area }\end{array}$ & $\begin{aligned}= & 0.532 \\
& \text { Solar } \\
& \text { Savings } \\
& \text { Fraction }\end{aligned}$ \\
\hline
\end{tabular}

D. Annual Auxiliary Heat Required

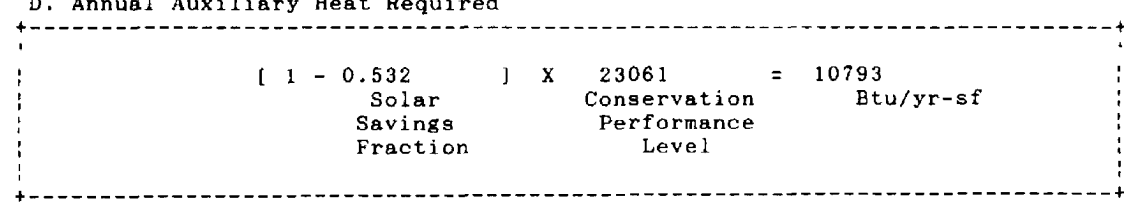

E. Comparative Auxiliary Heat

(From Previous Calculation or frum Table G)
Btu/yr-sf
End of Worksheet II




\section{Ernie's Worksheet III}

Worksheet III: Thermal Mass / Comfort

A. Heat Capacity of Sheetrock and Interior Furnishings

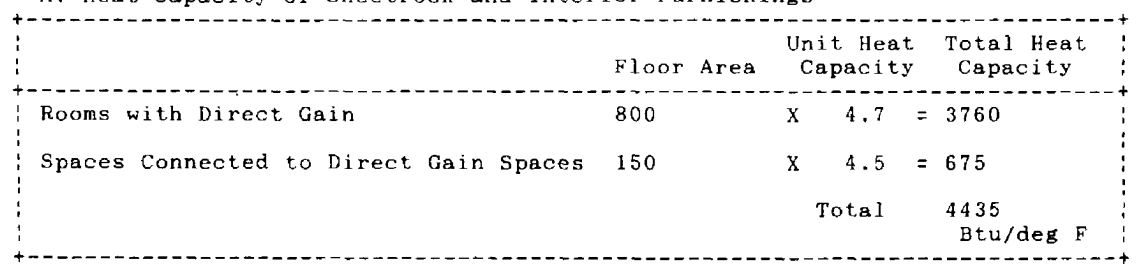

B. Heat Capacity of Mass Surfaces Enclosing Direct Gain Spaces

\begin{tabular}{|c|c|c|c|c|c|c|}
\hline \multicolumn{2}{|c|}{$\begin{array}{l}\text { Mass Description } \\
\text { (include thickness) }\end{array}$} & Area & \multicolumn{2}{|c|}{$\begin{array}{r}\text { Unit Heat } \\
\text { Capacity }\end{array}$} & & $\begin{array}{l}\text { Total Heat } \\
\text { Capacity }\end{array}$ \\
\hline Trombe walls & & & $\mathrm{X}$ & 8.8 & $=$ & 0 \\
\hline Water walls & & & $\mathrm{x}$ & 10.4 & $=$ & 0 \\
\hline $\begin{array}{c}\text { Exposed Slab } \\
\text { in Sun }\end{array}$ & Living Room & 300 & $\mathrm{x}$ & 13,4 & $=$ & 4020 \\
\hline $\begin{array}{l}\text { Exposed Slab } \\
\text { not in Sun }\end{array}$ & other connected & 150 & $\mathrm{x}$ & 1.8 & $=$ & 270 \\
\hline Other Mass & & & $\mathrm{X}$ & & $=$ & 0 \\
\hline Other Mass & & & $\mathrm{x}$ & & $=$ & 0 \\
\hline Other Mass & & & $\mathrm{x}$ & & $=$ & 0 \\
\hline & & & & & & $\begin{array}{l}4290 \\
B t u / \text { deg } F\end{array}$ \\
\hline
\end{tabular}

C. Heat Capacity of Mass Surfaces

Enclosing Spaces Connected to Direct Gain Spaces

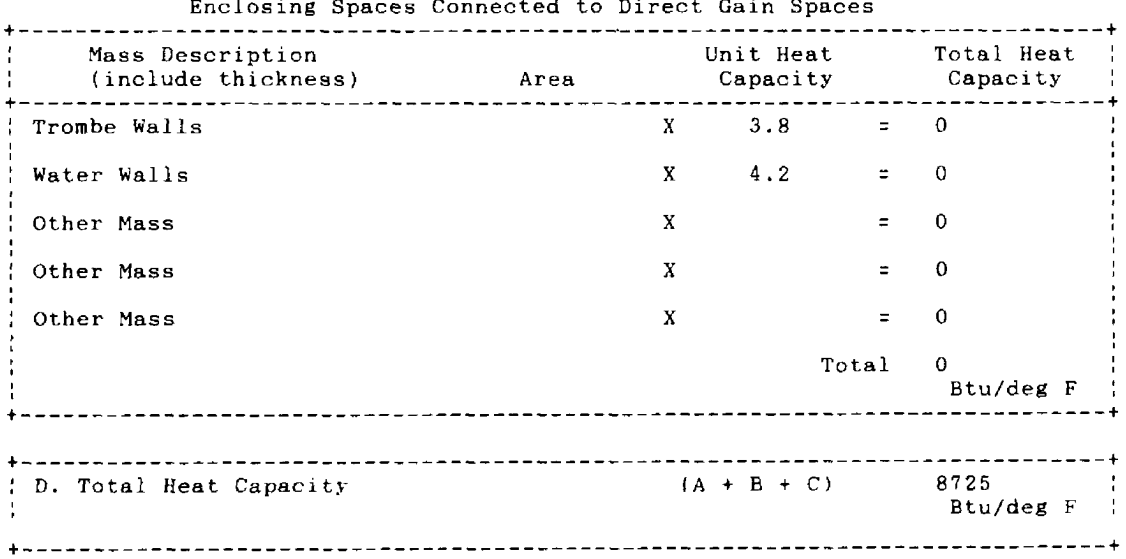

E. Total Heat Capacity per Square Foot

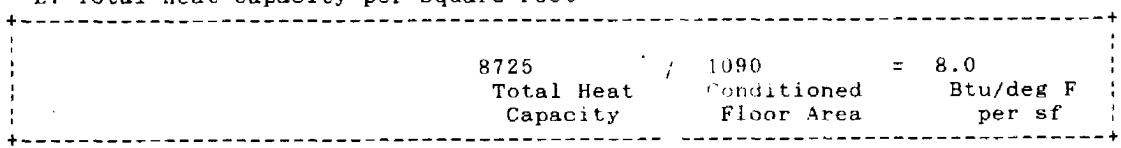

F. Clear Winter Day Temperature Swing

\begin{tabular}{|c|c|c|c|c|c|}
\hline & $\begin{array}{l}\text { Total } \\
\text { Projected Area } \\
\text { Worksheet II) }\end{array}$ & & $\begin{array}{l}\text { Comfort } \\
\text { Factor } \\
\text { (Table I) }\end{array}$ & & \\
\hline Direct Gain & 127.2 & $\mathrm{x}$ & 870 & $=110664$ & \\
\hline \multirow[t]{4}{*}{$\begin{array}{l}\text { Sunspaces or } \\
\text { Vented Trombe Walls }\end{array}$} & 0.0 & $\mathrm{x}$ & 290 & $=0$ & \\
\hline & & & Total & 110664 & \\
\hline & & & & $/ 8725$ & \\
\hline & & & & & $=12.7$ \\
\hline
\end{tabular}

- End of worksheet III -- 


\section{Ernie's Worksheet IV}

Worksheet lis: Auxiliary Cooling

A. Opaque Surfaces

\begin{tabular}{|c|c|c|c|c|c|c|c|c|}
\hline Description & $\begin{array}{l}\text { Heat } \\
\text { Loss }\end{array}$ & & $\begin{array}{c}\text { Radiant } \\
\text { Barrier } \\
\text { Factor }\end{array}$ & & $\begin{array}{c}\text { Absorp- } \\
\text { tance }\end{array}$ & & $\begin{array}{l}\text { Heat } \\
\text { Gain } \\
\text { Factor }\end{array}$ & Load \\
\hline Ceilings/Roofs & 30.4 & $\mathrm{x}$ & 1.0 & $\mathrm{x}$ & 0.60 & $\mathrm{x}$ & 23.5 & $=429$ \\
\hline & 0.0 & $\mathrm{X}$ & & $x$ & & $\mathrm{x}$ & 23.5 & $=0$ \\
\hline Walls & 42.5 & & & $x$ & 0.70 & $\mathrm{x}$ & 15.4 & $=458$ \\
\hline & 0.0 & & & $x$ & & $\mathrm{x}$ & 15.4 & $=0$ \\
\hline Doors & 6.8 & & & $\mathrm{x}$ & 0.84 & $\mathrm{x}$ & 15.4 & $=88$ \\
\hline & & & & & & & Total & $\begin{array}{l}975 \\
\mathrm{kBtu} / \mathrm{yr}\end{array}$ \\
\hline
\end{tabular}

B. Non-solar Glazing

\begin{tabular}{|c|c|c|c|c|c|c|c|c|}
\hline Description & $\begin{array}{r}\text { Rough } \\
\text { Frame } \\
\text { Area }\end{array}$ & & $\begin{array}{c}\text { Net } \\
\text { Area } \\
\text { Factor }\end{array}$ & & $\begin{array}{l}\text { Shade } \\
\text { Factor }\end{array}$ & & $\begin{array}{l}\text { Heat } \\
\text { Gain } \\
\text { Factor }\end{array}$ & Load \\
\hline North Glass & 36 & $\mathrm{x}$ & 0.8 & $\mathrm{x}$ & 0.8 & $\mathrm{x}$ & 19.8 & $=456$ \\
\hline East Glass & 0.0 & $\mathrm{X}$ & 0.8 & $\mathrm{X}$ & 1.0 & $\mathrm{x}$ & 28.9 & $=0$ \\
\hline West Glass & 0.0 & $x$ & 0.8 & $\mathrm{x}$ & 1.0 & $\mathrm{X}$ & 31.2 & $=0$ \\
\hline Skylights & 0.0 & $\mathrm{x}$ & 0.8 & $\mathrm{X}$ & 1.0 & $\mathrm{X}$ & 35.4 & $=0$ \\
\hline & & & & & & & Total & ${ }^{456} \mathrm{kBt}$ \\
\hline
\end{tabular}

C. Solar Glazing

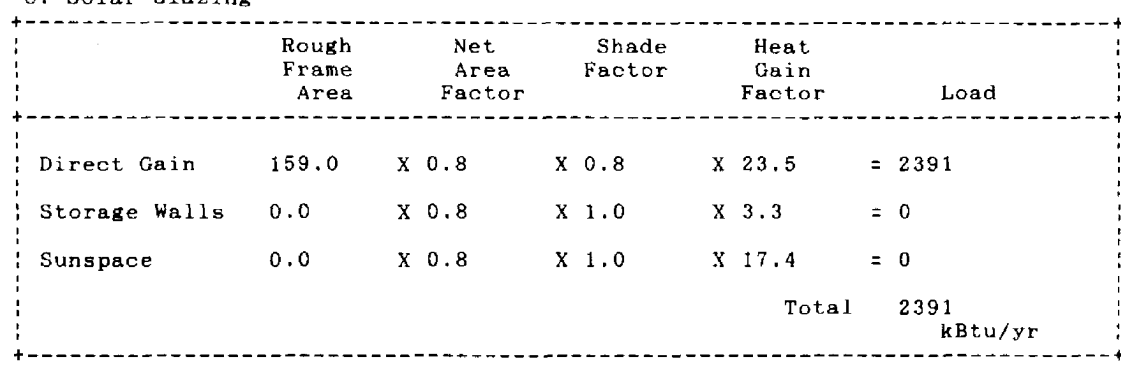

D. Internal Gain

$300 \quad+130 \quad x 3$
Constant
Component $\begin{gathered}\text { Variable } \begin{array}{l}\text { Number of } \\ \text { Compont }\end{array} \\ \vdots\end{gathered}$

E. Cooling Load per Square Foot

$\begin{aligned} & 1000 \times 4512 \\ &(A+B+C+D) \text { F } 1090 \\ & \text { Floor Area } 4139 \\ & \text { Btu/yr-sf }\end{aligned}$

F. Adjustment for Thermal Mass and Ventilation

Strategy: Night Vent with Ceiling Fan
(Table O)

G. Annual Auxiliary Cooling Required

G. Annual Auxiliary Cooling Required
(E-F) 2399
Btu/yr-sf

H. Comparison Cooling

H. Comparison Cooling
(From Previous Calculation or from Table P)
Btu/yr-sf
Compare Line G to Line H




\section{SECTION III.ENERGY-EFFICIENCY PERFORMANCE GOALS}

Energy-efficiency performance goals are given in this section. These performance goals are presented in the spirit of goals for design. They are suitable as guideline values. They are moderately ambitious goals but represent numbers that you can expect to meet or beat just by following the guidance.

The goals are performance targets and are simple to use. You compare the performance goals for your area with the bottom-line numbers from the BuilderGuide worksheets. If your numbers are equal to or less than the corresponding goal numbers, then you have succeeded in meeting your objective.

Design guidance is given in Section I. For guidance on how to reach the conservation performance goals, refer to the insulation guidelines on pages 20 and 21 . These tables give suggestions for components, such as R-values for walls, ceiling, and perimeter, window type, and equipment efficiencies. If these component recommendations are followed, then the house will likely meet the conservation performance goal. Annual auxiliary heat performance goals are less than the corresponding conservation performance goals to account for the passive solar heating contribution. For guidance on how to reach these goals, refer to the guidelines for passive solar glazing area on page 25. Annual cooling energy performance goals are based on a house without passive solar features; thus it will be necessary to minimize the summer heating consequences of the passive solar elements and to compensate in other ways, such as appropriate shading and ventilation.

Because the performance goals are given as $\mathrm{Btu} / \mathrm{ft}^{2}$ of house, larger houses have an inherent advantage because of a smaller surface-tovolume ratio. To remove this bias, it is recommended that the performance goals be adjusted, based on the size of the house. The following factors are suggested:

$\begin{array}{cc}\text { House size, } \mathrm{ft}^{2} & \text { Factor } \\ 500 & 1.30 \\ 1000 & 1.07 \\ 1500 & 1.00 \\ 2000 & 0.96 \\ 3000 & 0.93 \\ 4000 & 0.91\end{array}$

Multiply the $\mathrm{Btu} / \mathrm{ft}^{2}$ performance goals in the tables by the appropriate factor to obtain the corrected goals. The factors are based on a one-story house. You will find that two-story houses have an inherent advantage for houses larger than about $600 \mathrm{ft}^{2}$. 
The goals are voluntary guidelines. They have no force in law or regulation. However, they have been developed based on the principle of economic optimization. This means that the added cost of the energyefficient features should be economically justified, based on the payback in energy savings that will accrue over the life of the house.

\section{Step One: Conservation Performance Goals}

Your conservation performance goal is the maximum annual Btu $/ \mathrm{ft}^{2}$ that your house should require for heating before you account for passive solar gains. This number is calculated on Worksheet I in BuilderGuide. Conservation performance goals are given on page 76 for 43 cities in the United States. Two values are listed for each city, one for houses that are heated with gas and one for houses that are heated with electricity. If the conservation performance level of your house design is less than the goal, then you are okay. The conservation performance level is calculated on Worksheet I of BuilderGuide. It depends on the areas of external surfaces and on the insulation R-values you are using. It indicates the heat required to maintain the house comfortable before solar gains are taken into account.

If your location does not correspond to one of the cities listed in the table, you should adjust the performance goal for a city in the same region of the United States that has similar heating degree days. The adjustment is the ratio of heating degree days. For example, on the Navajo Indian Reservation near Ganado, Arizona, we could start with Denver, Colorado. Heating degree days are 6016 in Denver and 6416 in Ganado. The conservation performance goal for an electrically heated house would be:

$27008 \times(6416 / 6016)=28813 \mathrm{Btu} / \mathrm{ft}^{2}-\mathrm{yr}$.

Heating degree days for the 43 cities are listed on page 79 .

\section{Step Two: Auxiliary Heat Performance Goals}

Your auxiliary heat performance goal is the maximum annual $\mathrm{Btu} / \mathrm{ft}^{2}$ that your house should require for heating after you account for passive solar gains.

Auxiliary heat performance goals are given on page 77 for 43 cities in the United States. Two values are listed for each city, one for houses that are heated with gas, and one for houses that are heated with electricity. If the auxiliary heat performance level of your house design is less than the performance goal, then you are okay. The auxiliary heat performance level is calculated on Worksheet II of BuilderGuide. It depends on the conservation performance level carried over from Worksheet I and on the passive solar savings that you will achieve. This depends on the size and type of passive solar heating systems that you use. The auxiliary heat performance level indicates the heat required to maintain the house comfortable in the winter. 
These performance goals are based on the assumption that the site is not shaded in the winter--that solar access is not impeded. In many cases, this will not be a good assumption because of site constraints, neighboring buildings or trees, or trees on the property that the owner rightly does not want to cut or prune. In these cases, the auxiliary heat performance goals must necessarily be relaxed--perhaps up to the conservation performance goals (corresponding to a zero solar savings fraction).

If your location does not correspond to one of the cities listed in the table, you should adjust the performance goal value of a city in the same region of the United States that has similar heating degree days. The adjustment is the ratio of heating degree days. For example, in Ganado, Arizona, we could start with Denver, Colorado. Heating degree days are 6016 in Denver and 6416 in Ganado. The auxiliary heat performance goal for an electrically heated house would be:

$$
17116 \times(6416 / 6016)=18254 \mathrm{Btu} / \mathrm{ft}^{2}-\mathrm{yr}
$$

Heating degree days for the 43 cities are listed on page 79 .

\section{Step Three: Comfort / Thermal Mass Performance Goals}

This performance goal is easy to describe:

The temperature swing on a clear winter day should not exceed $13^{\circ} \mathrm{F}$.

The temperature swing of your design is calculated on Worksheet III of BuilderGuide. If the value exceeds $13^{\circ} \mathrm{F}$, then you have too much solar gain for the amount of thermal mass in the house. You should either increase mass or decrease direct solar gain. If you have too much direct gain and do not want to sacrifice solar performance, you can convert some of the direct gain to an indirect system, such as a Trombe wall or a sunspace. A Trombe wall contributes nothing to temperature swing (assuming that it is unvented, as recommended). A sunspace contributes about one-third as much to temperature swing as does the same glass area of direct gain.

\section{Step Four: Summer Cooling Performance Goals}

Your summer cooling performance goal is the maximum annual $\mathrm{Btu} / \mathrm{ft}^{2}$ that your house should require for cooling.

Summer cooling performance goals are given on page 78 for 43 cities in the United States. If the summer cooling requirement of your house design is less than the performance goal, then you are okay. The summer cooling performance level is calculated on Worksheet IV of BuilderGuide. It depends on the insulation levels, window areas, shading, and the use of either night-vent cooling or ceiling fans. The summer cooling 
performance level indicates the cooling system output required to maintain the house comfortable in the summer.

If your location does not correspond to one of the cities listed in the table, you should adjust the performance goal for a city in the same region of the United States that has similar cooling degree days. The adjustment is the ratio of cooling degree days. For example, on the Tohono Oo'dham Indian Reservation near Tucson, Arizona, we could start with Phoenix. Cooling degree days are 3746 in Phoenix and 2840 in Tucson. The summer cooling performance goal would be:

$$
16479 \times(2840 / 3746)=12493 \mathrm{Btu} / \mathrm{ft}^{2}-\mathrm{yr}
$$

Cooling degree days for the 43 cities are listed on page 79 . 
Performance Goals for Conservation, $\mathrm{Btu} / \mathrm{ft}^{2}$ per year

BuilderGuide Worksheet I results on Line E should not exceed these targets.

House heating

Albuquerque, NM

Atlanta, GA

Birmingham, AL

Bismarck, ND

Boise, ID

Boston, MA

Brownsville, TX

Buffalo, NY

Burlington, VT

Charleston, SC

Cheyenne, WY

Chicago, IL

Cincinnati, $\mathrm{OH}$

Denver, CO

El Paso, TX

Fort Worth, TX

Fresno, CA

Great Falls, MT

Jackonsville, FL

Lake Charles, LA

Las Vegas, NV

Los Angeles, CA

Medford, OR

Memphis, TN

Minneapolis, MN

Nashville, TN

New York, NY

Oklahoma City, OK

Omaha, NE

Philadelphia, PA

Phoenix, AZ

Pittsburgh, PA

Portland, ME

Portland, OR

Reno, NV

Salt Lake City, UT

San Antonio, TX

San Diego, CA

San Francisco, CA

Seattle, WA

Tampa, FL

Topeka, KS

Washington, DC
Gas

34729

26419

24801

50048

35048

31161

6844

42101

49807

19258

42441

35569

34091

35478

20515

20772

19531

46378

13204

14614

19215

17183

31174

28097

49791

25868

34346

28106

34274

34520

12634

36849

46977

30961

30410

34649

14713

17015

24476

31712

8305

29401

33061
Electricity

23139

18711

16729

43468

26571

27429

6202

32467

40668

13437

31968

30796

27016

27008

16985

14738

15989

35385

9579

11673

14137

11134

23501

19571

38776

20936

27885

21171

29582

27536

12634

28860

38073

24650

22742

26149

10321

9830

21597

25275

7188

25157

25032 
Performance Goals for Auxiliary Heat, $\mathrm{Btu} / \mathrm{ft}^{2}$ per year

BuilderGuide Worksheet II results on Line D should not exceed these targets.

House heating

Albuquerque, NM

Atlanta, GA

Birmingham, AL

Bismarck, ND

Boise, ID

Boston, MA

Brownsville, TX

Buffalo, NY

Burlington, VT

Charleston, SC

Cheyenne, WY

Chicago, IL

Cincinnati, $\mathrm{OH}$

Denver, CO

El Paso, TX

Fort Worth, TX

Fresno, CA

Great Falls, MT

Jackonsville, FL

Lake Charles, LA

Las Vegas, NV

Los Angeles, CA

Medford, OR

Memphis, TN

Minneapolis, MN

Nashville, TN

New York, NY

Oklahoma City, OK

Omaha, NE

Philadelphia, PA

Phoenix, AZ

Pittsburgh, PA

Portland, ME

Portland, OR

Reno, NV

Salt Lake City, UT

San Antonio, TX

San Diego, CA

San Francisco, CA

Seattle, WA

Tampa, FL

Topeka, KS

Washington, DC
Gas

26210

23288

21689

46390

30587

28527

4475

40109

46781

15977

33030

33067

31437

26458

15570

17437

15956

41913

10131

12000

14557

11793

28081

25262

46682

23745

31964

24291

30826

31880

8321

34289

43957

28599

22618

29702

11503

11997

19013

28448

5126

25835

30203
Electricity

14636

14633

12989

39068

21103

24236

3975

30751

37925

10602

21355

27788

24285

17116

10696

10864

12476

29760

7077

9312

8974

6950

19701

15642

36016

17950

24982

15754

24409

23793

8321

26789

34978

22058

13902

19228

7667

6040

14053

22392

4271

20024

20374 
Performance Goals for Summer Cooling, Btu/ $\mathrm{ft}^{2}$ per year

BuilderGuide Worksheet IV results on Line G should not exceed these targets.

\begin{tabular}{|c|c|}
\hline Albuquerque, NM & 10548 \\
\hline Atlanta, GA & 11173 \\
\hline Birmingham, AL & 9973 \\
\hline Bismarck, ND & 4299 \\
\hline Boise, ID & 6541 \\
\hline Boston, MA & 4449 \\
\hline Brownsville, TX & 18514 \\
\hline Buffalo, NY & 3889 \\
\hline Burlington, VT & 3693 \\
\hline Charleston, SC & 13547 \\
\hline Cheyenne, WY & 2683 \\
\hline Chicago, IL & 7096 \\
\hline Cincinnati, OH & 5077 \\
\hline Denver, CO & 2961 \\
\hline El Paso, TX & 12150 \\
\hline Fort Worth, TX & 14592 \\
\hline Fresno, CA & 14593 \\
\hline Great Falls, MT & 3959 \\
\hline Jackonsville, FL & 14447 \\
\hline Lake Charles, LA & 14485 \\
\hline Las Vegas, NV & 15209 \\
\hline Los Angeles, CA & 7827 \\
\hline Medford, OR & 5941 \\
\hline Memphis, TN & 11573 \\
\hline Minneapolis, MN & 5045 \\
\hline Nashville, TN & 9747 \\
\hline New York, NY & 6355 \\
\hline Oklahoma City, OK & 9055 \\
\hline Omaha, NE & 8125 \\
\hline Philadelphia, PA & 6609 \\
\hline Phoenix, AZ & 16479 \\
\hline Pittsburgh, PA & 4633 \\
\hline Portland, ME & 2175 \\
\hline Portland, OR & 3549 \\
\hline Reno, NV & 5551 \\
\hline Salt Lake City, UT & 7553 \\
\hline San Antonio, TX & 14887 \\
\hline San Diego, CA & 8587 \\
\hline San Francisco, CA & 2962 \\
\hline Seattle, WA & 1519 \\
\hline Tampa, FL & 18197 \\
\hline Topeka, KS & 10485 \\
\hline Washington, DC & \\
\hline
\end{tabular}




\section{Heating and Cooling Degree Days}

These are 30-year averages (1951-1980) taken from Climatography of the United States No.81 published by the National Oceanic and Atmospheric Administration. The base temperature is $65^{\circ} \mathrm{F}$.

Heating DD Cooling DD

Albuquerque, NM

Atlanta, GA

Birmingham, AL

Bismarck, ND

Boise, ID

Boston, MA

Brownsville, TX

Buffalo, NY

Burlington, VT

Charleston, SC

Cheyenne, WY

Chicago, IL

Cincinnati, $\mathrm{OH}$

Denver, CO

El Paso, TX

Fort Worth, TX

Fresno, CA

Great Falls, MT

Jackonsville, FL

Lake Charles, LA

Las Vegas, NV

Los Angeles, CA

Medford, OR

Memphis, TN

Minneapolis, MN

Nashville, TN

New York, NY

Oklahoma City, OK

Omaha, NE

Philadelphia, PA

Phoenix, AZ

Pittsburgh, PA

Portland, ME

Portland, OR

Reno, NV

Salt Lake City, UT

San Antonio, TX

San Diego, CA

San Francisco, CA

Seattle, WA

Tampa, FL

Topeka, KS

Washington, DC
4414

2943

9075

5802

5593

609

6798

7953

2147

7310

6455

4950

6014

2664

2407

2647

7766

1402

1579

2532

1595

4798

3207

8007

3756

4922

3735

6194

4947

1442

5950

7501

4691

6030

5802

1606

1284

3161

5121

739

5319

4267
1254

1670

1891

473

742

699

3772

476

379

2093

309

740

1159

680

2096

2809

1769

391

2520

2682

3029

728

645

2067

662

1661

1051

1914

1166

1075

3746

645

254

332

357

981

2983

842

115

184

3324

1380

1311 


\section{Basis for the Energy-Efficiency Performance Goals}

\section{Conservation Performance Goals}

Conservation performance goals have been generated based on the Automated Residential Energy Standards (ARES) computer program developed at the Pacific Northwest Laboratory for the United States Department of Energy. This program was mandated by federal legislation.

ARES computes a set of component values that are economically optimum for a set of assumed energy costs, component costs, and financial parameters. These costs and parameters are part of the data base stored within the program. Refer to the program documentation for these assumptions and for the associated financial algorithms. The energy calculations in ARES are based on regression analysis of annual heating and cooling numbers calculated using the DOE-2 computer program developed at the Lawrence Berkeley Laboratory. Nationalaverage economic parameters were used.

The conservation performance goals were generated in two steps. The first step was to run the ARES program for each of the cities. The ARES output is a set of component values. These results are the guideline values given on pages 20 and 21 for houses heated by gas and electricity, respectively. In the second step, the component values were inserted into BuilderGuide Worksheet I. The area takeoffs that were used are for a onestory $1500-\mathrm{ft}^{2}$ house as determined in the automatic basecase generation. The conservation performance level is the number calculated on Line $\mathrm{E}$ of Worksheet I.

The table of component values could be interpreted as a set of prescriptive standards. We prefer not to characterize them in this way because it is really the net result that is important to keep under control--the overall building heat loss. This depends both on building design and on the component values. It is possible to influence the net result by changing any of several inputs. For example, the designer can compensate for a lower wall R-value by using a higher ceiling $\mathrm{R}$-value or by designing a more compact house with a small wall-surface area. Component values can be usually be relaxed somewhat if the house is two stories because the ceiling area is reduced.

\section{Auxiliary Heating Performance Goals}

The goals for auxiliary heating performance level are based on work at the Los Alamos National Laboratory on balancing conservation and passive solar. The procedure is to calculate a global economic life-cycle optimum considering both conservation and passive solar heating. The results were presented as guidelines for both insulation levels, presented in terms of a parameter called a conservation factor, and the loadcollector ratio (LCR), a parameter that is used in calculating the solar savings fraction. Rather than using the Los Alamos conservation factors, we used the insulation values calculated by ARES, as indicated 
previously. This will not change the passive solar optimization to any significant degree.

The auxiliary heating performance goals were calculated in three steps, starting with the conservation values determined previously: (1) the passive solar glazing area was set to achieve the desired value of LCR. The LCR values from Table I of the Los Alamos/American Society of Heating, Refrigerating, and Air-Conditioning Engineers publication, Passive Solar Heating Analysis, were multiplied by a factor of 1.3 to reduce the glazing area by $30 \%$. This was done to bring the maximum guideline glazing fractions within current guidelines. The LCR values corresponding to the high fuel cost were used for electrically heated houses. This corresponds to $\$ 0.07 / \mathrm{kWh}$. For houses heated by gas, the LCR values for low-cost fuel were used, corresponding to $\$ 11 / \mathrm{million}$ Btu delivered heat (one-half the high-cost value). (2) BuilderGuide was then run to determine the solar savings fraction achieved. (3) These SSF values were multiplied by a factor of 0.70 to compute the auxiliary heat performance goal. The 30\% factor provides a margin to account for a less-than-ideal solar-gain situation, such as site shading or off-south orientation. The resulting goals still represent the use of an aggressive passive solar strategy in cases where this would be economically justified. The SSF values computed (prior to the 0.7 adjustment) assume that the windows are unshaded during winter hours from 9 am to $3 \mathrm{pm}$ and that the solar glazing orientation is true south. If winter shading is extreme or the site or design precludes good orientation, then the performance goals should be relaxed as described in Step Two.

The solar system used for the BuilderGuide calculation is either direct gain or a combination of direct gain and sunspace, where appropriate. Sunspace type SSC1 was used. This is a semi-enclosed sunspace with vertical glazing. The total passive solar area was adjusted to match the Los Alamos guideline LCR value. If this area was below $155 \mathrm{ft}^{2}$, then $105 \mathrm{ft}^{2}$ was used (this is $7 \%$ of the floor area, which is the suntempering limit). If the area was greater than $155 \mathrm{ft}^{2}$, then a sunspace was used to account for all glass area exceeding $105 \mathrm{ft}^{2}$.

\section{Summer Cooling Performance Goals}

The summer cooling goals are the numbers calculated by BuilderGuide for the same $1500-\mathrm{ft}^{2}$ house design that was used to calculate the conservation performance goals. Note that this is a nonsolar house in that there is only $45 \mathrm{ft}^{2}$ of window on each facade. This house has night ventilation but no ceiling fan. The numbers for the gas-heated house were used.

The cooling values for a nonsolar house were used as performance goals because it was not felt that designers of solar houses should be excused for building houses that use more cooling energy than do nonsolar houses. Of course, if passive solar is added to the house, then the summer cooling load will be greater than that for the comparable nonsolar house. The designer can compensate by shading windows, decreasing west windows, adding night ventilation, adding a ceiling fan, or by using a combination of these. Experience has shown that this is quite practical and is usually done anyway by conscientious designers. 


\section{GLOSSARY OF TERMS}

Auxiliary Heating System: a term for the system (gas, electric, oil, etc.) that provides the nonsolar portion of the house's heating energy needs, referred to as the "auxiliary heat".

British Thermal Unit (Btu): a unit used to measure heat. One Btu is about equal to the heat released from burning one kitchen match.

Conservation: in addition to energy conservation in the general sense, the term is used to refer to the nonsolar, energy-saving measures in a house that are primarily involved with improving the building envelope to guard against heat loss--the insulation, the air infiltration reduction measures, and so forth.

Direct Gain: a passive solar system in which the sunlight falls directly into the space where it is stored and used.

Glazing: often used interchangeably with window or glass, the term actually refers specifically to the clear material that admits sunlight, and so it can also be plastic. Double and triple glazing refer to two or three panes.

Indirect Gain: a passive solar system in which the sunlight falls onto thermal mass that is positioned between the glazing and the space to be heated, i.e., a Thermal Storage Wall or Trombe Wall.

Low-Emittance: the term refers to a surface's ability to absorb and reradiate heat. A material with a low emittance absorbs and re-radiates relatively small amounts of heat. Low-emittance or "low-e" glass has a thin layer of a low emittance film or coating on the glass surface. The low-e glass reflects radiant heat, so it will tend to keep heat energy inside the house during the winter and keep heat energy outside the house during the summer.

Passive Solar: design and construction techniques that help a building make use of solar energy by nonmechanical means, as opposed to active solar techniques that use equipment such as roof-top collectors.

Phase-Change Materials: materials such as salts or waxes that store and release energy by changing "phase"; most materials store energy when they turn liquid at a certain temperature and release energy when they turn solid at a certain temperature. Some phase-change materials, however, remain solid but undergo chemical changes that store and release energy. Phase-change materials can be used as thermal mass, but few products are commercially available at this time.

Purchased Energy: although the terms are often used interchangeably, a house's "purchased energy" is generally greater than its "auxiliary heat" because heating systems are seldom $100 \%$ efficient, and more energy is purchased than is actually delivered to the house. 
R-Value: a unit that measures the resistance to heat flow through a given material. The higher the R-value, the better insulating capability the material has. The R-value is the reciprocal of the U-value (see below).

Radiant Barrier: reflective material used in hot climates to block radiant heat, particularly in a house's roof.

Shading Coefficient: a measure of how much solar heat will be transmitted by a glazing material compared with a single pane of clear uncoated glass that has a shading coefficient (SC) of 1 . For example, clear double-pane glass might have an SC in the range of 0.88 .

Reflective glass might have SCs of 0.03-0.06. In general, lower shading coefficients are desirable when heat gain is a problem.

Sunspace: a passive solar system, sometimes also referred to as an isolated gain system, in which sunlight is collected and stored in a space separate from the living space, and must be transferred there either by natural convection or by fans.

Suntempering: a modest form of a direct-gain passive solar system. Suntempered houses increase south-facing glass to about $7 \%$ of the total floor area but add no thermal mass beyond the "free" mass already in a typical house--gypsum board, framing, conventional furnishings, and floor coverings.

Temperature Swing: a measure of the number of degrees the temperature in a space will vary during the course of a sunny winter day without the furnace operating; an indicator of the amount of thermal mass in the passive solar system.

Thermal Mass: material that stores heat or coolness. The thermal storage capacity of a material is a measure of the amount of heat stored when the material changes temperature by $1^{\circ} \mathrm{F}$. Although all materials will store some heat, thermal mass added to passive solar buildings is usually dense material such as brick or concrete masonry but can also be tile, water, phase-change materials, etc.

Thermal Storage Wall: a passive solar system also sometimes called a Trombe Wall or an indirect-gain system; a south-facing glazed wall usually made of masonry but can also be made of containers of water.

Trombe Wall: a thermal storage wall of masonry material, referred to by the name of its inventor, Dr. Felix Trombe.

U-Value: a unit representing the heat loss per square foot of surface area per degree $\mathrm{F}$ of temperature difference. The U-value is the reciprocal of the R-value (see above). 


\section{Technical Basis for the Guidelines and BuilderGuide}

\section{More than a Decade of Experience}

The concentrated effort of research, design, construction, monitoring, and evaluation of actual buildings that started at the First Passive Solar Conference in Albuquerque, New Mexico, in 1976 has continued up to the present. It is estimated that more than 200,000 passive solar homes have been built in the United States during this time. This wealth of experience has been reviewed by NREL, the Technical Committee of PSIC, and the Standing Committee on Energy of the NAHB and is distilled into these Guidelines.

\section{Analysis Procedures}

The analysis procedures used throughout the Guidelines and in BuilderGuide were developed using simple, well-established methods for estimating the performance of passive solar heating and natural cooling strategies. These procedures were developed at the Los Alamos National Laboratory with funding from the U.S. Department of Energy Solar Buildings Program.

\section{Annual Heat Loss (BuilderGuide Worksheet I)}

The heat-loss calculation is based on a straightforward summation of the traditional elements that make up the building heat-loss coefficient (excluding the solar components--the solar effects are accounted for in Worksheet II). The worksheet procedure estimates the annual heat loss by multiplying the heat-loss coefficient by annual degree days (times 24 to convert from days to hours). Degree days for each month were determined using an appropriate base temperature that accounts for an assumed thermostat setting of 70 degrees, an assumed internal heat generation of $36 \mathrm{Btu} / \mathrm{day}-\mathrm{ft}^{2}$ of floor area, and the total building loss coefficient. This forms the basis of the table of heating degree-day multipliers. The result of the worksheet is an estimate of the annual heat required to maintain comfort, excluding both positive and negative effects resulting from the solar components. In this estimate, no solar heating credit is given to east, west, and north windows, because it is assumed that these will be protected by vegetation or other shading in accordance with the guideline recommendations. This is a conservative assumption, because there will always be some solar gain through these windows.

\section{Annual Auxiliary Heat (BuilderGuide Worksheet II)}

The tables of passive solar savings fractions are calculated using the solar load ratio (SLR) method (References 21 and 22). Monthly solar savings fraction (SSF) values are determined using correlation fits to the results of hourly computer simulation calculations for a variety of climates. These 12 values are converted into an annual value and entered into tables accessed by BuilderGuide. The SLR method gives answers that agree within about $5 \%$ of the hourly computer simulations and within $11 \%$ of the measured passive solar performance of 55 buildings monitored under the Solar Buildings Program. The SSF 
estimates account properly for both solar gains and heat losses through the solar aperture, and thus correct for omitting the solar components from the calculation of annual heat loss.

\section{Temperature Swing (BuilderGuide Worksheet III)}

The temperature swing estimate on Worksheet III is based on the diurnal heat capacity (DHC) method (Reference 23). The method is an analytic procedure in which the total heat stored in the building during one day is estimated by summing the effective heat storage potential of all the various materials in the building for a 24-hour periodic cycle of solar input. Rooms with direct gain are assumed to have radiative coupling of the solar heat to the mass. Rooms connected to rooms with direct gain are assumed to have convective coupling, which is rather less effective, especially for massive elements. The DHC of the sheetrock, framing, and furniture is approximated at 4.5 or $4.7 \mathrm{Btu} /{ }^{\circ} \mathrm{F}$ per $\mathrm{ft}^{2}$ of floor area. Tables accessed by BuilderGuide list the increased value of diurnal heat capacity for various conventional materials that are often used to provide extra heat storage, assuming these materials replace sheetrock.

The only numbers used in Worksheet III that are location-dependent are the comfort factors. The direct-gain comfort factor is $61 \%$ of the solar gain transmitted through vertical, south-facing double glazing on a clear January day. The driving effect of sunspaces and vented Trombe walls is assumed to result in one-third this value, based on data from monitored buildings. The origin of the $61 \%$ factor is to account for the nonsinusoidal shape of a typical daily room temperature variation.

\section{Annual Auxiliary Cooling (BuilderGuide Worksheet IV)}

The purpose of including the summer cooling estimates in the Builder Guidelines is to (1) determine if design elements added to promote passive solar heating will cause excessive summer cooling loads and (2) provide a rough estimate of the effectiveness of solar shading and natural cooling strategies. The analysis method is based on a modified monthly degree-day procedure in which the day is divided into day and night periods (Reference 24). All estimates are derived from correlations based on hourly computer simulations. Solar, conduction, and internal gains are estimated for each half-day period in each month. Delay factors are used to account for heat carryover from day to night and from night to day. The results are estimates of annual sensible cooling delivered by the air conditioner and do not include latent loads.

Because the original Los Alamos monthly procedure is too complex to be implemented in a worksheet, a simplified procedure is adopted on Worksheet IV. Heat Gain Factors and Internal Gain Factors are the calculated annual incremental cooling loads resulting from a one-unit incremental change in the respective heat input parameter (that is, a one-unit change in UA, glazing area, or number of bedrooms). The combined heat load resulting from all inputs is summed and then adjusted for thermal mass and ventilation. This correction includes a constant required to match the calculated cooling load of the basecase building. This linearized procedure gives accurate estimates for cooling 
loads that are less than about $150 \%$ of the base-case building; however, it underestimates very large cooling loads in poorly designed buildings.

The adjustment factors for ventilation properly account for maintaining comfort in hot and humid climates. Ventilation is restricted to times when the outside dew-point temperature is less than $62^{\circ} \mathrm{F}$. This restriction avoids ventilation when high humidity might cause discomfort.

\section{Getting Data}

Heating and cooling degree-day data can be obtained from the National Climatic Center, Asheville, North Carolina. Refer to Climatography of the United States No. 81, which lists monthly normals for the period 19511980 on a state-by-state basis. More than 2400 locations are listed in this data base. 


\section{REFERENCES}

\section{General}

1. A Sunbuilder's Primer, Solar Energy Research Institute.

2. Passive: It's a Natural, Solar Energy Research Institute.

3. The Passive Solar Construction Handbook, Steven Winter Associates/Northeast Solar Energy Center/National Concrete Masonry Association/Portland Cement Association/Brick Institute of America. Available for $\$ 29.95$ plus $\$ 3.00$ handling, from Steven Winter Associates, Attn: Publications, 6100 Empire State Building, New York, N.Y. 10001.

4. Suntempering in the Northeast, Steven Winter Associates. Available from Steven Winter Associates at the address above for $\$ 9.50$.

5. Passive Solar Design Handbook, Volumes I, II, III. Available from National Technical Information Service, U.S. Dept. of Commerce, 5285 Port Royal Road, Springfield, VA, 22161, \$32.00 each for I and II, $\$ 12.00$ for III.

6. Balcomb, J.D., et al. Passive Solar Heating Analysis. This volume supersedes and expands Volume III of the Passive Solar Design Handbook (Ref. 5). Available from ASHRAE, Publications, 1791 Tullie Circle NE, Atlanta, GA, 30329, $\$ 30.00$ for ASHRAE members, $\$ 60.00$ for nonmembers.

7. Living With the Sun (for consumers) and Building With the Sun (for builders), PPG Industries.

8. The Passive Solar Information Guide, PSIC.

9. Passive Solar Trends. Technical briefs from PSIC.

a. Infiltration in Passive Solar Construction

b. The State of the Art in Passive Solar Construction

c. Passive Solar in Factory-Built Housing

d. Radiant Barriers: Top Performers in Hot Climates

e. Glazings: The Design Considerations Aren't as Clear as Glass

f. Ideas for Passive Solar Remodeling

g. Passive Homes in the Marketplace (Class C Studies)

h. Daylighting in Commercial Buildings

i. Human Comfort and Passive Solar Design

j. Passive Design for Commercial Buildings

k. Passive Solar: Principles and Products

1. Increasing Design Flexibility

$\mathrm{m}$. Utilities and Passive: Predicting the Payoff 


\section{Insulation}

10. NAHB Insulation Manual, National Association of Home Builders, National Research Center. Available from NAHB Bookstore, 15th and M Streets, N.W., Washington, DC 20005. (202) 822-0200.

11. Lischkoff, James K. The Airtight House: Using the Airtight Drywall Approach, Iowa State University Research Foundation. Available for \$14.95; Attn: Sarah Terrones, EES Building, Iowa State University, Ames, IA 50011.

12. Spears, John. Radon Reduction in New Construction, Interim Guide, National Association of Home Builders, Environmental Protection Agency OPA 87-009, August 1987. Available from the EPA or the NAHB Bookstore, 15th and M Streets, N.W., Washington, DC 20005. (202) 822-0200. Also A Citizens Guide to Radon, What It Is, August 86, Environmental Protection Agency OPA 86-004. From Drew Gillett: Radon Reduction Techniques for Detached Housing, Technical Guide, 2nd Edition, EPA 6255-87 019. A builder would never read this, but it is the "Bible". Also Chuck Silver of SolarPlex wrote a training manual for the New York State Energy Office that contains much the same information but is much more readable.

\section{Appliances}

13. Saving Energy and Money with Home Appliances, Environmental Science Department, Massachusetts Audubon Society/American Council for an Energy Efficient Economy. Available for \$2.00 apiece from ACEEE, 1001 Connecticut Ave., N.W., Suite 535, Washington, DC 20036.

14. The Most Energy Efficient Appliances, 1988 Edition, ACEEE, $\$ 2.00$ each at address above.

\section{Site Planning}

15. Builder's Guide to Passive Solar Home Design and Land Development, National Fenestration Council. Available for \$12.00 from NFC, 3310 Harrison, White Lakes Professional Building, Topeka, KS 66611.

16. Site Planning for Solar Access, U.S. Department of Housing and Urban Development/American Planning Association. Available for $\$ 6.50$ from Superintendent of Documents, U.S. Government Printing Office, Washington, DC 20402.

\section{Sunspaces}

17. Jones, Robert W. and Robert D. McFarland. The Sunspace Primer: A Guide for Passive Solar Heating, available for $\$ 32.50$ from Van Nostrand Reinhold, 115 5th Avenue, New York, NY 10003.

18. Greenhouses for Living, from Steven Winter Associates, Attn: Publications, 6100 Empire State Building, New York, NY 10001 , $\$ 6.95$. 
19. Concept IV, from Andersen Corporation, Bayport, MN 55003, \$6.95.

20. Passive Solar Greenhouse Design and Construction, Ohio Department of Energy/John Spears, 8821 Silver Spring, MD 20910.

\section{Technical}

21. J. Douglas Balcomb, Robert W. Jones, Robert D. McFarland, and William O. Wray, "Expanding the SLR Method", Passive Solar Journal, Vol. 1, No. 2, 1982, pp. 67-90. Available from the American Solar Energy Society, 2400 Central Ave., Unit G-1, Boulder, CO 80301.

22. J. Douglas Balcomb, Robert W. Jones, Robert D. McFarland, and William O. Wray, Passive Solar Heating Analysis, American Society of Heating, Refrigerating, and AirConditioning Engineers, 1984. Available from ASHRAE, 1719 Tullie Circle, NE, Atlanta, GA 30329.

23. J. Douglas Balcomb and William O. Wray, Passive Solar Heating Analysis, Supplement One, Thermal Mass Effects and Additional SLR Correlations, American Society of Heating, Refrigerating, and Air Conditioning Engineers, 1987. See ASHRAE address above.

24. Robert D. McFarland and Gloria Lazarus, Monthly Auxiliary Cooling Estimation for Residential Buildings, LA-1 1394-MS, Los Alamos National Laboratory, Los Alamos, NM 87545, 1989.

\section{More Information}

Conservation and Renewable Energy Inquiry and Referral Service (CAREIRS)

Renewable Energy Information

Box 8900

Silver Spring, MD 20907

800-523-2929.

National Association of Home Builders

Attention: Technical Services

15th \& M Streets, N.W.

Washington, DC 20005.

National Concrete Masonry Association

Attention: Energy Engineer

2302 Horse Pen Road

Herndon, VA 22070. 